SANDIA REPORT

SAND97-2862

Unlimited Release

Printed January 1999
MS0619

Review \& Approval

Dept. 12690

For DOE/OSTI

\title{
The Use of a Beryllium Hopkinsoisato Characterize In-Axis and Cross-Axis Accelerometer Response in Shock Environments
}

Vesta I. Bateman and Fred A. Brown

Prepared by

Sandia National Laboratories

Albuquerque, New Mexico 87185 and Livermore, California 94550

Sandia is a multiprogram laboratory operated by Sandia Corporation, a Lockheed Martin Company, for the United States Department of Energy under Contract DE-AC04-94AL85000.

Approved for public release; further dissemination unlimited. 
Issued by Sandia National Laboratories, operated for the United States Department of Energy by Sandia Corporation.

NOTICE: This report was prepared as an account of work sponsored by an agency of the United States Government. Neither the United States Government nor any agency thereof, nor any of their employees, nor any of their contractors, subcontractors, or their employees, makes any warranty, express or implied, or assumes any legal liability or responsibility for the accuracy, completeness, or usefulness of any information, apparatus, product, or process disclosed, or represents that its use would not infringe privately owned rights. Reference herein to any specific commercial product, process, or service by trade name, trademark, manufacturer, or otherwise, does not necessarily constitute or imply its endorsement, recommendation, or favoring by the United States Government, any agency thereof, or any of their contractors or subcontractors. The views and opinions expressed herein do not necessarily state or reflect those of the United States Government, any agency thereof, or any of their contractors.

Printed in the United States of America. This report has been reproduced directly from the best available copy.

Available to DOE and DOE contractors from Office of Scientific and Technical Information

P.O. Box 62

Oak Ridge, TN 37831

Prices available from (615) 576-8401, FTS 626-8401

Available to the public from

National Technical Information Service

U.S. Department of Commerce

5285 Port Royal Rd

Springfield, VA 22161

NTIS price codes

Printed copy: A05

Microfiche copy: A01

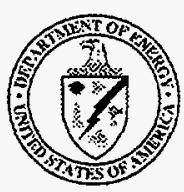




\section{DISCLAIMER}

Portions of this document may be illegible in electronic image products. Images are produced from the best available original document. 
SAND97-2862

Unlimited Release

Printed January 1999

\title{
The Use of a Beryllium Hopkinson Bar to Characterize In-Axis and Cross-Axis Accelerometer Response in Shock Environments
}

\author{
Vesta I. Bateman \\ Fred A. Brown \\ Engineering Sciences Center \\ Sandia National Laboratories \\ P. O. Box 5800 \\ Albuquerque, NM 87185-0555
}

\section{Abstract}

The characteristics of a piezoresistive accelerometer in shock environments have been studied at Sandia National Laboratories in the Mechanical Shock Laboratory. A beryllium Hopkinson bar capability with diameters of $0.75 \mathrm{in}$. and 2.0 in has been developed to extend our understanding of the piezoresistive accelerometer, in two mechanical configurations, in the high frequency, high shock environments where measurements are being made. The in-axis performance of the piezoresistive accelerometer determined from measurements with a beryllium Hopkinson bar and a certified laser doppler vibrometer as the reference measurement is presented. The cross-axis performance of the accelerometer subjected to static compression on a beryllium cylinder, static strain on a steel beam, dynamic strain on a steel beam (ISA-RP 37.2, Paragraph 6.6), and compressive shocks in a split beryllium Hopkinson bar configuration is also presented. The performance of the accelerometer in a combined in-axis and cross-axis shock environment is shown for one configuration. Finally, a failure analysis conducted in cooperation with ENDEVCO gives a cause for the occasional unexplained failures that have occurred in some applications. 


\section{Contents}

Abstract 3

Introduction 8

Hopkinson Bar Configurations $\quad 11$

Hopkinson Bar Analysis for In-Axis Response $\quad 14$

In-Axis Accelerometer Performance 16

Hopkinson Bar Analysis for Cross-Axis Response 18

Cross-Axis Accelerometer Performance 19

Combined Shock Environment Performance $\quad 23$

Failure Mode Analysis 24

Conclusions and Future Work $\quad 27$

References $\quad 29$

\section{Appendix}

A In-Axis Performance of the Piezoresistive Accelerometer 31

Time History and Fourier Transform for the ENDEVCO 7270A 32

Mounted on a 0.75 in. Diameter Titanium Hopkinson Bar.

Time History and Fourier Transform for the ENDEVCO 7270AM4 33

Mounted on a 0.75 in. Diameter Titanium Hopkinson Bar.

Time History and Fourier Transform for the ENDEVCO 7270A 34

Mounted on a 0.75 in. Diameter Beryllium Hopkinson Bar.

Time History and Fourier Transform for the ENDEVCO 7270AM4 35

Mounted on a 0.75 in. Diameter Beryllium Hopkinson Bar.

Five Accelerometer Responses Measured on the Titanium 36

Hopkinson Bar at $100,000 \mathrm{~g}$.

Five Laser Doppler Vibrometer Accelerations Calculated from 36

Responses Measured on the Beryllium Hopkinson Bar at 40,000 g.

Frequency Response Functions for the ENDEVCO 7270A Mounted 37 on a 0.75 in. Diameter Titanium Hopkinson Bar.

Frequency Response Functions for the ENDEVCO 7270AM4 38

Mounted on a 0.75 in. Diameter Titanium Hopkinson Bar.

Frequency Response Functions for the ENDEVCO 7270A and the ENDEVCO 7270AM4 Mounted on a 0.75 in. Diameter Beryllium Hopkinson Bar. 
B Cross-Axis and Combined Shock Environment Performance of the Piezoresistive Accelerometer

ENDEVCO 7270A Response for a Static Strain ( $250 \mu \varepsilon$ Amplitude) 41 Applied to the Beryllium Insert (0.75 in. Diameter).

ENDEVCO 7270A Response for a Compressive Shock Applied to 41 the Beryllium Insert (0.75 in. Diameter).

ENDEVCO 7270AM4 Response for a Compressive Shock Applied 42 to the Beryllium Insert ( 0.75 in. Diameter).

Strain Response for the Beryllium Insert (2.0 in. Diameter).

ENDEVCO 7270A and 7270AM4 Response for a Static Strain (100 $\mu \varepsilon$ Amplitude) Applied to the Beryllium Insert (2.0 in. Diameter).

Axial Strain Response to Compressive Shock on the Beryllium

Insert (2.0 in. Diameter).

Lateral Strain Response to Compressive Shock on the Beryllium

Insert (2.0 in. Diameter).

Consistent Axial Acceleration Measured on the Beryllium Insert (2 44 in. Diameter).

ENDEVCO 7270A-60K Base Strain Response to Cross-Axis

Compressive Shock ( $250 \mu \varepsilon$ Amplitude) with $0^{\circ}$ Angle and $30 \mathrm{kHz}$ Analog Filter (2 in. Diameter Beryllium Insert).

ENDEVCO 7270A-60K Base Strain Response to Cross-Axis

Compressive Shock ( $250 \mu \varepsilon$ Amplitude) with $45^{\circ}$ Angle and 30

$\mathrm{kHz}$ Analog Filter (2 in. Diameter Beryllium Insert).

ENDEVCO 7270A-60K Base Strain Response to Cross-Axis

Compressive Shock ( $250 \mu \varepsilon$ Amplitude) with $90^{\circ}$ Angle and 30 $\mathrm{kHz}$ Analog Filter (2 in. Diameter Beryllium Insert).

ENDEVCO 7270AM4-200K Acceleration Response to Cross-Axis

Compressive Shock ( $250 \mu \varepsilon$ Amplitude) with $15^{\circ}$ Angle and 30

$\mathrm{kHz}$ Analog Filter (2 in. Diameter Beryllium Insert).

ENDEVCO 7270AM4-200K Acceleration Response to Cross-Axis

Compressive Shock ( $250 \mu \varepsilon$ Amplitude) with $65^{\circ}$ Angle and 30

$\mathrm{kHz}$ Analog Filter (2 in. Diameter Beryllium Insert).

ENDEVCO $7270 \mathrm{~A}-60 \mathrm{~K}$ Response to Combined Shock at $45^{\circ}$ on a

Titanium Hopkinson.

ENDEVCO 7270AM4-200K Response to Combined Shock at $45^{\circ}$

on a Titanium Hopkinson. 
C Piezoresistive Accelerometer Cable Response 49

Strain Gage Measurement for No. 1. 50

Cable Measurement for No. 1 . 51

Laser Doppler Vibrometer Measurement for No. 1. 52

Strain Gage Measurement for No. 2. 53

Cable Measurement for No. 2. 54

Laser Doppler Vibrometer Measurement for No. 2. 55

Strain Gage Measurement for No. 3.

Cable Measurement for No. 3. 57

Laser Doppler Vibrometer Measurement for No. 3.

Strain Gage Measurement for No. 4.

Cable Measurement for No. 4 . 60

Laser Doppler Vibrometer Measurement for No. 4.

Strain Gage Measurement for No. 5 . 62

Cable Measurement for No. 5 . 63

Laser Doppler Vibrometer Measurement for No. 5.

Strain Gage Measurement for No. 6.

Cable Measurement for No. 6 . 66

Laser Doppler Vibrometer Measurement for No. 6.

Strain Gage Measurement for No. $7 . \quad 68$

Cable Measurement for No. 7. 69

Laser Doppler Vibrometer Measurement for No. 7.

Strain Gage Measurement for No. 8. 71

Cable Measurement for No. 8. 72

Laser Doppler Vibrometer Measurement for No. 8. 73

Strain Gage Measurement for No. 9.

Cable Measurement for No. 9 . 75

Laser Doppler Vibrometer Measurement for No. 9.

Strain Gage Measurement for No. 10 . 77

Cable Measurement for No. 10 . 78

Laser Doppler Vibrometer Measurement for No. $10 . \quad 79$

Strain Gage Measurement for No. 11 . 80

Cable Measurement for No. 11 . 81

Laser Doppler Vibrometer Measurement for No. 11. 


\section{Figures}

1 Two Mechanical Configurations for a Piezoresistive Accelerometer ENDEVCO 7270A AND 7270AM4.

2 Beryllium Hopkinson Bar Configuration for Normal Input (0.75 in. and 11 2.0 in. Diameters).

3 Beryllium Hopkinson Bar Anomalies.

4 Split Beryllium Hopkinson Bar Configuration for Cross-Axis Input (0.75 in. and 2.0 in. Diameters).

5 Insert for Split Beryllium Hopkinson Bar Configuration (0.75 in. Diameter).

6 Two Flats on the Beryllium Insert for Static Compression and Mechanical Compressive Shock Cross-Axis Experiments (2 in. Diameter).

7 Titanium Hopkinson Bar with Two $45^{\circ}$ Flats for the ENDEVCO 7270A.

8 Titanium Hopkinson Bar with Two $45^{\circ}$ Flats for the ENDEVCO 7270AM4.

9 Theoretical Prediction of Axial and Lateral Accelerations for the Beryllium Hopkinson Bar.

10 Axial Strain Response to Compressive Shock on the Beryllium Insert 20 (0.75 in. Diameter).

11 Lateral Strain Response to Compressive Shock on the Beryllium Insert 20 (0.75 in. Diameter).

12 Static Strain Response for the Beryllium Insert (0.75 in. Diameter). 22

13 Orientation of the Sensor in the ENDEVCO 7270A and the ENDEVCO 23 7270AM4.

14 Hopkinson Bar Configuration for Cable Response Investigations.

\section{Tables}

I Experiment Matrix for In-Axis Accelerometer Study. 9

II Environments for the Cross-Axis and Combined Shock 9 Accelerometer Study.

III Percent Deviation Between Accelerometer and LDV Measurements 17 with Beryllium Hopkinson Bar.

IV Percent Deviation Between Accelerometer and Strain Gage 17 Measurements with Titanium Hopkinson Bar.

V Static Base Strain Results. 21

VI Static Beam Results. 22

VII Dynamic Beam Strain Results. 22

VIII Summary of Accelerometer Performance in Combined Shock. 23

IX Failure Analysis of Eleven ENDEVCO 7270A Accelerometers. 25

$X$ Hopkinson Bar Cable Investigation Summary. 26 


\section{The Use of a Beryllium Hopkinson Bar to Characterize In-Axis and Cross-Axis Accelerometer Response in Shock Environments}

\section{Introduction}

Sandia National Laboratories (SNL) conduct impact experiments for a variety of structures. These impact experiments include earth and rock penetrator experiments in which a penetrator structure is propelled at velocities of $1000 \mathrm{fps}$ (nominal) into earth or rock. During an impact experiment, metal to metal contact may occur within the structure and produce high frequency, high amplitude shocks. The piezoresistive accelerometer, which frequently measures the field experiment response of various high reliability structures, must withstand these severe shock environments. The piezoresistive accelerometer has several desirable characteristics: dc response, low power requirements, minimal zero shift, and high resonant frequency. A bandwidth of at least $10 \mathrm{kHz}$ is needed for many applications because more sophisticated analyses are being performed with the experimental data. Additionally, requirements are being made to qualify components for frequency ranges of $10 \mathrm{kHz}$. For example, recent Army research has found that armored vehicle components can be damaged by the high frequency content of ballistic shock $[1,2,3]$. To enhance survivability of the new generation of combat vehicles, the Army has specified a minimum frequency range of $10 \mathrm{kHz}$ for the design and qualification of components. Qualification to even higher frequencies is desired, if reasonably possible. Since there is no capability to calibrate or characterize accelerometers with shock inputs for frequencies above 10 $\mathrm{kHz}$, the SNL Mechanical Shock Laboratory has been given the task of characterizing accelerometers for the conditions shown in Tables I and II. The two areas of high frequency performance and high amplitude shock (acceleration level) performance for the piezoresistive accelerometer are being pursued because measurements are being made in these environments.

The SNL Mechanical Shock Laboratory has a titanium Hopkinson bar capability to characterize accelerometers up to 200,000 $\mathrm{g}$ that has been used to determine the characteristics of a piezoresistive accelerometer at these high acceleration levels [4]. The SNL titanium Hopkinson bar with strain gages as the reference measurement has been calibrated for a bandwidth of dc to $10 \mathrm{kHz}$ with an uncertainty of $+6 \%$ [5]. This capability was used to characterize the piezoresistive accelerometer initially.

The piezoresistive accelerometers are being characterized over the extended bandwidth of dc to $50 \mathrm{kHz}$ to provide better interpretation of high frequency 


\section{Table I: Experiment Matrix for In-Axis Accelerometer Study.}

\begin{tabular}{ccc} 
Low Frequency & $\begin{array}{c}\text { Low Amplitude } \\
\text { (up to 20,000 g) }\end{array}$ & $\begin{array}{c}\text { High Amplitude } \\
\text { (up to 200,000 g) }\end{array}$ \\
$\begin{array}{c}\text { (dc-10 kHz) } \\
\text { High Frequency } \\
\text { (dc-50 kHz) }\end{array}$ & Titanium & Titanium \\
\hline
\end{tabular}

\section{Table II: Environments for the Cross-Axis and Combined Shock Accelerometer Study.}

\section{Environment}

Static Compression

Static Strain

Dynamic strain
Experimental Configuration

Beryllium Cylinder

Steel Beam

Steel Beam

Compressive Mechanical Shock Beryllium Cylinder in a Split Hopkinson Bar Configuration

Combined Shock

Titanium Hopkinson Bar with $45^{\circ}$ Flats

measurements. To achieve this goal, a beryllium Hopkinson bar capability has been developed to extend the upper limit of the frequency range for Hopkinson bar calibration and characterization of accelerometers. The reference measurement for the beryllium Hopkinson bar in a single bar configuration is a commercial laser doppler vibrometer (LDV) that has been certified by the SNL Primary Electrical Standards Laboratory [6]. The LDV is the Polytec PI Model OFV-3000 controller and Model OFV-302 sensor head*. The in-axis performance of the piezoresistive accelerometer in two different mechanical packages has been determined from measurements with a beryllium Hopkinson bar [7].

The rectangular package that uses two \#4-40 screws for mounting will be referred to as the flat package in this report. The cylindrical package that uses a single \#1/428 mounting stud will be referred to as the can package. These accelerometers are the ENDEVCO* Model 7270A (flat package) and the ENDEVCO* Model 7270AM4 (can package) as shown in Fig. 1. Both configurations have been studied to determine if there are any differences in the performance characteristics between *Reference to a commercial product implies no endorsement by SNL or the Department of Energy or lack of suitable substitute. 
the two accelerometers. In some cases, it has been suspected that the flat package exhibited beam mode response (with fixed end conditions) in high frequency environments. It has been hypothesized that the can package might eliminate this beam response and the subsequent frequency content in the measured accelerometer response data.

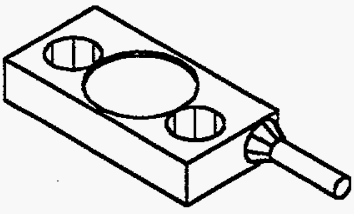

Accelerometer, Flat Configuration

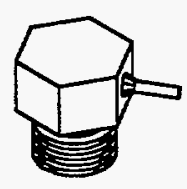

Accelerometer, Can Configuration

\section{Figure 1: Two Mechanical Configurations for a Piezoresistive Accelerometer, ENDEVCO 7270A AND 7270AM4.}

Others have tried to extend the frequency range of the Hopkinson bar by removing dispersion effects from the data [8,9] instead of using beryllium for the bar. The Hopkinson bar material for these experiments is typically titanium. However, this technique is not a valid approach to extend the bandwidth because there is no coherence in the data above $\sim 15 \mathrm{kHz}$ for the typical Hopkinson bar materials of aluminum, steel and titanium. A beryllium Hopkinson bar allows measurement of frequencies in the bandwidth of dc to $50 \mathrm{kHz}$ with acceptable coherence because the beryllium's high stress wave speed can create a shorter pulse duration without dispersion than other Hopkinson bar materials that are used for the current accelerometer studies.

Results of characterizations of the accelerometers subjected to cross-axis static compression on a beryllium cylinder, static strain on a steel beam, dynamic strain on a steel beam, and compressive shocks in a split beryllium Hopkinson bar configuration are also presented. The static compression experiments have been performed in order to identify the mechanism that causes the cross-axis response in the accelerometers. The static deflection and dynamic strain experiments with a steel beam have been performed according to ISA-RP 37.2, Paragraph 6.6, because this recommended practice is the only established method for determining base strain response in accelerometers. Beryllium is used for the static compression and compressive mechanical shocks because of its low Poisson's ratio, 0.07 . The result is that beryllium has negligible response in the accelerometer's sensitive axis, so these cross-axis experiments may be considered pure cross-axis environments. 
The performance of the accelerometer in a combined in-axis and cross-axis shock environment is shown for one configuration. Finally, a failure analysis conducted in cooperation with ENDEVCO explains the occasional unexplained failures that make it unreliable for some applications.

\section{Hopkinson Bar Configurations}

The beryllium Hopkinson bar configuration for characterizing accelerometers for normal or in-axis input is shown in Figure 2. Normal input in this configuration

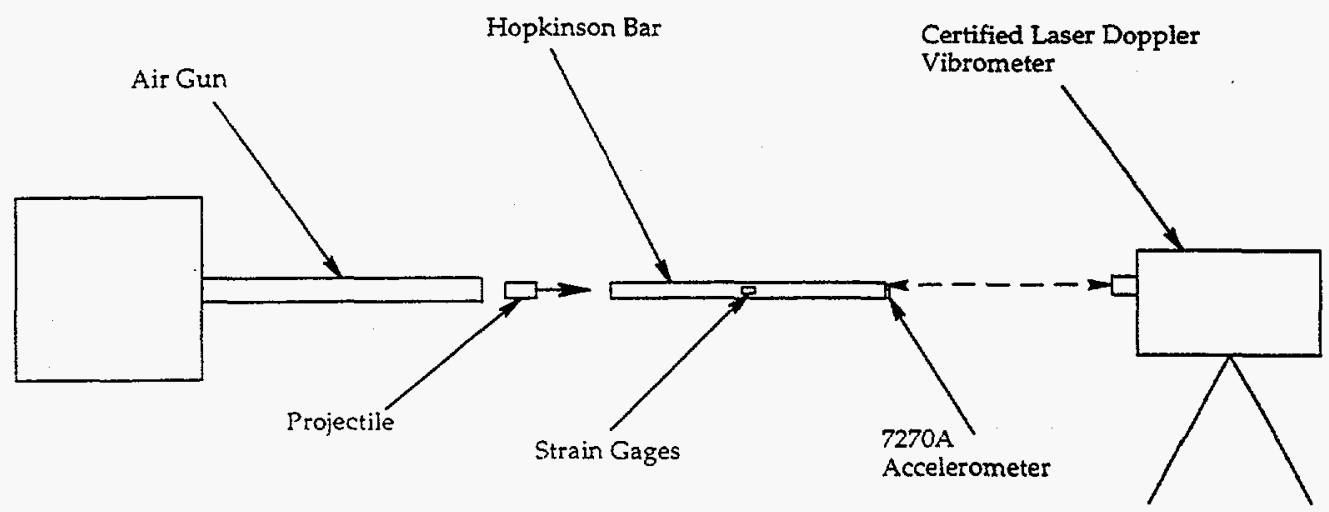

Figure 2: Beryllium Hopkinson Bar Configuration for Normal Input (0.75 in. and 2.0 in. Diameters).

is an input that is normal to the mounting surface or parallel to an integral mounting stud. A maximum shock magnitude of $70,000 \mathrm{~g}$ is used for the beryllium bar to insure that the beryllium will not yield because it is a health hazard in particle form. Both of the mechanical configurations for the piezoresistive accelerometer have been characterized with the normal input that is parallel to their sensitive axis. The reference measurement is the LDV as shown. Strain gages cannot be used as the reference measurement because the beryllium bar's response exhibits two anomalies that are shown in Figure 3: the high rate of damping and the non-return to zero of the stress time history. The SNL Mechanical Shock Laboratory has a titanium Hopkinson bar capability to characterize accelerometers up to $200,000 \mathrm{~g}$ that has been used to determine the characteristics of a piezoresistive accelerometer at these high acceleration levels [4]. The SNL titanium Hopkinson bar is the same configuration as Figure 2 but has strain gages as the reference measurement with an uncertainty of $+6 \%$ [5].

A configuration that uses a quartz crystal to directly measure the acceleration applied to an accelerometer mounted on a flyaway device at the end of the bar was 
investigated [10]. However, it was found that the Hopkinson bar material for this configuration is limited to aluminum that matches the impedance of the quartz crystal.

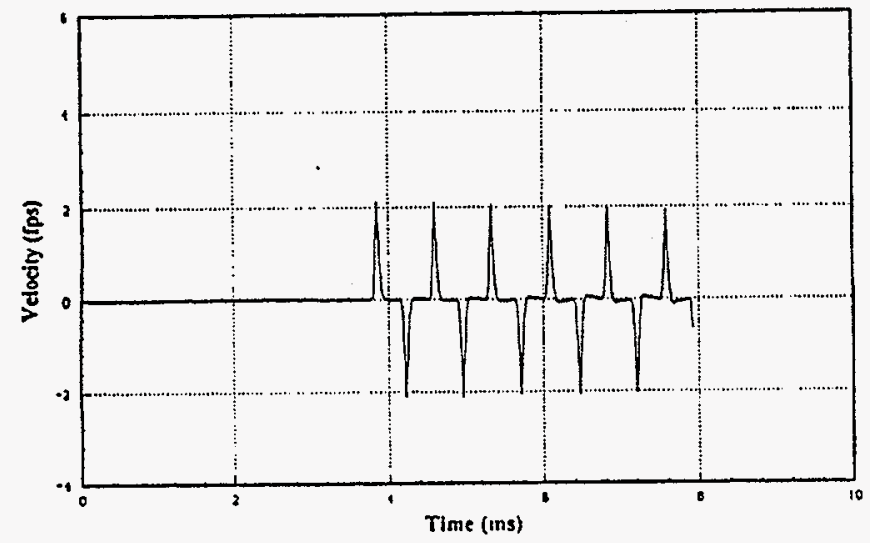

Titanium Bar

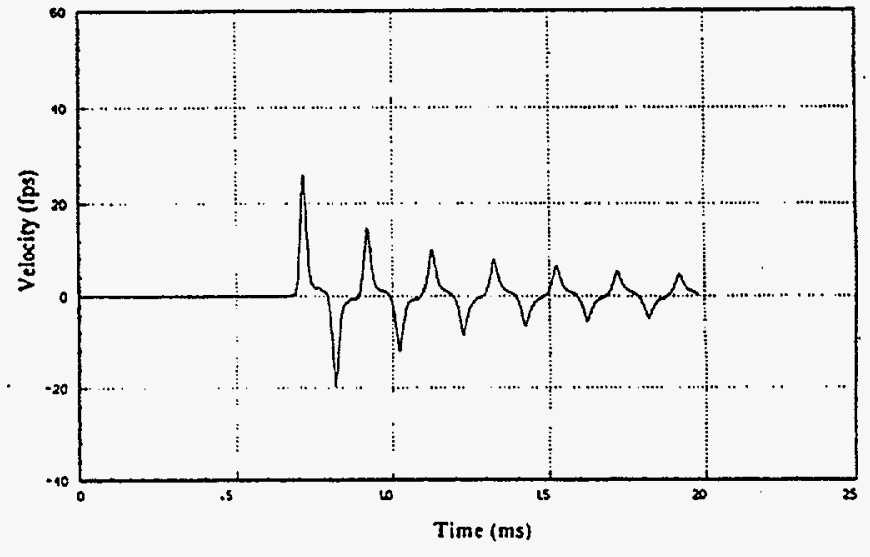

Beryllium Bar

\section{Figure 3: Beryllium Hopkinson Bar Anomalies.}

Cross-axis sensitivity of the piezoresistive accelerometers has been studied with the beryllium split Hopkinson bar configurations shown in Figures 4, 5, and 6. An in-axis response is the response of an accelerometer whose sensitive axis is in the direction of the shock. An out-of-axis or cross-axis response is the response of an accelerometer whose sensitive axis is not in the direction of the shock but is perpendicular to the to the direction of the shock. With beryllium's Poisson's ratio of 0.07 , the cross-axis performance is obtained with negligible motion in the accelerometer's sensitive axis. A cross-axis configuration with the accelerometers mounted normal to the stress wave on the end of the bar was proposed previously [4] but was abandoned because the end-modes at $120 \mathrm{kHz}$ in the Hopkinson bar caused the accelerometers to resonate and break.

Acceleration responses for the ENDEVCO 7270A and 7270AM4 mounted on titanium Hopkinson bars with two $45^{\circ}$ flats on the end have been obtained with the configurations shown in Figures 7 and 8, respectively. A bar was machined to accommodate two accelerometers of the same model at the same time. The $45^{\circ}$ flats provide a combined in-axis and cross-axis shock environment.

No special preparations of the beryllium Hopkinson bar interfaces with the inserts are made other than insuring that the surfaces are flat and polished. Careful alignment of the bars and the insert is required. All Hopkinson bars used for the results shown in this paper are freely supported. Both time domain calculations, as a percent difference from the reference measurement (LDV or strain gages), and frequency domain calculations, as frequency response functions, are made with the Hopkinson bar data. 


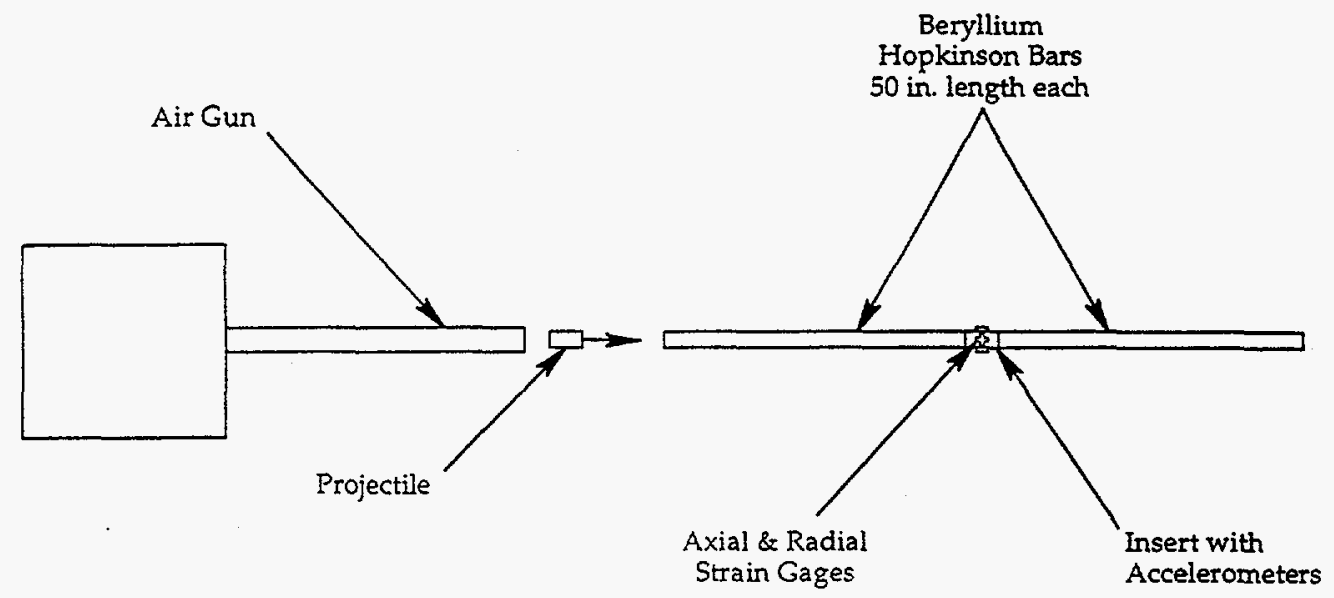

Figure 4: Split Beryllium Hopkinson Bar Configuration for Cross-Axis Input (0.75 in. and 2.0 in. Diameters).

Beryllium Flat Package Insert
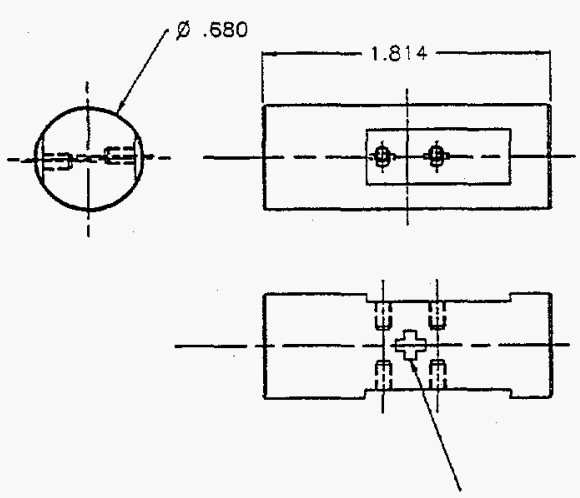

Axial \& Radial

Strain Gages
Beryllium Can Package Insert
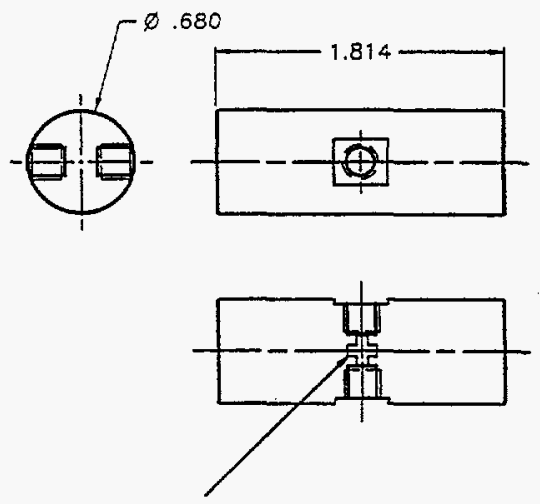

Axial \& Radial

Strain Gages

Figure 5: Insert for Split Beryllium Hopkinson Bar Configuration with 0.75 in. diameter.
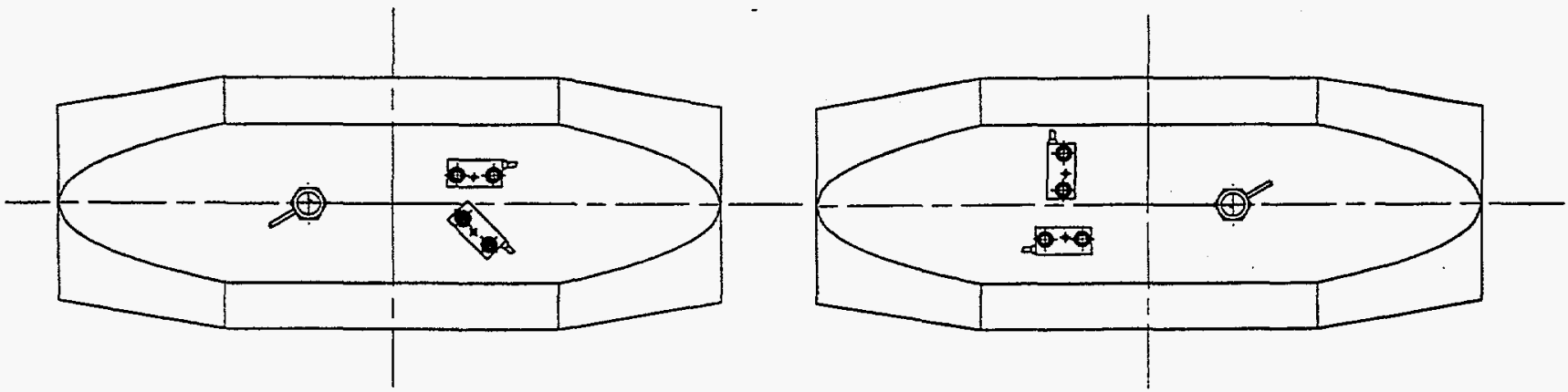

Figure 6: Two Flats on the Beryllium Insert for Static Compression and Mechanical Compressive Shock Cross-Axis Experiments ( 2 in. Diameter). 


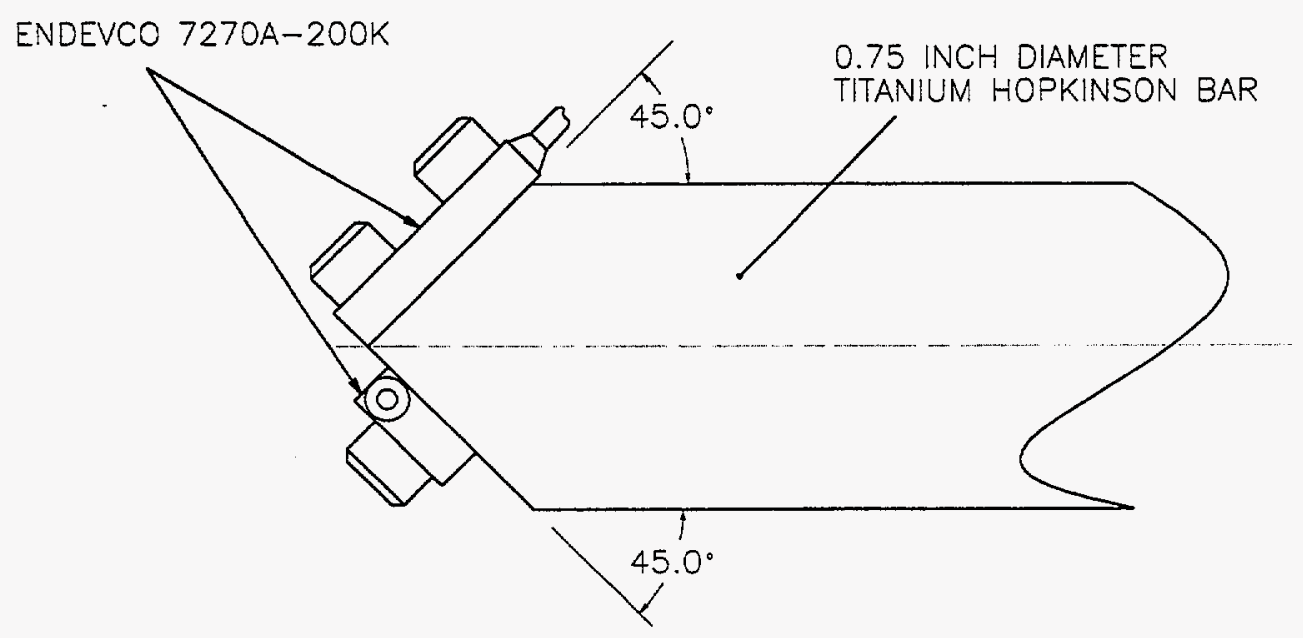

Figure 7: Titanium Hopkinson Bar with Two $45^{\circ}$ Flats for the ENDEVCO 7270A.

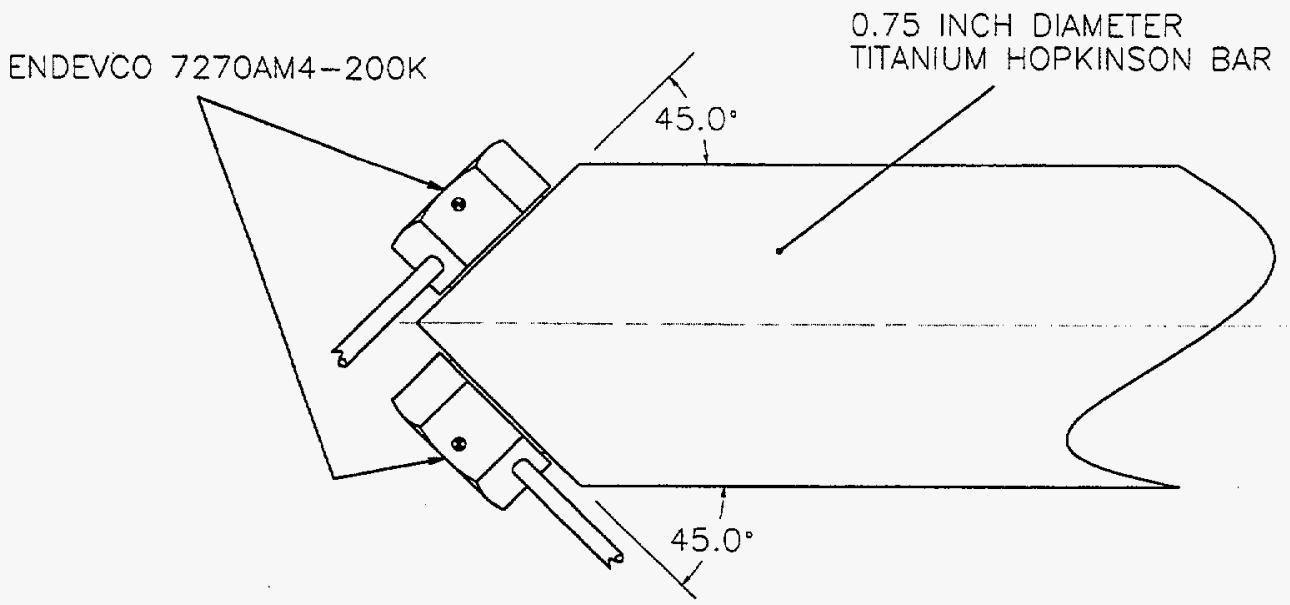

Figure 8: Titanium Hopkinson Bar with Two $45^{\circ}$ Flats for the
ENDEVCO 7270AM4.

\section{Hopkinson Bar Analysis for In-Axis Response}

The theory of stress wave propagation in a Hopkinson bar is well documented in the literature $[11,12]$. The results of this theory are summarized as follows:

A Hopkinson bar is defined as a perfectly elastic, homogeneous bar of constant cross-section.

A stress wave will propagate in a Hopkinson bar as a one-dimensional elastic wave without attenuation or distortion if the wavelength, $\lambda$, is large relative to the diameter, $\mathrm{D}$, or $10 \mathrm{D} \leq \lambda$. 
For a one-dimensional stress wave propagating in a Hopkinson bar, the motion of a free end of the bar as a result of this wave is:

$$
v=2 c \varepsilon
$$

or,

$$
a=2 c \frac{d \varepsilon}{d t}
$$

where,

$$
c=\sqrt{\frac{E}{\rho}}
$$

and $v$ and $a$ are the velocity and acceleration, respectively, of the end of the bar, $c$ is the wave propagation speed in the bar, $E$ is the modulus of elasticity, $\rho$ is the density for the Hopkinson bar material, and $\varepsilon$ is the strain measured in the bar at a location that is not affected by reflections during the measurement interval.

The motion of an accelerometer mounted on the end of the bar will be governed by equations (1) and (2) if the mechanical impedance of the accelerometer is much less than that of the bar or if the thickness of the accelerometer is much less than the wavelength. The requirement on the strain gage is that the gage length (g.l.) be much less than the wavelength or $\lambda \geq 10$ g.l.

The Mechanical Shock Laboratory Hopkinson bars, used for accelerometer characterizations, are made of either $6 \mathrm{AL}, 4 \mathrm{~V}$ titanium alloy $(6 \%$ aluminum and $4 \%$ vanadium) or beryllium ( $99 \%$ pure) with a 0.76 inch diameter. The titanium bar is $72 \mathrm{in.} \mathrm{long,} \mathrm{and} \mathrm{the} \mathrm{beryllium} \mathrm{bar} \mathrm{is} 50$ in. long. The bar is supported in a way that allows it to move freely in the axial direction. A low pressure air gun is used to fire a 3 inch long hardened tool steel (for titanium) or magnesium (for beryllium) projectile at the end of the bar. This impact creates a stress pulse that propagates toward the opposite end of the Hopkinson bar. Regulating the air gun pressure that determines the impact speed controls the amplitude of the pulse. Placing a number of index cards on the impact surface controls the shape (approximately a half sine) and duration of the pulse. The LDV is located at the end of the beryllium bar on which the accelerometer is mounted and measures velocity at a point next to the accelerometer. This LDV with high frequency (up to $1.5 \mathrm{MHz}$ ) and high velocity $(10 \mathrm{~m} / \mathrm{s})$ capability was purchased from a commercial source and has been certified by the Primary Electrical Standards Department at SNL. For the 1000 $\mathrm{mm} / \mathrm{s} / \mathrm{V}$ range (positive velocity), the total uncertainty with approximately a $95 \%$ 
confidence level for the velocity is $+5 \%$. When the LDV is used over $90 \%$ of its range, this LDV has a $+2-3 \%$ uncertainty for all specified frequencies and velocities. The uncertainty decreases for decreasing velocity scales. The LDV provides a reference velocity measurement for velocities up to $10 \mathrm{~m} / \mathrm{s}$ and for frequencies up to $1.5 \mathrm{MHz}$. This reference measurement provides information in a bandwidth that is not available from strain gages that are generally considered to have a bandwidth of no greater than dc- $40 \mathrm{kHz}$. Since these piezoresistive accelerometers and the Hopkinson bars have resonance at these high frequencies of $100^{\prime} \mathrm{s}$ of $\mathrm{kHz}$, the LDV is a useful diagnostic tool. Ref. [5] gives the details of the certification process.

All accelerometers in this study were calibrated in the SNL Calibration Laboratory using two methods: 1) shaker calibration and 2) dropball calibration. The two methods are traceable to the National Institute of Standards and Technology, NIST, formerly NBS as described elsewhere [13].

\section{In-Axis Accelerometer Performance}

To assess in-axis performance, the velocity (strain gages or LDV) and acceleration (accelerometer) records can be compared by converting to either velocity or acceleration as shown in (1) and (2). Hopkinson bar accelerometer calibration methods documented in the literature [14-17] generally use velocity, in which case the accelerometer record is integrated and compared directly to the strain record converted to velocity by the factor $2 c$. This provides smooth curves for comparison of time histories, however the higher frequency information is lost due to the integration process. Since it was desired to preserve the frequency response of the data, acceleration is used for the comparison of the data. Consequently, the time derivative of the strain records was required, and the resulting signal may be contaminated by high frequency noise created in the process of calculating the derivative. This problem was essentially eliminated by: 1 ) adequate sample rate of $500 \mathrm{kHz}$ or higher; 2) low pass digital filtering with a cutoff frequency well above the frequency range of interest $(10 \mathrm{kHz})$; and most importantly, 3$)$ an accurate differentiation algorithm which was derived using the Fourier series reconstruction techniques in [17]. This algorithm results in an exact derivative of the digitized signal providing the Sampling Theorem has not been violated, that is, the data is not aliased [18]. With the reference acceleration and the accelerometer response, inaxis performance may be assessed in both the time-domain and the frequency domain.

Each mechanical configuration for the accelerometer was mounted directly to the end of a beryllium Hopkinson bar and subjected to shock pulses of about $40,000 \mathrm{~g}$ and $70,000 \mathrm{~g}$ with nominal pulse duration of about $15-20 \mu \mathrm{s}$ in all cases. The magnitude of the accelerometer responses was compared to the acceleration 
magnitude derived from the LDV measurements. The results of these experiments are summarized in Table III. The percent deviations vary from $2 \%$ to $7 \%$ and no significant difference was observed in the two packages. Time history plots comparing the accelerometer response with the reference measurement, either strain gages or the LDV, are shown in Appendix A with their corresponding Fourier transforms. A resonance above $100 \mathrm{kHz}$ for the can package is evident but not for the flat package. This resonance has been confirmed elsewhere in unpublished results. These results are similar to those obtained for the titanium Hopkinson bar in Table IV [4] and confirm the integrity of the beryllium Hopkinson bar configuration.

\title{
Table III: Percent Deviation Between Accelerometer and LDV Measurements with Beryllium Hopkinson Bar.
}

\author{
Accelerometer \\ Can Package (1/4-28) \\ Flat Package (4-40)
}
$\underline{40,000 \mathrm{~g}}$
$3 \%$
$4 \%$
$\underline{70,000 \mathrm{~g}}$
$2 \%$
$7 \%$

\section{Table IV: Percent Deviation Between Accelerometer and Strain Gage Measurements with Titanium Hopkinson Bar.}

$\begin{array}{cccc}\text { Accelerometer } & \underline{\mathbf{1 0}, 000 \mathrm{~g}} & \underline{\mathbf{2 0 , 0 0 0 g}} & \underline{\mathbf{5 0 , 0 0 0 g}} \\ \text { Can Package }(1 / 4-28) & 4 \% & 6 \% & 6 \% \\ \text { Flat Package (4-40) } & 4 \% & 3 \% & 4 \%\end{array}$

Next, frequency response functions (frf's) were calculated for both accelerometer configurations for the shock levels of $40,000 \mathrm{~g}$ and 70,000 $\mathrm{g}$ with a nominal duration of 15 to $20 \mu \mathrm{s}$. The process of calculating these requires five consistent shocks at each level. The consistency of the time-domain domain data required for the frf calculation is demonstrated in Appendix A. The large deviations in the frf's beyond $10 \mathrm{kHz}$ for titanium and $50 \mathrm{kHz}$ for beryllium are caused by the loss of coherence and not an accelerometer response. Also, poor coherence, not the accelerometer, causes the low frequency deviations in the beryllium frf's. The frf's calculated for the ENDEVCO 7270A and 7270AM4 from data measured with both titanium and beryllium Hopkinson bars are shown in Appendix A.

The magnitude, phase and coherence of frequency response functions were calculated so that a quantitative evaluation could be made of the frequency response for the ENDEVCO 7270A and 7270AM4. The reference acceleration data, calculated from either strain gages or the LDV, and the accelerometer response data were used to calculate a frf, $\mathrm{H}(\mathrm{j} \omega)$, using the equations below [19]. 


$$
H(j \omega)=\frac{H_{1}+H_{2}}{2}
$$

where,

$$
H_{1}(j \omega)=\frac{\sum_{n=1}^{5} G_{x y}}{\sum_{n=1}^{5} G}
$$

and

$$
H_{2}(j \omega)=\frac{\sum_{n=1}^{5} G_{y y}}{\sum_{n=1}^{5} G_{y x}}
$$

and where $G_{x y}$ is the cross-spectrum between the reference acceleration, $x$, and the accelerometer response, $y ; G_{y x}$ is the cross-spectrum between the accelerometer response, $y$, and the reference acceleration, $x ; G_{y y}$ is the auto-spectrum of the accelerometer response, $y$; and $G_{x x}$ is the auto-spectrum of the reference acceleration, $\mathrm{x}$. The frf, $\mathrm{H}_{1}$ is biased by the error on the reference acceleration, and the frf, $\mathrm{H}_{2}$ is biased by the error on the accelerometer response. The Hopkinson bar data for these frf calculations have noise on both the reference acceleration and the accelerometer response, so the average of the two frf's in (4) is used. The summations are performed for the ensemble of five reference accelerations and their corresponding accelerometer responses. The coherence, $\gamma^{2} \times y(j \omega)$, was also calculated for an ensemble of five data sets according to the equation [19],

$$
\gamma_{x y}^{2}(j \omega)=\frac{H_{1}}{H_{2}}
$$

as a measure of the linearity between the reference acceleration and the accelerometer response and of the noise in these data.

\section{Hopkinson Bar Analysis for Cross-Axis Response}

The axial motion, a, at a location in the Hopkinson bar other than the free end is

$$
a=c \frac{d \varepsilon}{d t}
$$


where $\varepsilon$ is the axial strain. The radial motion, $y$, is

$$
y=r \varepsilon
$$

where $r$ is the radius of the Hopkinson bar and $\varepsilon_{\mathrm{r}}$ is the radial strain. Since the relationship between axial and radial strain is

$$
\varepsilon r=\mu \varepsilon
$$

where $\mu$ is Poisson's ratio, then the final expression for radial acceleration, ay, is

$$
a_{y}=\frac{\mu r}{c} \frac{d a}{d t}
$$

A prediction of the axial and radial acceleration for the beryllium Hopkinson bar using the equations above is shown in Figure 9. Strain measurements co-located with the accelerometers for the flat package insert of Figure 5 in the split Hopkinson bar configuration are shown in Figures 10 and 11 and indicate a Poisson's ratio of about 0.07 .

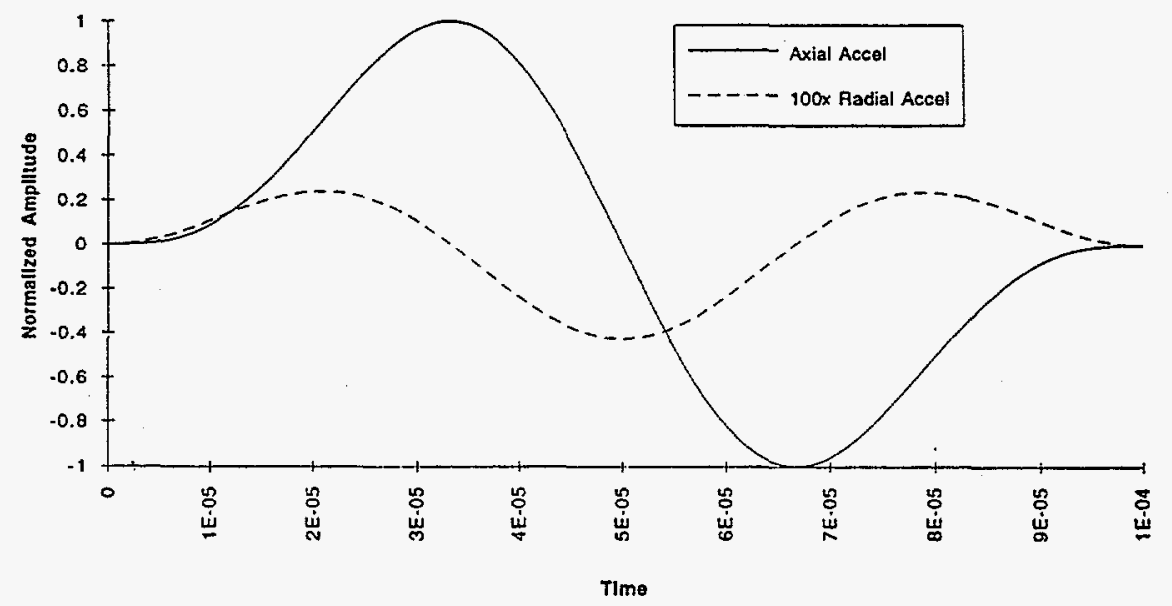

Figure 9: Theoretical Prediction of Axial and Lateral Accelerations for the Beryllium Hopkinson Bar.

\section{Cross-Axis Accelerometer Performance}

Two accelerometer responses measured on the insert are shown in Appendix B. This response is base strain dominated because it does not correspond to either of the curves in Fig. 9 but follows the general shape of the lateral strain response in 


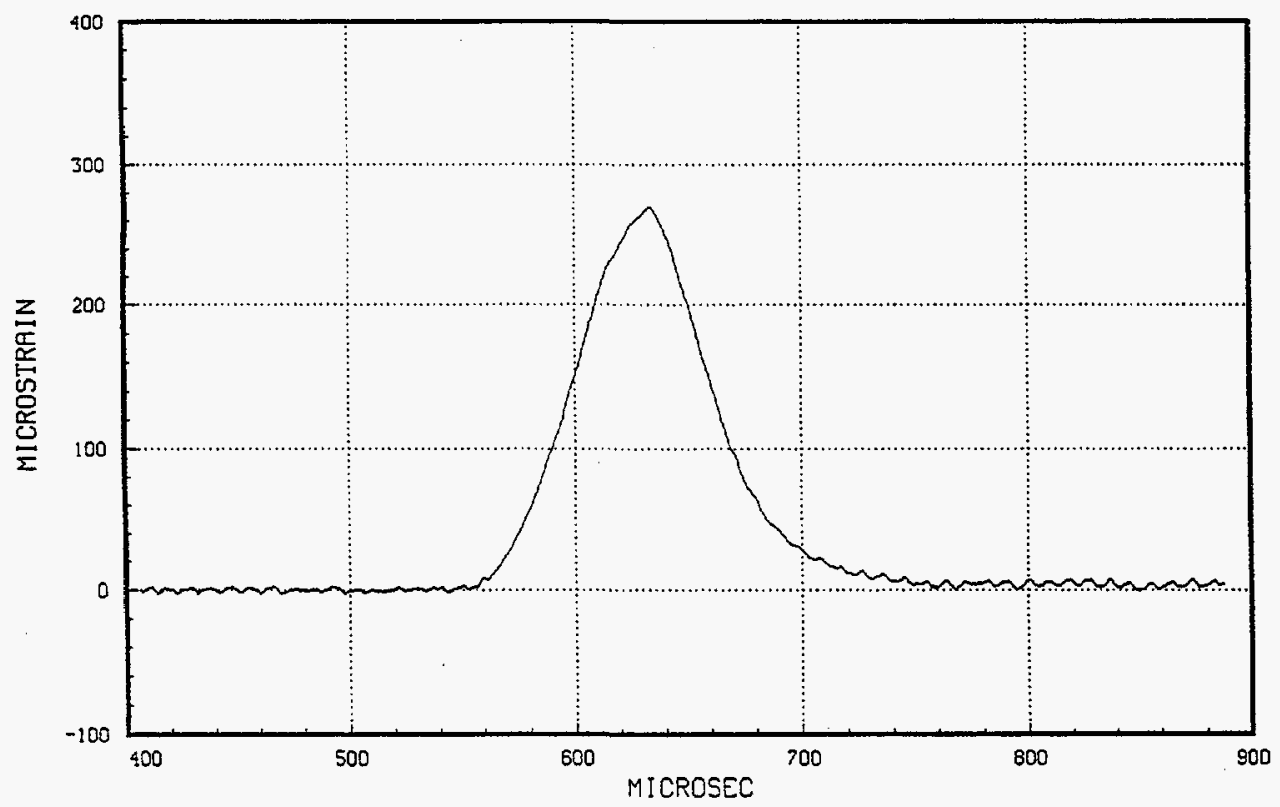

Figure 10: Axial Strain Response to Compressive Shock on the Beryllium Insert (0.75 in. Diameter).

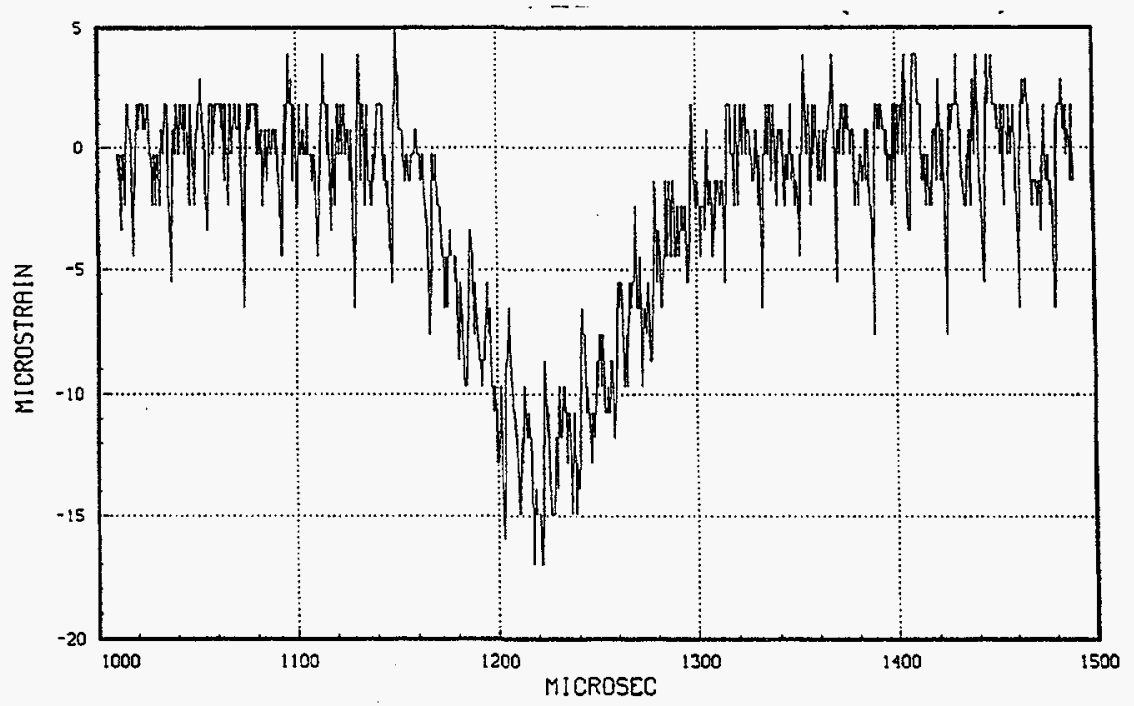

Figure 11: Lateral Strain Response to Compressive Shock on the Beryllium Insert (0.75 in. Diameter).

Fig. 10. A compressive static load was applied to the insert with the results shown in Fig. 12 (strain) and Appendix B (accelerometer response). Since the sensitivity of the accelerometer is approximately $1 \mu \mathrm{V} / \mathrm{g}$ and the applied strain was about $250 \mu \varepsilon$, these results are consistent with the manufacturer's specifications of $<0.5 \mathrm{mv}$ output for a strain of $250 \mu \varepsilon$. The orientations of the sensor in the two mechanical packages are shown in Figure 13. The precise orientation in the 7270AM4 allowed orientation of the sensor with the beams in line with the shock and oriented at $90^{\circ}$ to the shock, and the results are shown in Appendix B. 
The characterization of the cross-axis response of the ENDEVCO 7270A and $7270 \mathrm{AM} 4$ accelerometers continued in the four environments of static strain on a beam of $250 \mu \varepsilon$; dynamic beam strain experiments at $250 \mu \varepsilon$ (as per ISA-RP 37.2, Paragraph 6.6); and static compression experiments up to $100 \mu \varepsilon$ and mechanical compressive shock with a 2 in. diameter split Hopkinson bar configuration. The larger diameter beryllium hardware allows the investigation of more orientations of the accelerometers. The orientation of the sensors for the static compression and mechanical compressive shock cross-axis experiments are shown in Figure 6. Radial strain measurements verified the performance of the beryllium. For the static and dynamic base strain experiments, a steel beam as specified in ISA-RP 37.2, Paragraph 6.6 was used. This recommended practice creates maximum surface strain at the fixed end of a cantilever beam. The transducers are mounted at this location and subjected to base strain. The base strain is one-dimensional surface strain because the beam has a very large radius of curvature that minimizes the motion at the transducer and the centrifugal acceleration, $\mathrm{r} \omega^{2}$. The results of the static compression, static beam, and dynamic beam strain are shown in Tables VVII, respectively. The response of the accelerometers in these three environments is a base strain response and is consistent with the manufacturer's specifications of $<0.5 \mathrm{mv}$ output for a strain of $250 \mu \varepsilon$. Raw data for the static compression strain are shown in Appendix B.

The ENDEVCO 7270A (flat package) shows a base strain response when subjected to a compressive mechanical shock. The ENDEVCO 7270AM4 (can package) shows a base strain response when the beams are in line to the shock and an acceleration response when the beams are in other orientations to the shock. Time history plots of these responses are shown in Appendix B. These data have a $20 \mathrm{kHz}$ frequency component that is the first axial mode of the insert. The data cannot be filtered to eliminate this resonant response without severely compromising the rise time of the initial response.

Table V: Static Base Strain Results.

\begin{tabular}{|c|c|c|c|c|}
\hline $\begin{array}{c}\text { Accelerometer } \\
\text { Type }\end{array}$ & Orientation & $\begin{array}{c}\text { Torque } \\
(\mathbf{i n}-\mathbf{l b})\end{array}$ & $\begin{array}{c}\text { Strain Sensitivity } \\
(\mathrm{g} / \mu \varepsilon)\end{array}$ & $\begin{array}{c}\text { Voltage output } \\
\text { at 250 } \mu \varepsilon(\mathrm{mv})\end{array}$ \\
\hline 7270AM4-200K & $80^{\circ}$ & 75 & 0.5816 & 0.187 \\
\hline $7270 \mathrm{AM} 4-200 \mathrm{~K}$ & $25^{\circ}$ & 75 & 0.0612 & 0.019 \\
\hline $7270 \mathrm{~A}-60 \mathrm{~K}$ & In Line & 9 & 0.1531 & 0.064 \\
\hline $7270 \mathrm{~A}-60 \mathrm{~K}$ & $45^{\circ}$ & 9 & 0.4184 & 0.166 \\
\hline $7270 \mathrm{~A}-60 \mathrm{~K}$ & $90^{\circ}$ & 9 & 0.3061 & 0.124 \\
\hline
\end{tabular}


Table VI: Static Beam Results.

\begin{tabular}{|c|c|c|c|c|}
\hline $\begin{array}{c}\text { Accelerometer } \\
\text { Type }\end{array}$ & Orientation & $\begin{array}{c}\text { Torque } \\
(\mathbf{i n}-\mathbf{l b})\end{array}$ & $\begin{array}{c}\text { Strain Sensitivity } \\
(\mathrm{g} / \mu \varepsilon)\end{array}$ & $\begin{array}{c}\text { Voltage output } \\
\text { at 250 } \mu \varepsilon(\mathbf{m v})\end{array}$ \\
\hline $7270 \mathrm{AM} 4-200 \mathrm{~K}$ & In Line* & 75 & 3.2260 & 1.090 \\
\hline $7270 \mathrm{AM} 4-200 \mathrm{~K}$ & $15^{\circ}$ & 75 & 0.2368 & 0.080 \\
\hline $7270 \mathrm{~A}-60 \mathrm{~K}$ & In Line & 9 & 0.4232 & 0.175 \\
\hline $7270 \mathrm{~A}-60 \mathrm{~K}$ & $45^{\circ}$ & 9 & 0.6772 & 0.280 \\
\hline $7270 \mathrm{~A}-60 \mathrm{~K}$ & $90^{\circ}$ & 9 & 0.0943 & 0.039 \\
\hline
\end{tabular}

Table VII: Dynamic Beam Strain Results.

\begin{tabular}{|c|c|c|c|c|}
\hline $\begin{array}{c}\text { Accelerometer } \\
\text { Type }\end{array}$ & Orientation & $\begin{array}{c}\text { Torque } \\
(\mathbf{i n}-1 \mathbf{b})\end{array}$ & $\begin{array}{c}\text { Strain Sensitivity } \\
(\mathrm{g} / \mu \varepsilon)\end{array}$ & $\begin{array}{c}\text { Voltage output } \\
\text { at 250 } \mu \varepsilon(\mathbf{m v})\end{array}$ \\
\hline 7270AM4-200K & In Line & 75 & 3.1370 & 1.060 \\
\hline $7270 \mathrm{AM} 4-200 \mathrm{~K}$ & $15^{\circ}$ & 75 & 0.5387 & 0.182 \\
\hline $7270 \mathrm{AM} 4-200 \mathrm{~K}$ & $15^{\circ}$ & 30 & 0.1717 & 0.058 \\
\hline $7270 \mathrm{~A}-60 \mathrm{~K}$ & In Line & 9 & 0.3918 & 0.162 \\
\hline $7270 \mathrm{~A}-60 \mathrm{~K}$ & $90^{\circ}$ & 9 & 0.0435 & 0.018 \\
\hline $7270 \mathrm{~A}-60 \mathrm{~K}$ & $45^{\circ}$ & 9 & 0.5804 & 0.240 \\
\hline
\end{tabular}

* 0.009 in shim

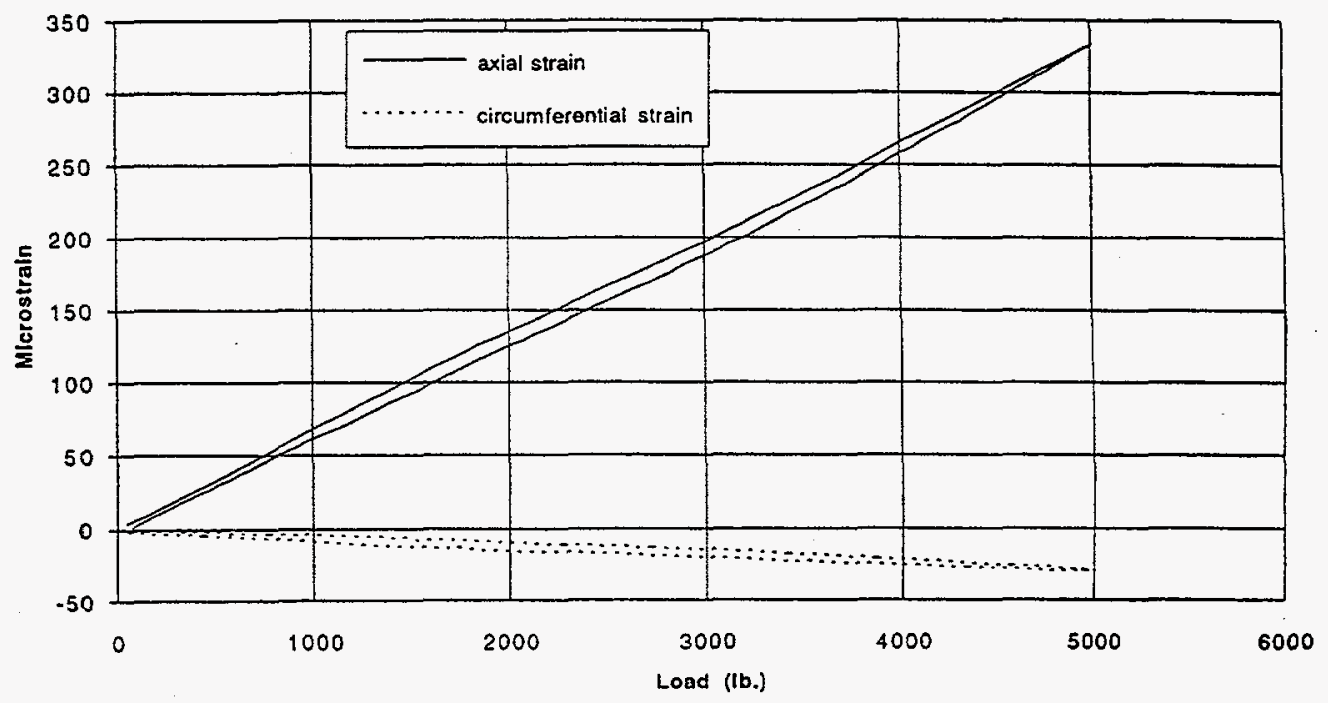

Figure 12: Strain Response for a Compressive Static Force Applied to the Beryllium Insert. 


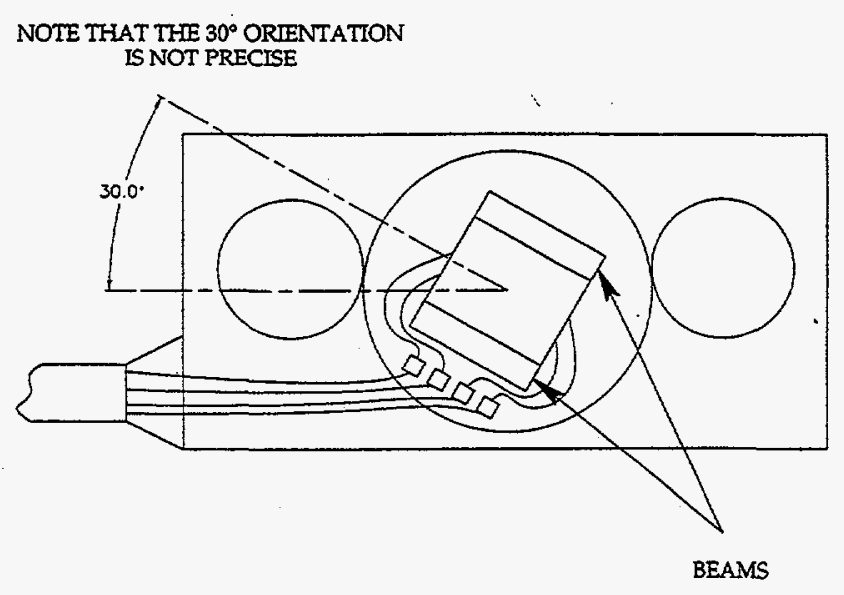

a) ENDEVCO 7270A

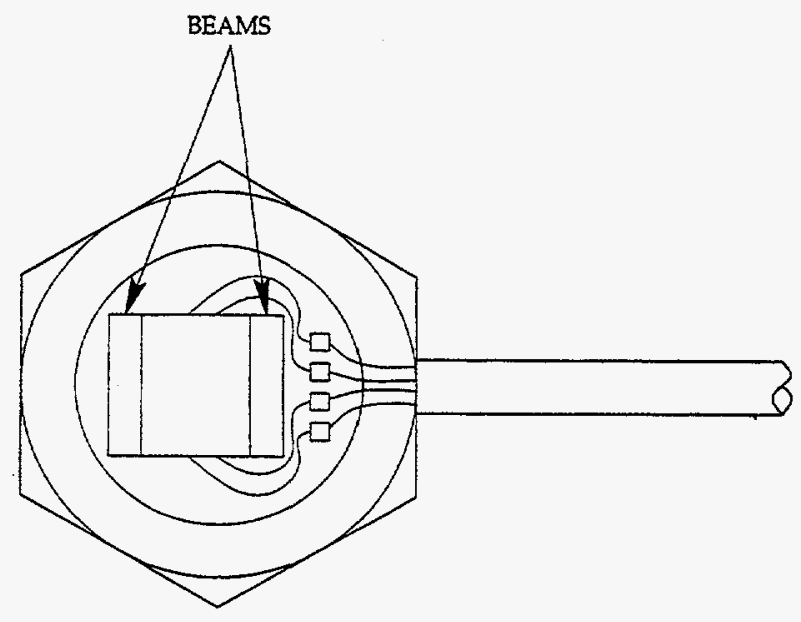

b) ENDEVCO 7270AM4

Figure 13: Orientation of the Sensor in the ENDEVCO 7270A and the ENDEVCO 7270AM4.

\section{Combined Shock Environment Performance}

The ENDEVCO 7270A and 7270AM4 accelerometers were mounted on their respective titanium Hopkinson bar shown in Figures 7 and 8. The nominal amplitude of the applied shock pulse was measured with both the references of strain gages and the LDV and agreed within $1 \%$. The results are shown in Table VIII, and time history plots are in Appendix B. Only one measurement from the 7270AM4 was obtained because the other accelerometer resonated and failed. Both the screws for the 7270A and the stud for the 7270AM4 had backed out after the shock pulse. The loose accelerometers chattered on their flats and caused the accelerometers to resonate. It is hypothesized that the ends modes of the bar caused the screws/stud to loosen. ENDEVCO has donated two accelerometers so that SNL can investigate this problem.

\section{Table VIII: Summary of Accelerometer Performance in Combined Shock.}

\begin{tabular}{|c|c|c|c|c|}
\hline $\begin{array}{c}\text { Nominal } \\
\text { Amplitude }\end{array}$ & $\begin{array}{c}\text { Accelerometer } \\
\text { Model }\end{array}$ & $\begin{array}{l}\text { In-Axis } \\
\text { Ampltide }\end{array}$ & $\begin{array}{c}\text { Accelerometer } \\
\text { Response }\end{array}$ & $\begin{array}{c}\text { Percentage } \\
\text { Error }\end{array}$ \\
\hline $49,500 \mathrm{~g}$ & $7 \overline{270 \mathrm{AM} 4}$ & $35,000 \mathrm{~g}$ & $\overline{37,500 \mathrm{~g}}$ & $\overline{+7.1 \%}$ \\
\hline $50,000 \mathrm{~g}$ & $7270 \mathrm{~A}$ & $35,350 \mathrm{~g}$ & $37,000 \mathrm{~g}$ & $+4.7 \%$ \\
\hline $50,000 \mathrm{~g}$ & $7270 \mathrm{~A}$ & $35,350 \mathrm{~g}$ & $39,000 \mathrm{~g}$ & $+10.3 \%$ \\
\hline
\end{tabular}




\section{Failure Mode Analysis}

On June 6, 1998, twenty-seven Model 7270A (flat package) accelerometers were given to ENDEVCO for failure analysis. Sixteen of the twenty-seven accelerometers had equal input/output resistances indicated that the sensors were intact; their failure mode is assumed to be cable failure. The remaining eleven accelerometers had specific complaints, including cable failure, as noted in Table IX. Three of the accelerometers showed evidence of exposure to high temperature or an electromagnetic environment because parts of the sensor were melted. These three accelerometers were purchased by Eglin AFB. The failure analyses performed in cooperation with ENDEVCO have provided a great insight as to the failure modes of the 7270A. The overwhelming majority of the failures are due to cable failure that is explained below.

During a SNL program to develop a transducer with high input impedance, a response was measured that did not appear to originate with the sensor. The cable used with the transducer is the ENDEVCO 7270A cable. This cable is silverplated, 36 gage copper conductors with a silverplated-copper shield and fluorocarbon jacket. The cable was taped to a titanium Hopkinson bar with a 0.75 in. diameter and a $72 \mathrm{in.} \mathrm{length} \mathrm{as} \mathrm{shown} \mathrm{in} \mathrm{Figure} \mathrm{14.} \mathrm{All} \mathrm{investigations} \mathrm{were} \mathrm{conducted} \mathrm{at} \mathrm{a}$ nominal velocity of $10 \mathrm{fps}$ magnitude and $90 \mu$ s duration (measured at $10 \%$ amplitude). An amplifier gain of 50 was used unless otherwise noted, and an excitation of $10 \mathrm{~V}$. was provided on the black and red wires unless otherwise noted. The results of this investigation are summarized in Table $X$. These investigations show that the cable generates its own voltage output when it is subjected to a shock in line with the cable. This cable response can be as much as $10 \%$ of the transducer output. It is hypothesized that the movement of the wires inside their insulation causes the cable output. The movement of the wires eventually breaks the wires that can be misinterpreted as sensor failure. The cable is subjected to shock in most applications because the cables are secured to a structure that undergoes a shock environment. These investigations explain not only the failure mode of the cable, but also mysterious transducer output without excitation from other shock experiments. It has been recommended to ENDEVCO that a methodology for isolating the cable from shock waves be developed in cooperation with SNL. 


\section{Table IX: Failure Analysis of Eleven ENDEVCO 7270A Accelerometers.}

\begin{tabular}{|c|c|c|}
\hline Model, S/N & Complaint & Action \\
\hline $\begin{array}{l}7270 \mathrm{~A}-20 \mathrm{~K} \\
\text { AG5L3 }\end{array}$ & $\begin{array}{l}\text { Resonant frequency } \\
\text { ringing during applied } \\
\text { shock pulse. }\end{array}$ & $\begin{array}{l}\text { Shocked unit at } 4908 \mathrm{~g} \text {; slight after pulse } \\
\text { ringing present (typical output) Sens. } \\
10.25 \mu \mathrm{V} @ 0.171 \mathrm{mS}, \mathrm{ZMO} 41.8 \mathrm{mV}\end{array}$ \\
\hline $\begin{array}{l}7270 \mathrm{~A}-20 \mathrm{~K} \\
\text { A19YF }\end{array}$ & $\begin{array}{l}\text { No output: unit gauge } \\
\text { resistance values } \\
\text { change when tapped on } \\
\text { bench. (i.e. } R-W \text { gage } \\
17 \Omega \text { before, } 496 \Omega \text { after) }\end{array}$ & $\begin{array}{l}\text { Could not duplicate changing gage } \\
\text { resistance. Shocked at } 4850 \text { g, output } \\
\text { normal. Sens. } 9.646 \mu \mathrm{V} @ 0.174 \mathrm{mS}, \mathrm{ZMO} \\
22.6 \mathrm{mV} \text {; Zin } / \text { Zout }=605 / 604\end{array}$ \\
\hline $\begin{array}{c}7270 \mathrm{~A}-20 \mathrm{~K} \\
\mathrm{AG} 502\end{array}$ & $\begin{array}{l}\text { dc offset shifts with } \\
\text { cable movement }\end{array}$ & $\begin{array}{l}\text { Verified complaint. Circuit open at G-B } \\
\text { when cable is bent in a cross-axis direction } \\
\text { away from the serial number face. } \\
\text { (otherwise output is } 73.5 \mathrm{mV} \text { ) }\end{array}$ \\
\hline $\begin{array}{c}7270 \mathrm{~A}-20 \mathrm{~K} \\
\mathrm{~B} 91 \mathrm{AF}\end{array}$ & & $\begin{array}{l}\text { All four gages intact. BW trace on ceramic } \\
\text { open!! }\end{array}$ \\
\hline $\begin{array}{c}7270 \mathrm{~A}-20 \mathrm{~K} \\
\mathrm{~B} 72 \mathrm{CF}\end{array}$ & $\begin{array}{l}\text { Purchased by Eglin } \\
\text { AFB. }\end{array}$ & $\begin{array}{l}\text { GB links all have tiny pimples at mid- } \\
\text { length. Fused one downside gage. }\end{array}$ \\
\hline $\begin{array}{l}\text { 7270A-60K } \\
\text { A51KF }\end{array}$ & $\begin{array}{l}\text { Displays ringing during } \\
\text { dropball calibration. }\end{array}$ & $\begin{array}{l}\text { Shocked } 5 \text { times between } 4259 \text { and } 4880 \mathrm{~g} \text {. } \\
\text { Only showed typical after-pulse resonant } \\
\text { frequency ringing. Sens. } 1.738 \mu \mathrm{V} @ 0.171 \\
\mathrm{mS}, \mathrm{ZMO}-81.6 \mathrm{mV}\end{array}$ \\
\hline $\begin{array}{l}7270 \mathrm{~A}-200 \mathrm{~K} \\
\mathrm{AFFH} 2\end{array}$ & $\begin{array}{l}\text { Open - Purchased by } \\
\text { Eglin AFB. }\end{array}$ & $\begin{array}{l}\text { One link of GB fused. Adjacent links \& } \\
\text { aluminum have been melted. }\end{array}$ \\
\hline $\begin{array}{l}\text { 7270A-200K } \\
\text { AP693 }\end{array}$ & Open & $\begin{array}{l}\text { One link of WG broken, piece missing. } \\
\text { Another edge flaked by shrapnel. }\end{array}$ \\
\hline $\begin{array}{l}7270 \mathrm{~A}-200 \mathrm{~K} \\
\text { AD288 }\end{array}$ & Open & Masses loose. \\
\hline $\begin{array}{l}\text { 7270A-200K } \\
\text { A44BF }\end{array}$ & No output & $\begin{array}{l}\text { Failed glassbond. Gross die fracture, } \\
\text { additional crack. INCLUSION IN } \\
\text { GLASSBOND. }\end{array}$ \\
\hline $\begin{array}{l}\text { 7270A-200K } \\
\text { DN81F }\end{array}$ & $\begin{array}{l}\text { No output - Purchased } \\
\text { by Eglin AFB. }\end{array}$ & $\begin{array}{l}\text { Severe ohmic heating to GB. } 6 \text { links } \\
\text { vaporized, remaining } 2 \text { links shorted by } \\
\text { fused Silicon. Traces leadwire to GB } \\
\text { deeply melted. }\end{array}$ \\
\hline
\end{tabular}




\section{Table X: Hopkinson Bar Cable Investigation Summary.}

\begin{tabular}{|c|c|c|}
\hline No. & Description & Results \\
\hline 1 & $\begin{array}{l}\text { Cable taped to the bar. Cable shield } \\
\text { also tied to the bar. Cable conductors } \\
\text { connected to amplifier as shown. }\end{array}$ & $\begin{array}{l}\text { Oscillatory output with a period of about } \\
500 \mu \mathrm{s}(2 \mathrm{kHz}) \text { and peak magnitude of } 8.3 \\
\text { V. }\end{array}$ \\
\hline 2 & Same as No. 1 but no excitation voltage. & $\begin{array}{l}\text { Oscillatory output with a period of about } \\
350 \mu \mathrm{s}(3 \mathrm{kHz}) \text { and peak magnitude of } \\
10.1 \mathrm{~V} \text {. This means the output is self- } \\
\text { generated. }\end{array}$ \\
\hline 3 & $\begin{array}{l}\text { Same as No. } 1 \text { with green and white } \\
\text { wires disconnected from the amplifier } \\
\text { input. (Excitation voltage is still } \\
\text { applied.) }\end{array}$ & $\begin{array}{l}\text { Oscillatory output with a period of about } \\
350 \mu \mathrm{s}(3 \mathrm{kHz}) \text { and peak magnitude of } \\
2.0 \mathrm{~V} \text {. Output is capacitive coupling } \\
\text { through remaining wires. }\end{array}$ \\
\hline 4 & $\begin{array}{l}\text { Same as No. } 1 \text { but all conductors } \\
\text { disconnected from the amplifier. Cable } \\
\text { shield is still connected as shown. }\end{array}$ & $\begin{array}{l}\text { Oscillatory output with a period of about } \\
350 \mu \mathrm{s}(3 \mathrm{kHz}) \text { and peak magnitude of } \\
0.1 \mathrm{~V} \text {. }\end{array}$ \\
\hline 5 & $\begin{array}{l}\text { Same as No. } 4 \text { but cable shield is also } \\
\text { disconnected. }\end{array}$ & $\begin{array}{l}\text { Output is amplifier drift only - } \\
\text { magnitude is about } 40 \mathrm{mV} \text { or } 0.8 \mathrm{mV} \\
\text { peak before gain. This is the open } \\
\text { circuit, baseline noise. }\end{array}$ \\
\hline 6 & $\begin{array}{l}\text { A low impedance transducer ( } 350 \Omega \\
\text { bridge) is connected to the end cable } \\
\text { and powered. The cable is taped to the } \\
\text { bar as before. Transducer is just } \\
\text { hanging in the air. Shield is connected } \\
\text { as shown. }\end{array}$ & $\begin{array}{l}\text { Oscillatory output with an irregular } \\
\text { period and a peak magnitude of } 125 \mathrm{mV} \\
\text { peak-to-peak. Baseline noise has } \\
\text { dropped to } 3 \mathrm{mV} \text {. The } \mathbf{1 2 5} \mathrm{mV} \\
\text { represents about } \mathbf{1 0 \%} \text { of the transducer } \\
\text { response for this stress wave. }\end{array}$ \\
\hline 7 & $\begin{array}{l}\text { Same as No. } 2 \text { with the shield } \\
\text { disconnected. }\end{array}$ & $\begin{array}{l}\text { Oscillatory output with a period of about } \\
1200 \mu \mathrm{s}(833 \mathrm{~Hz}) \text { and peak magnitude of } \\
\pm 2 \mathrm{~V} \text {. }\end{array}$ \\
\hline 8 & Repeat of No. 2 . & $\begin{array}{l}\text { Oscillatory output with a period of about } \\
350 \mu \mathrm{s}(3 \mathrm{kHz}) \text { and peak magnitude of } \\
16.3 \mathrm{~V} \text {. }\end{array}$ \\
\hline 9 & $\begin{array}{l}\text { Same as No. } 8 \text { but cable removed from } \\
\text { the bar and hangs by the bar in the air. }\end{array}$ & $\begin{array}{l}\text { Output is amplifier drift only - } \\
\text { magnitude is about } 100 \mathrm{mV} \text { per } 1 \mathrm{~ms} \text {. }\end{array}$ \\
\hline 10 & $\begin{array}{l}\text { Same as No. } 9 \text { with no bar impact } \\
\text { (baseline noise plots). }\end{array}$ & $\begin{array}{l}\text { Output is amplifier drift only - } \\
\text { magnitude is about } 40 \mathrm{mV} \text { or } 0.8 \mathrm{mV} \\
\text { prior to amplifier gain. }\end{array}$ \\
\hline 11 & $\begin{array}{l}\text { Repeat of No. } 2 \text { with a longer duration } \\
\text { pulse }(169 \mu \mathrm{s}) \text { created by the use of } \\
0.0625 \text { in. thick felt instead of the index } \\
\text { cards used for the previous }\end{array}$ & $\begin{array}{l}\text { Oscillatory output with a period of about } \\
350 \mu \mathrm{s}(3 \mathrm{kHz}) \text { and peak magnitude of } \\
14.8 \mathrm{~V} \text {. }\end{array}$ \\
\hline
\end{tabular}




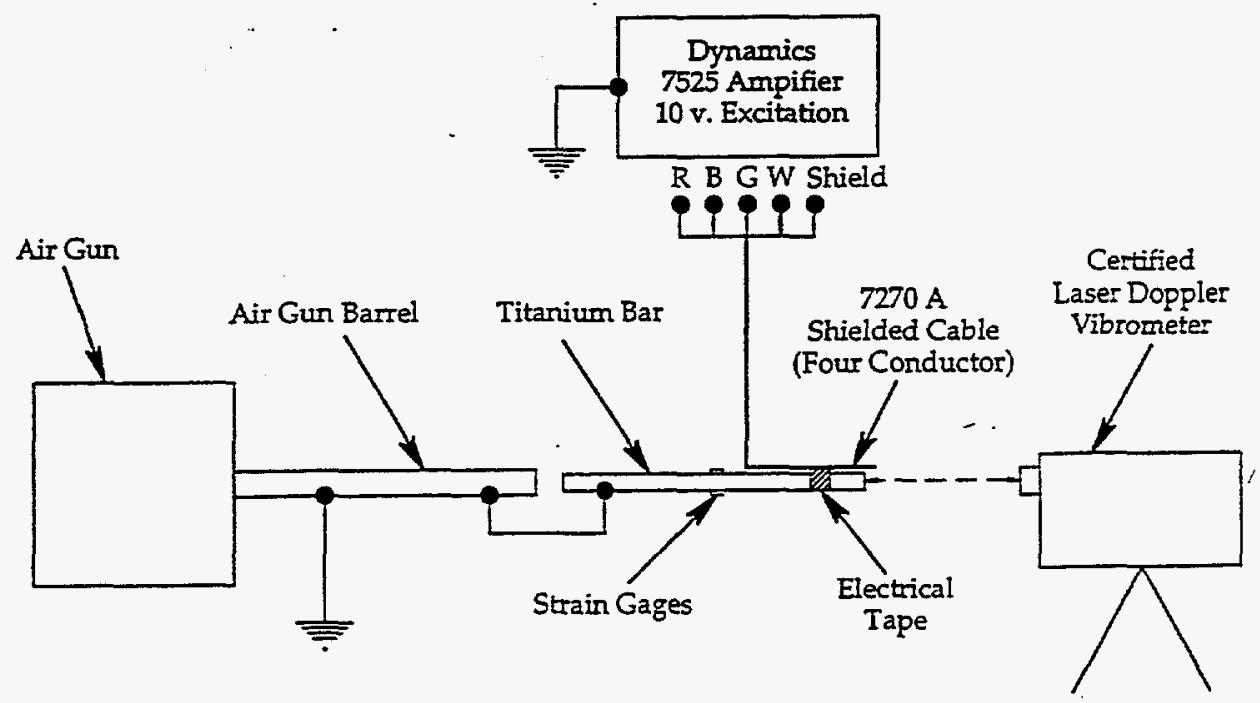

Figure 14: Hopkinson Bar Configuration for Cable Response
Investigations.

\section{Conclusions and Future Work}

Results in this report show the ENDEVCO 7270A and 7270AM4 are similar in response for in-axis shocks with the exception of a resonance noted in the can package at about $100 \mathrm{kHz}$ that is not apparent in the flat package. The in-axis characterizations include both time-domain results with a bandwidth of from dc to $100 \mathrm{kHz}$ and frequency-domain results with a bandwidth of from dc to $50 \mathrm{kHz}$. The results of the in-axis studies for these two accelerometers confirm the manufacturer's performance specifications for the accelerometers that were previously unconfirmed.

The characterization of the cross-axis response of the ENDEVCO 7270A and 7270AM4 accelerometers in the four environments of static compression experiments up to $100 \mu \varepsilon$; static strain on a beam of $250 \mu \varepsilon$, dynamic beam strain experiments at $250 \mu \varepsilon$ (as per ISA-RP 37.2, Paragraph 6.6), and mechanical compressive shock with split beryllium Hopkinson bar configuration have been completed. The cross axis response of the ENDEVCO 7270A is base strain sensitive, but the cross-axis response of the ENDEVCO 7270AM4 may be either base strain or 
acceleration. The accelerometer meets the manufacturer's specifications for base strain and cross axis sensitivity.

The characterization of the ENDEVCO 7270A and 7270AM4 accelerometers in a combined shock environment at $45^{\circ}$ has been completed. In every case, the accelerometer response was amplified by $4 \%$ to $10 \%$ in comparison to the reference measurement. The amount of amplification depends on both the mechanical package and orientation of the sensor to the shock. Since the accelerometers resonated and some failed in this environment, ENDEVCO has donated two accelerometers so that SNL can continue this part of the study.

Finally, a failure analysis conducted in cooperation with ENDEVCO gives a cause for the occasional unexplained failures that make this piezoresistive accelerometer questionable for some applications. When this analysis is combined with SNL measurements of the cable response in shock environments, a scenario emerges that explains mysterious unpowered accelerometer outputs and accelerometer failures. A configuration to apply simultaneous, perpendicular shocks is being constructed at the SNL Mechanical Shock Laboratory and will be used to continue the investigation of the failure modes for this accelerometer. These characterizations, accomplished at the high frequencies and high shock levels, will permit better interpretation of data measured in the presence of high frequency, high shock environments. 


\section{References}

1. Walton, Scott W., "New Ballistic Shock Protection Requirement for Armored Combat Vehicles," 60 $60^{\text {th }}$ Shock and Vibration Symposium, Vol. 1, November 1989.

2. Walton, Scott W., "The Significance of Shock Content Above $10 \mathrm{kHz}$ on Equipment," 63. Shock and Vibration Symposium, Vol. 1, November 1992.

3. Walton, Scott W., "Methodology Investigation Final Report of Correlation of Component Damage to Ballistic Shock II," U.S. Army Combat Systems Activity, Aberdeen Proving Ground, MD, TECOM Report No. 7-CO-M91-CSD-004, Report No. CSTA-7241.

4. Bateman, V. I., N. T. Davie, and F. A. Brown, "Characteristics of a Piezoresistive Accelerometer in Shock Environments up to $150,000 \mathrm{G}$," Proceedings of the 41st Annual Technical Meeting, Anaheim, CA, April 30-May 5, 1995, DT\&E Volume, pp. 217-224.

5. Bateman, V. I., W. B. Leisher, F. A. Brown, and N. T. Davie, "Calibration of a Hopkinson Bar With a Transfer Standard," Journal of Shock and Vibration, Vol. 1, No. 2, November-December, 1993, pp. 145-152.

6. Bateman, V. I., B. D. Hansche, and O. M. Solomon, "Use of a Laser Doppler Vibrometer for High Frequency Accelerometer Characterizations," Proceedings of the $66^{\text {th }}$ Shock and Vibration Symposium, Vol. II, October 30 -November 3, 1995, pp. 203-216.

7. Bateman, V. I., F. A. Brown, and N. T. Davie, "Use of a Beryllium Hopkinson Bar to Characterize a Piezoresistive Accelerometer in Shock Environments," Lournal of the Institute of Environmental Sciences, Volume XXXIX, No. 6, November/December 1996, pp. 33-39.

8. Umeda, Akira and Kazunaga Ueda, "Study on the Dynamic Force/Acceleration Measurements," Sensors and Actuators, A21-A23, 1990, pp. 285-288.

9. Ueda, K., and A. Umeda, "Characterization of Shock Accelerometers Using Davies Bar and Strain Gages," Experimental Mechanics, September 1993, pp. 228-233.

10. Togami, T. C., V. I. Bateman, and F. A. Brown, "Evaluation of a Hopkinson Bar Flyaway Technique for High Amplitude Shock Accelerometer Calibration," Proceedings of the 68 th Shock and Vibration Symposium, Vol. II, November 3-7, 1997.

11. Davies, R., "A Critical Study of the Hopkinson Pressure Bar," Philosophical Transactions, Series A, Royal Society of London, Vol. 240, pp. 352-375, January 8, 1948.

12. Kolsky, H., Stress Waves in Solids, Oxford University Press, 1953.

13. Bateman, V. I., R. G. Bell, and N. T. Davie, "Evaluation of Shock Isolation Techniques for a Piezoresistive Accelerometer," Proceedings of the 60th Shock and Vibration Symposium, David Taylor Research Center, Portsmouth, VA, November 1989. 


\section{References (cont.)}

14. Cannon, J. and D. Rimbey, "Transient Method of Calibrating a Piezoelectric Accelerometer for the High g-level Range," American Society of Mechanical Engineers No. 71-Vibr-43, ASME Vibrations Conference and the International Design Automation Conference, September 1971, Toronto, Canada.

15. Brown, G., "Accelerometer Calibration with the Hopkinson Pressure Bar," Instrument Society of America preprint No. 49.3.63, 18th Annual ISA Conference and Exhibit, September 1963, Chicago, Illinois.

16. Sill, R. D., "Shock Calibration of Accelerometers at Amplitudes to 100,000 g Using Compression Waves," Proceedings of the 29th International Instrument Symposium, Albuquerque, NM, May 2-6, 1983, pp. 503-516.

17. Stearns, S. D., "Integration and Interpolation of Sampled Waveforms," SAND771643, Sandia National Laboratories, January 1978.

18. Stearns, S. D., Digital Signal Analysis, Hayden Book Company Inc., 1975, pp. 37-40.

19. Bendat, J. S. and A.G. Piersol, Random Data, $2^{\text {nd }}$ Edition, John Wiley and Sons, 1986, pp.164-185. 


\section{Appendix A}

\section{In-Axis Performance of the Piezoresistive Accelerometer}




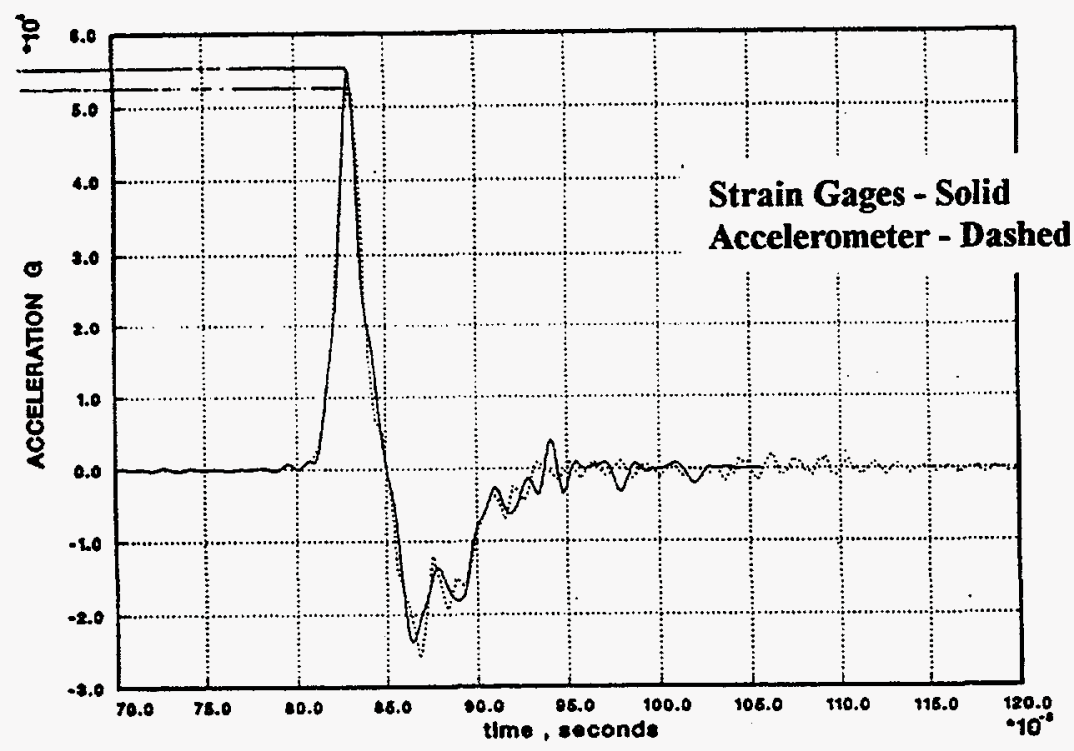

a) Time History

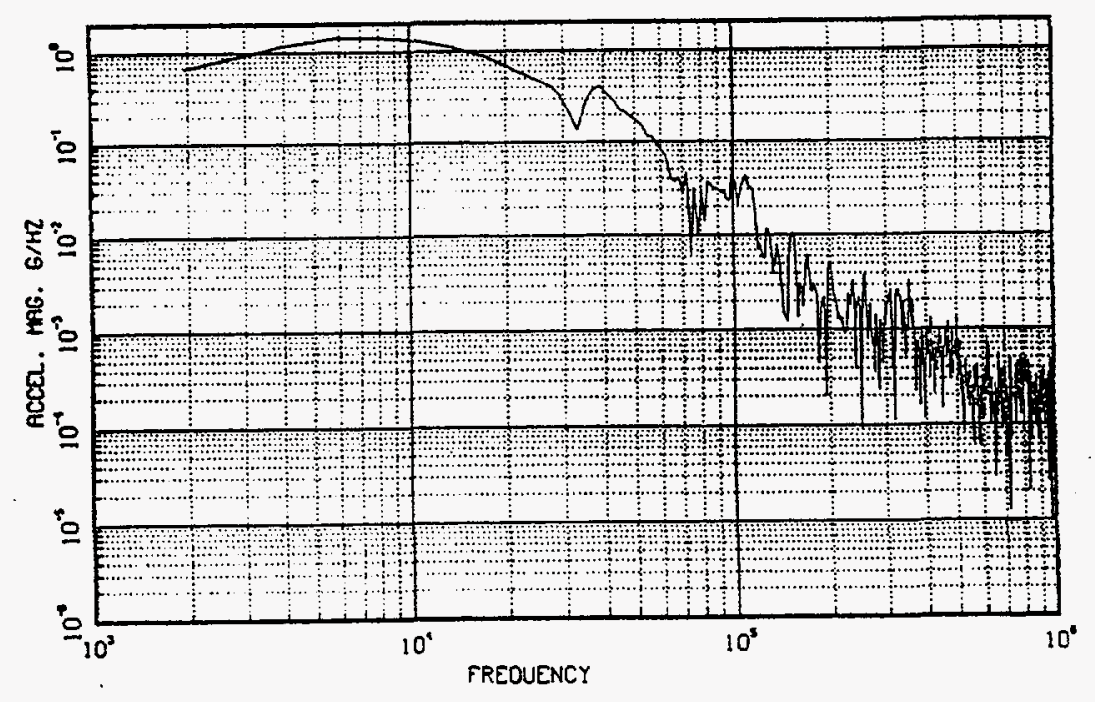

b) Fourier Transform

Time History and Fourier Transform for the ENDEVCO 7270A Mounted on a 0.75 in. Diameter Titanium Hopkinson Bar. 


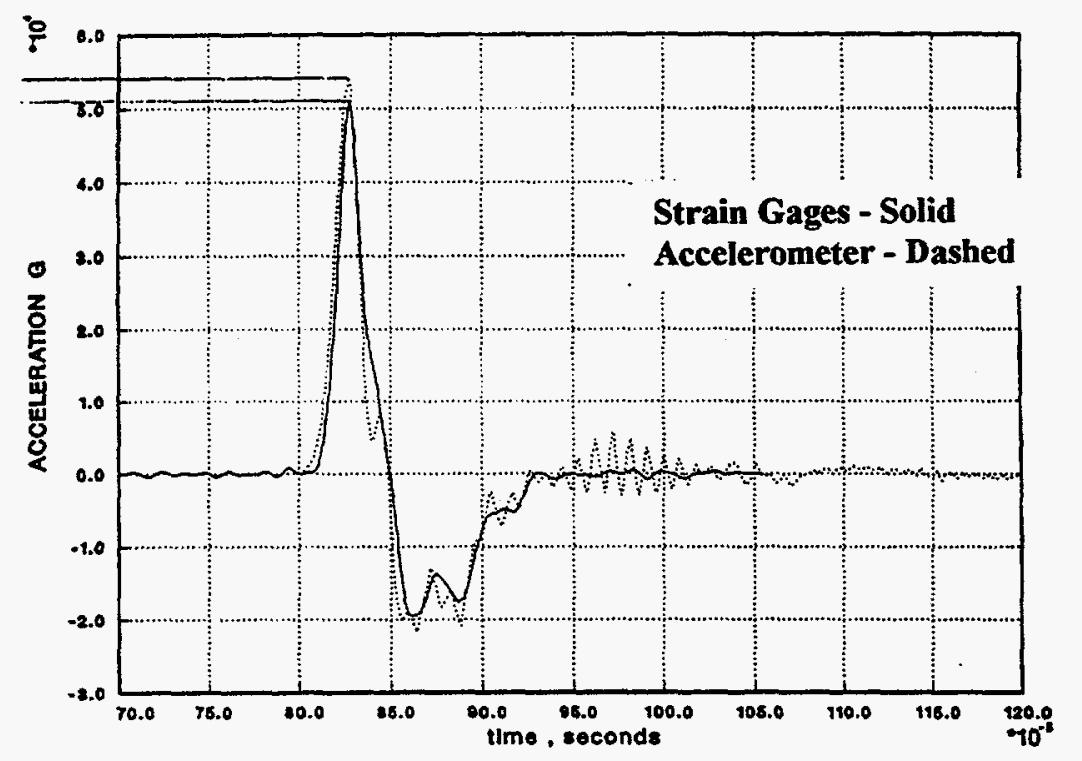

a) Time History

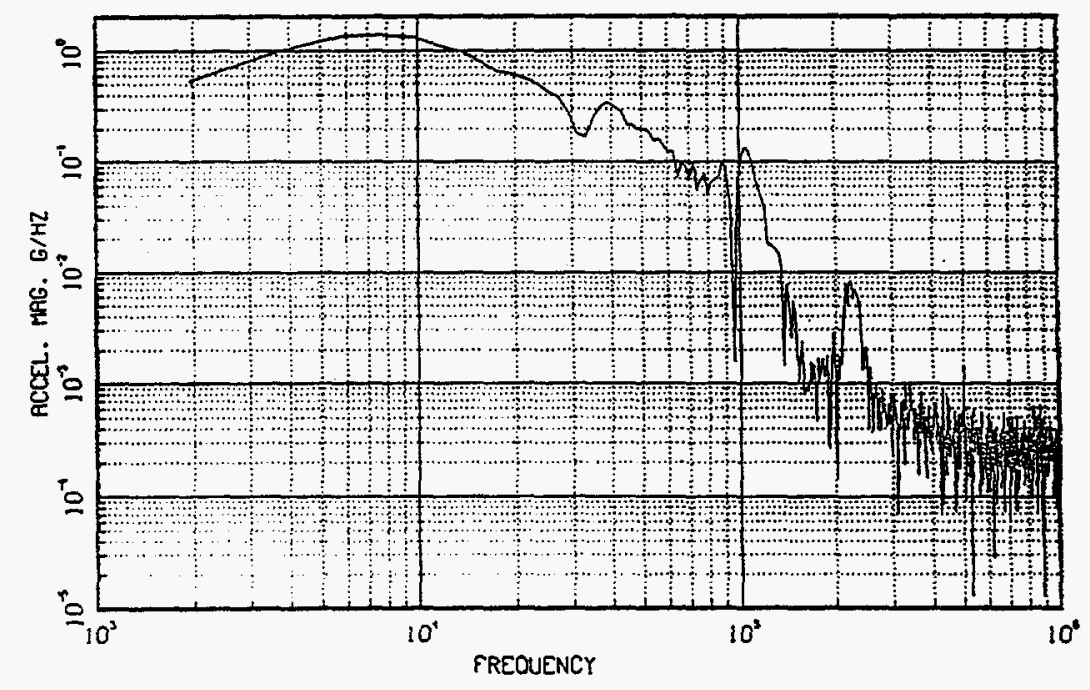

b) Fourier Transform

Time History and Fourier Transform for the ENDEVCO 7270AM4 Mounted on a 0.75 in. Diameter Titanium Hopkinson Bar. 


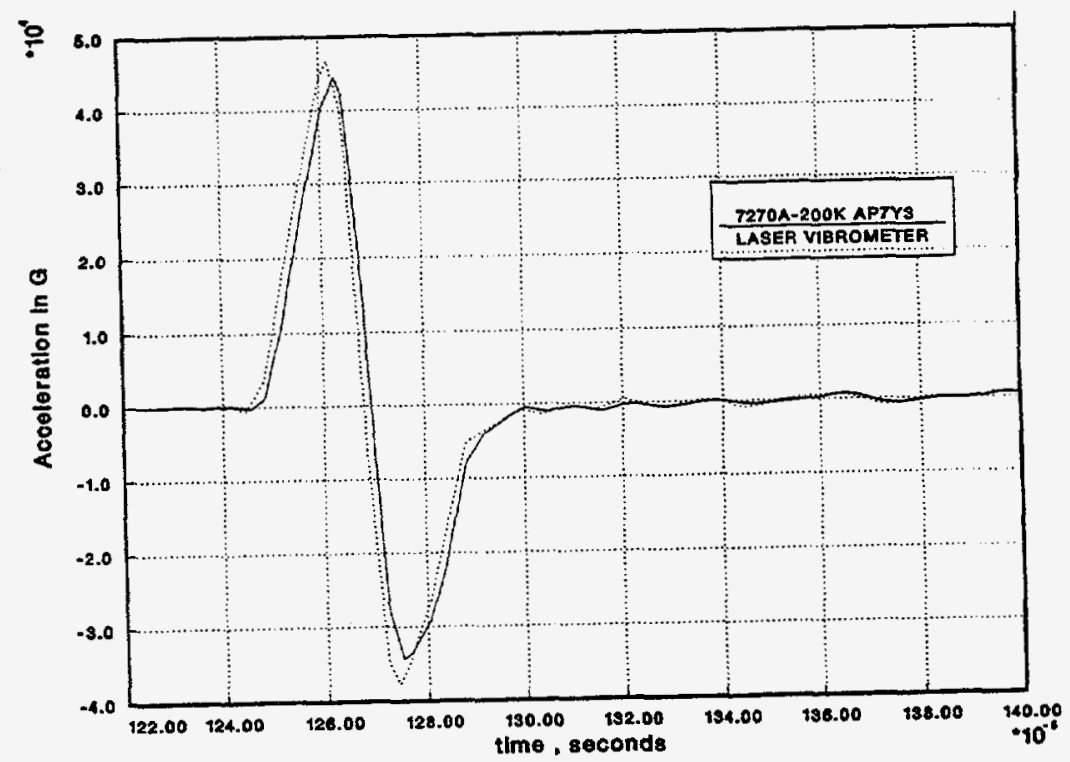

a) Time History

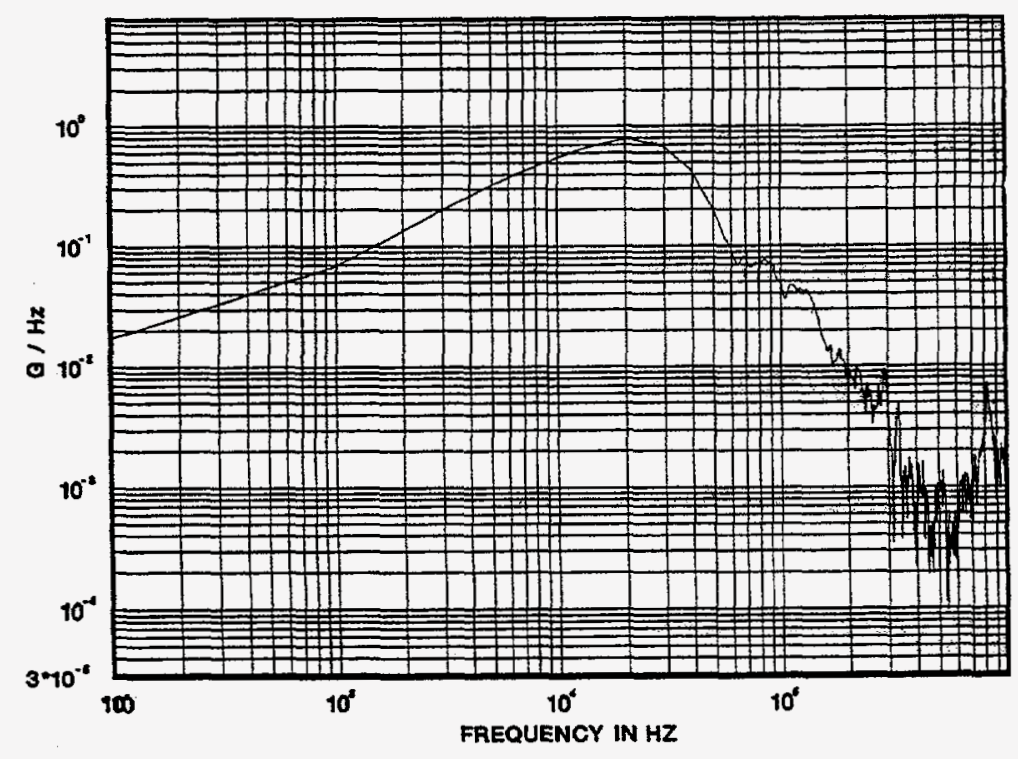

b) Fourier Transform

Time History and Fourier Transform for the ENDEVCO 7270A Mounted on a 0.75 in. Diameter Beryllium Hopkinson Bar. 


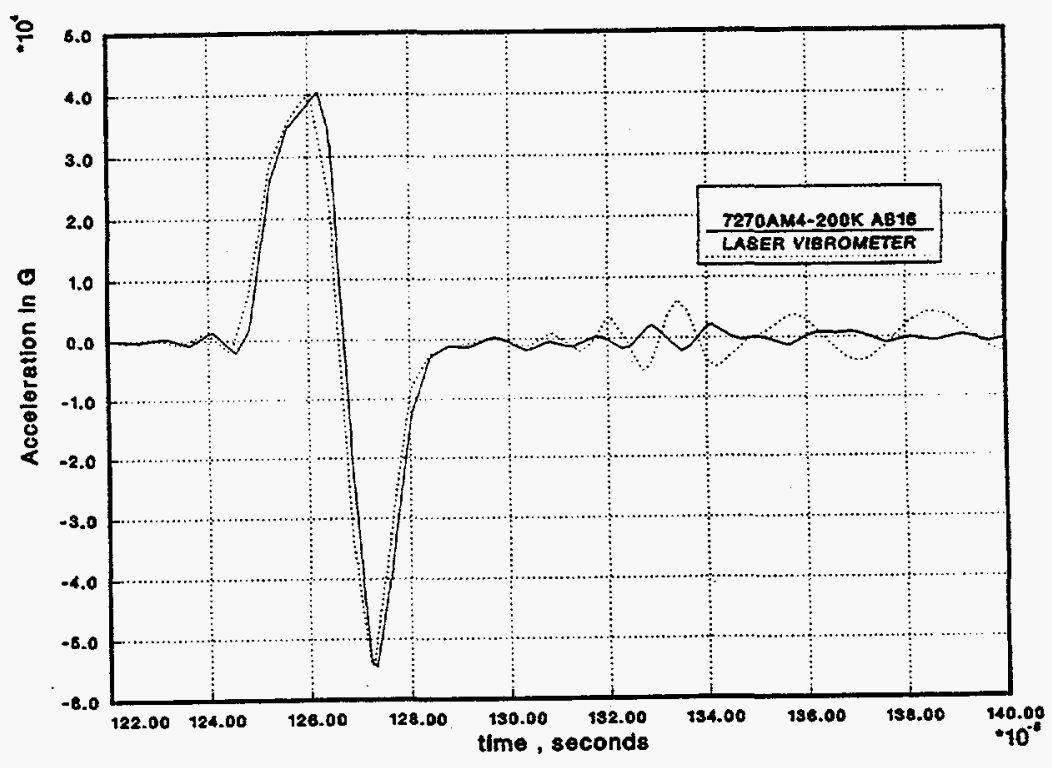

a) Time History

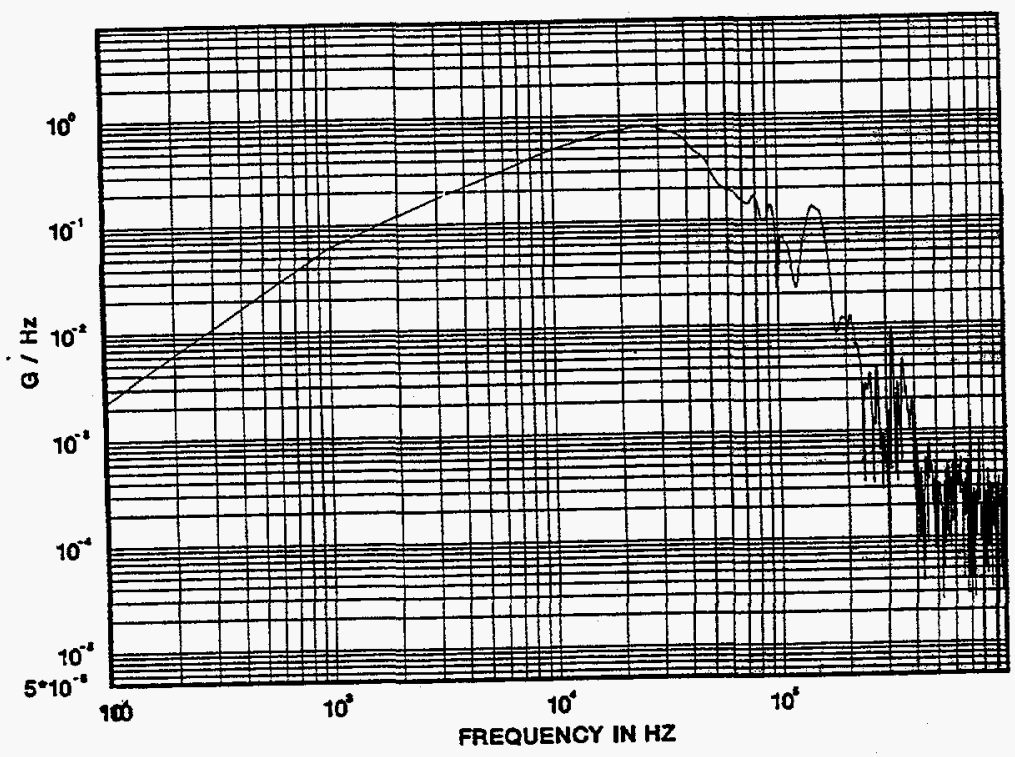

b) Fourier Transform

Time History and Fourier Transform for the ENDEVCO 7270AM4 Mounted on a 0.75 in. Diameter Beryllium Hopkinson Bar. 


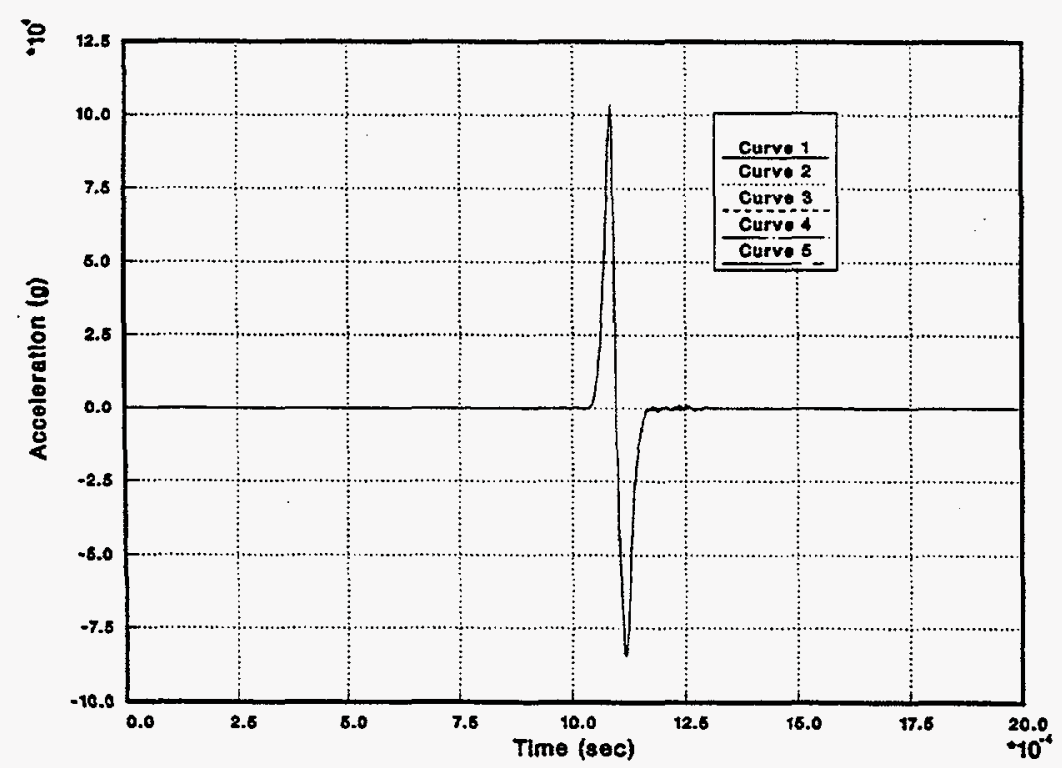

Five Accelerometer Responses Measured on the Titanium Hopkinson Bar at 100,000 g.

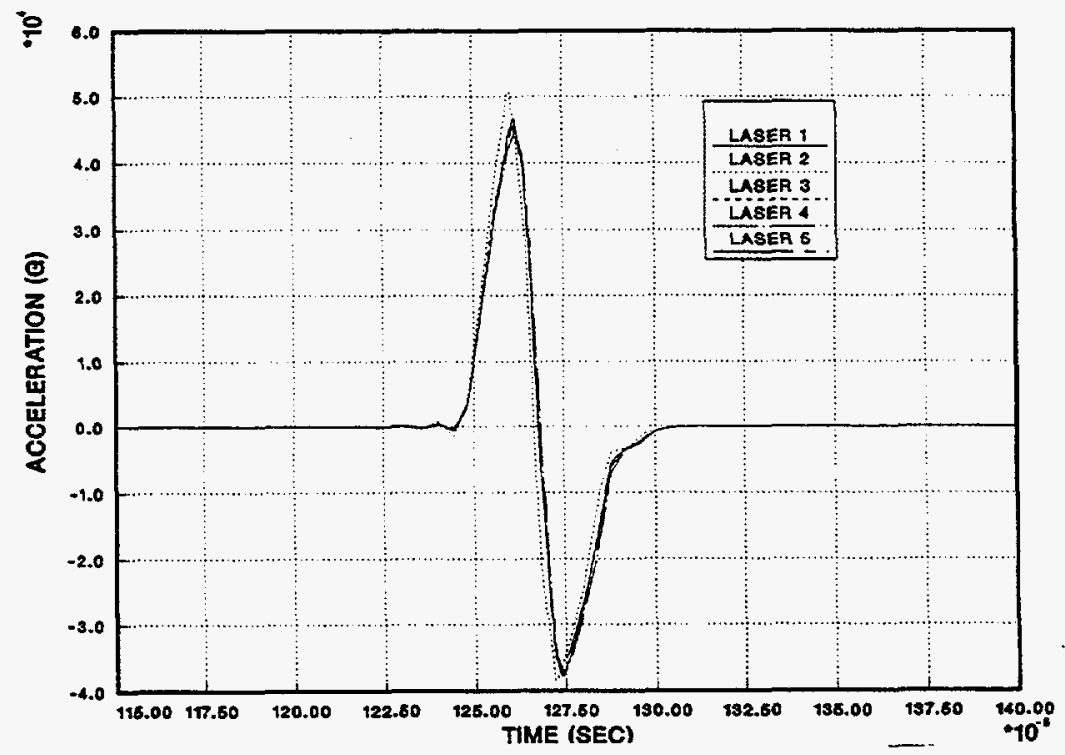

Five Laser Doppler Vibrometer Accelerations Calculated from Responses Measured on the Beryllium Hopkinson Bar at 40,000 g. 


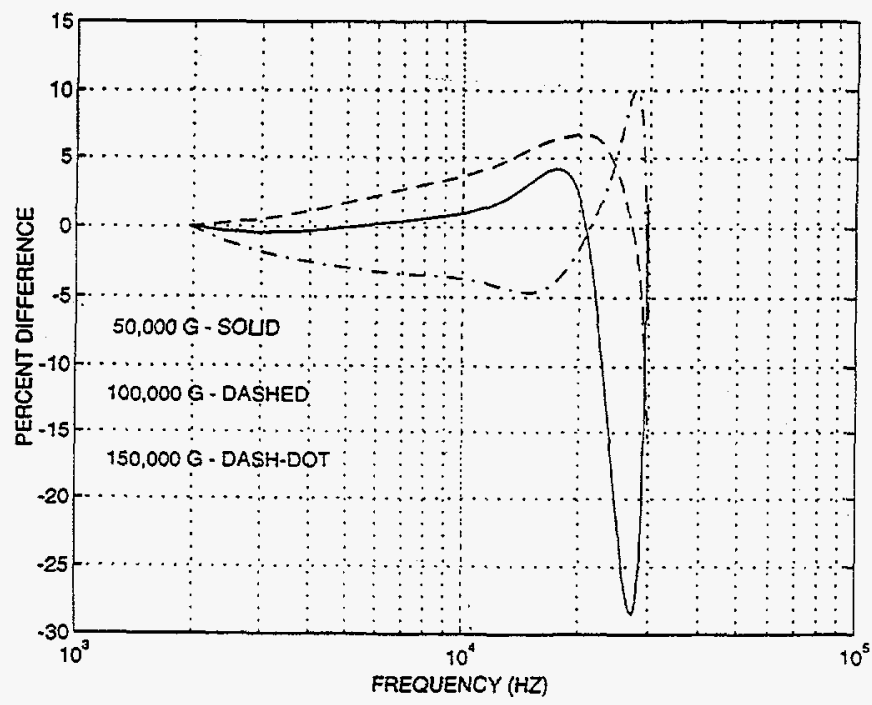

a) Magnitude

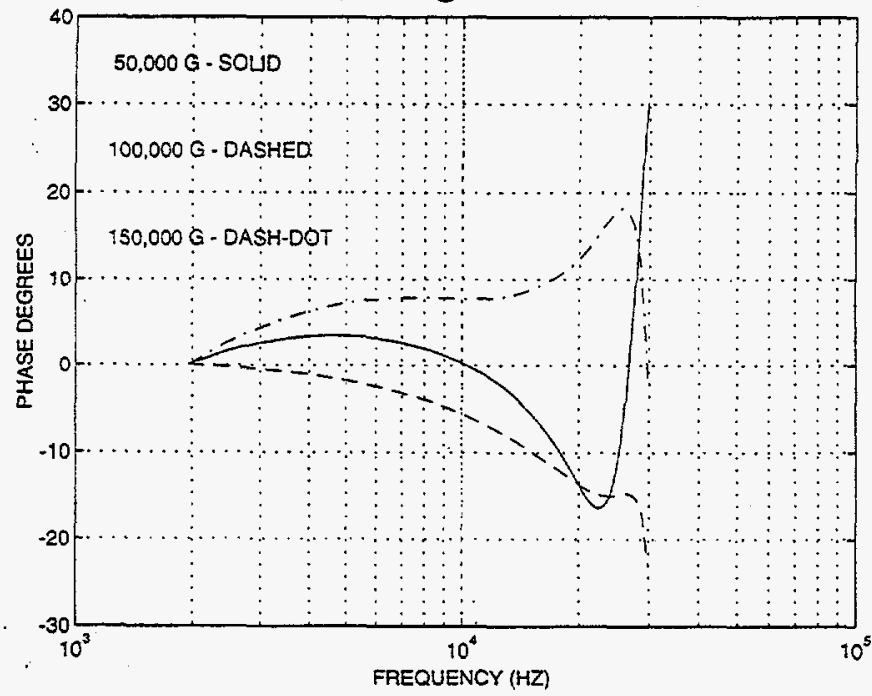

b) Phase

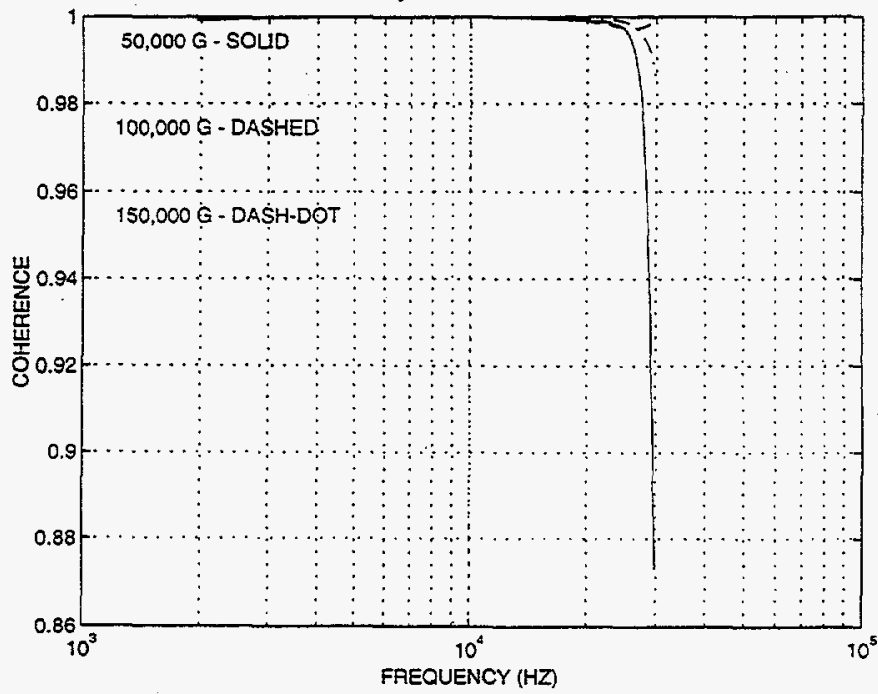

c) Coherence

Frequency Response Functions for the ENDEVCO 7270A Mounted on a 0.75 in. Diameter Titanium Hopkinson Bar. 


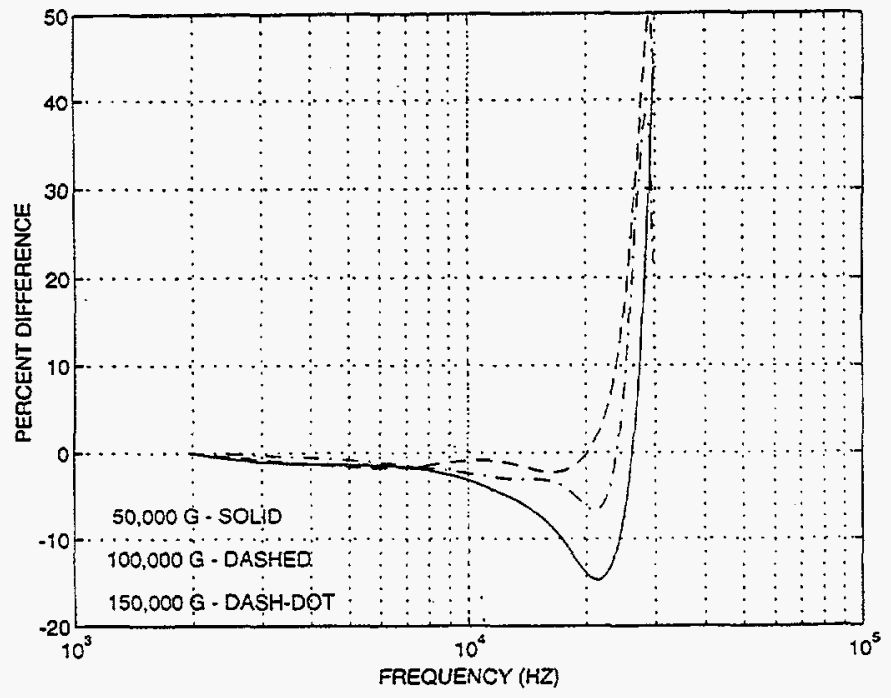

a) Magnitude

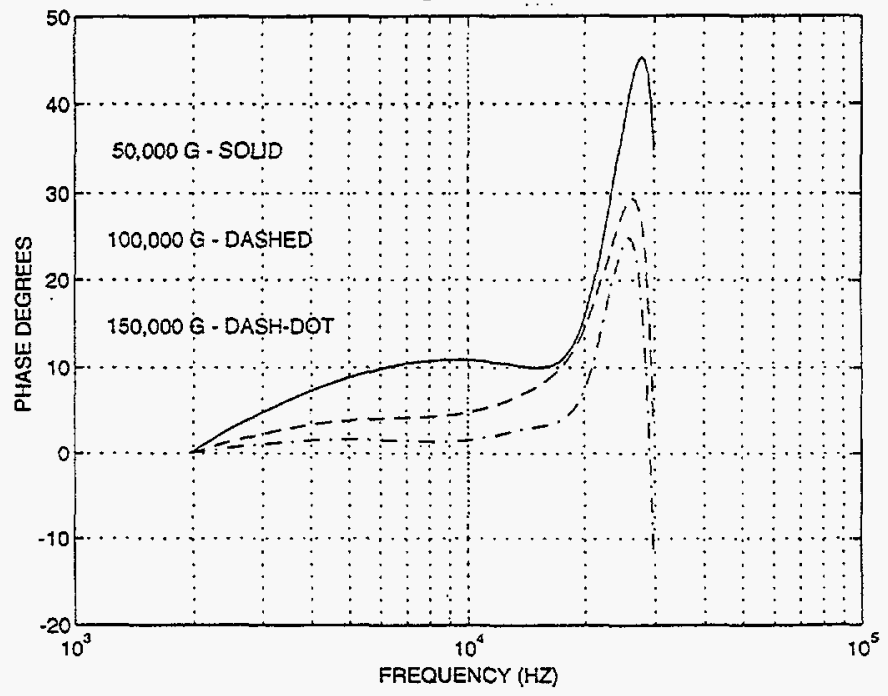

b) Phase

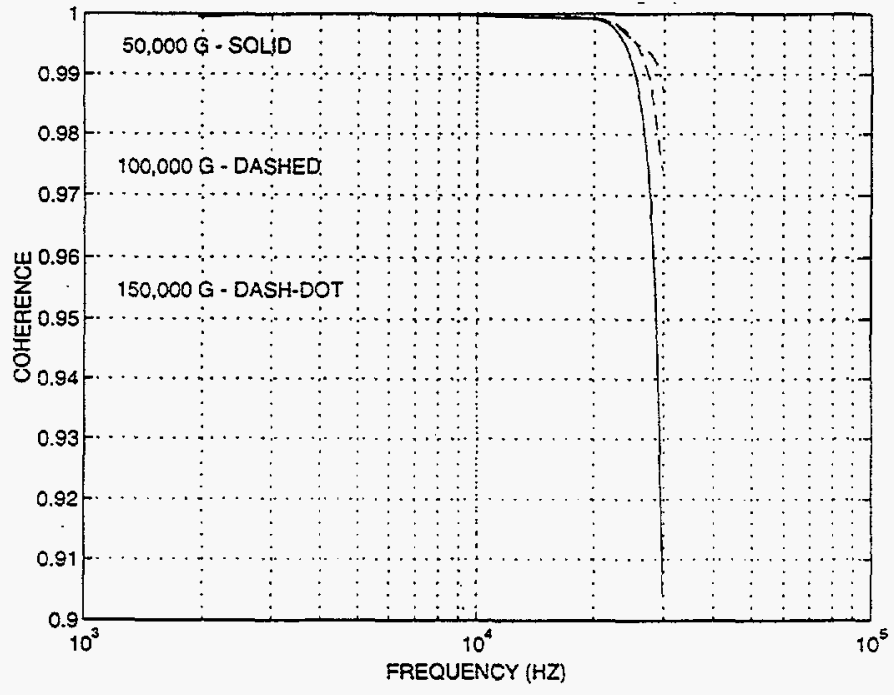

c) Coherence

Frequency Response Functions for the ENDEVCO 7270AM4 Mounted on a 0.75 in. Diameter Titanium Hopkinson Bar. 


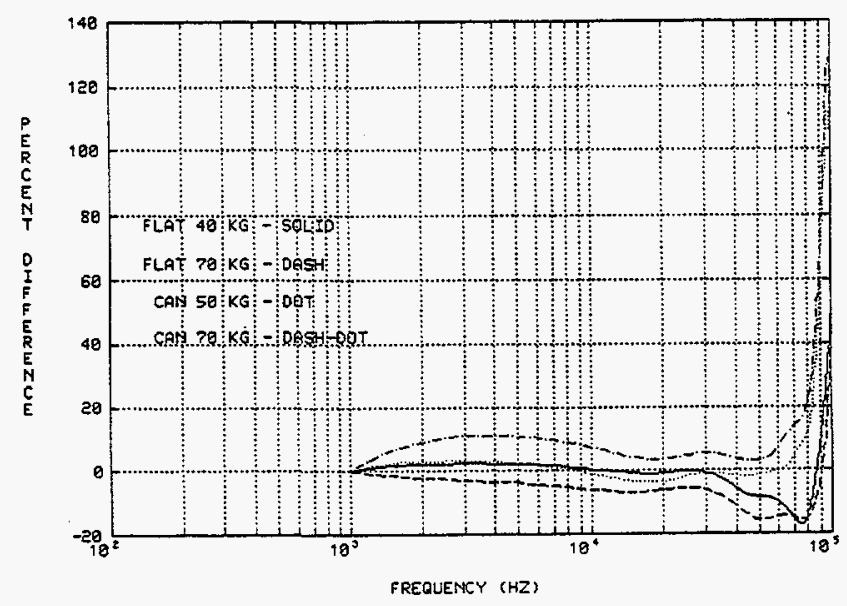

a) Magnitude

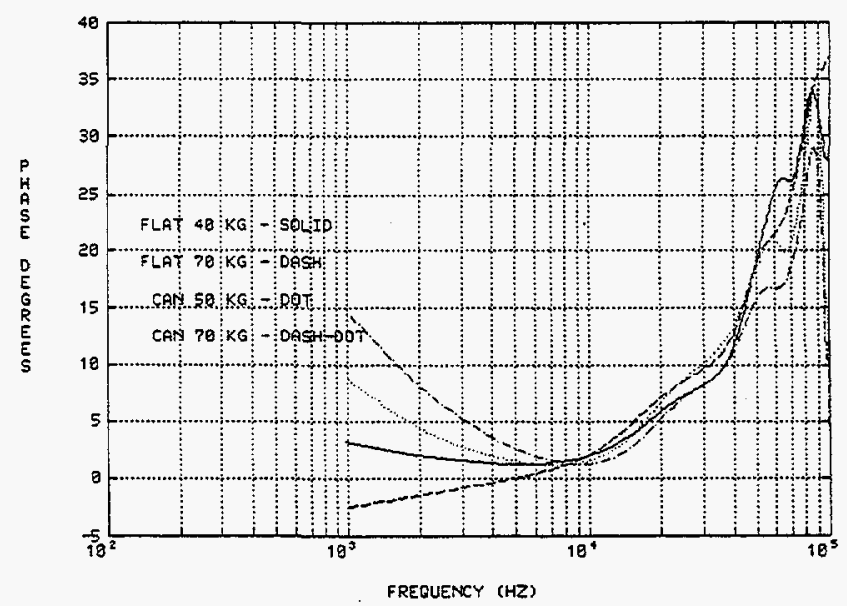

b) Phase

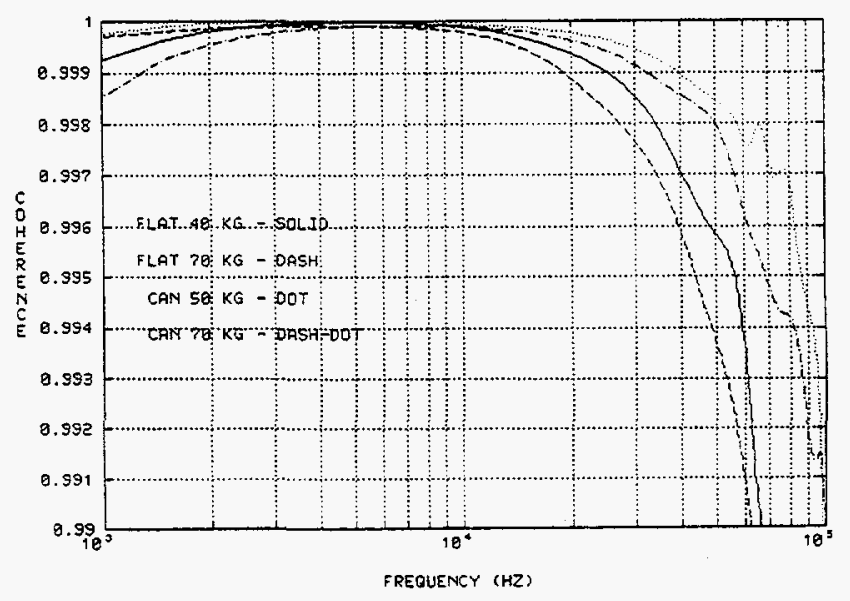

c) Coherence

Frequency Response Functions for the ENDEVCO 7270AM4 and the ENDEVCO 7270A Mounted on a 0.75 in. Diameter Beryllium Hopkinson Bar. 


\section{Appendix B}

Cross-Axis Performance of the Piezoresistive Accelerometer 


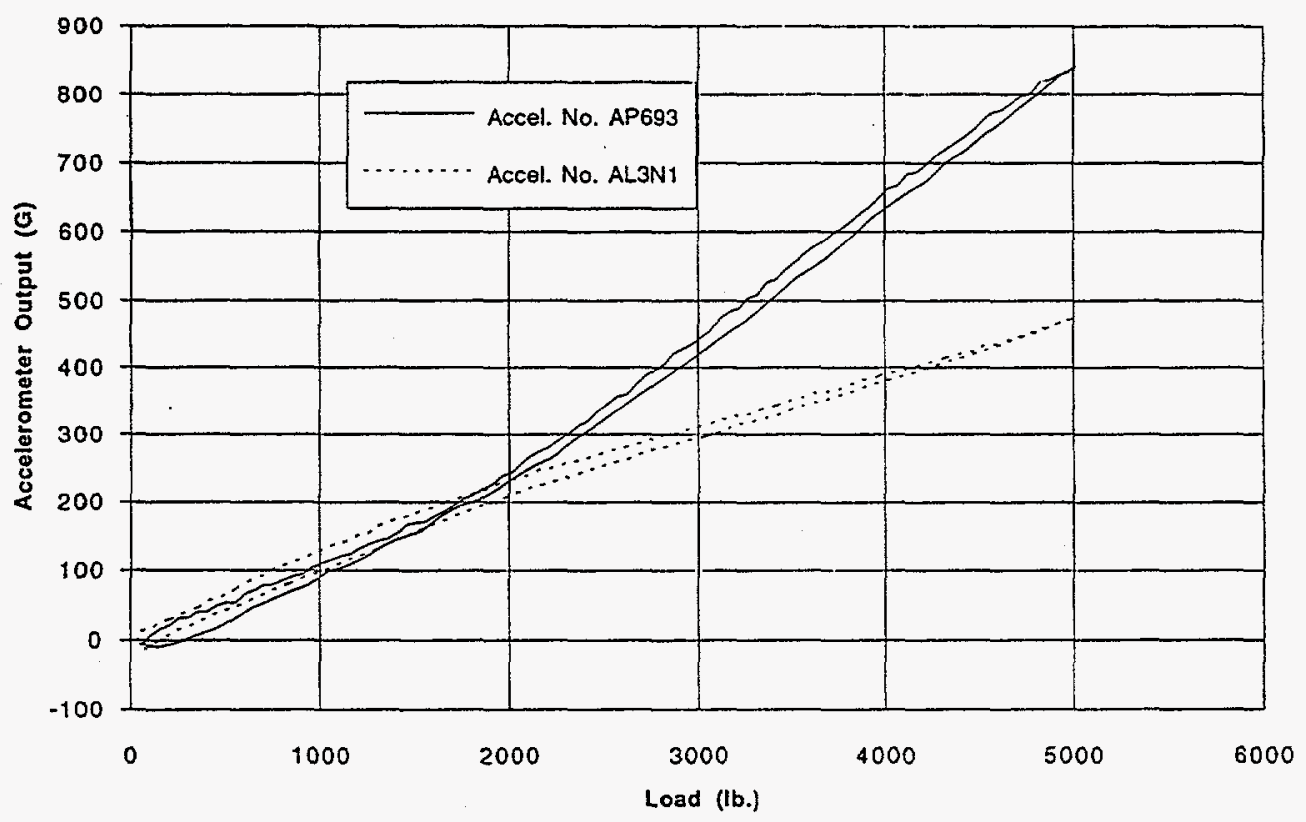

ENDEVCO 7270A Response for a Static Strain ( $250 \mu \varepsilon$ Amplitude) Applied to the Beryllium Insert (0.75 in. Diameter).

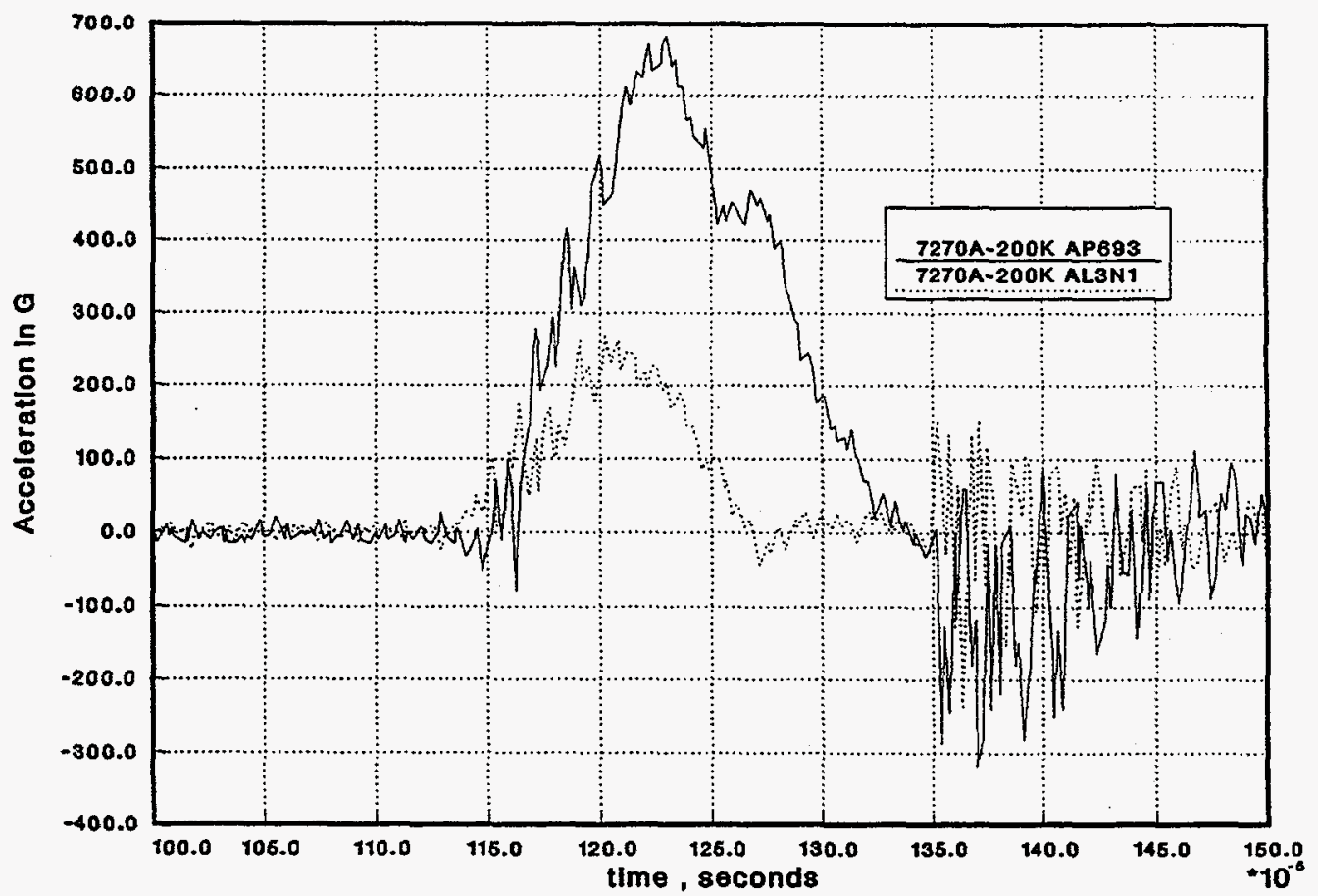

ENDEVCO 7270A Response for a Compressive Shock Applied to the Beryllium Insert (0.75 in. Diameter). 
BEAMS IN LINE TO SHOCK

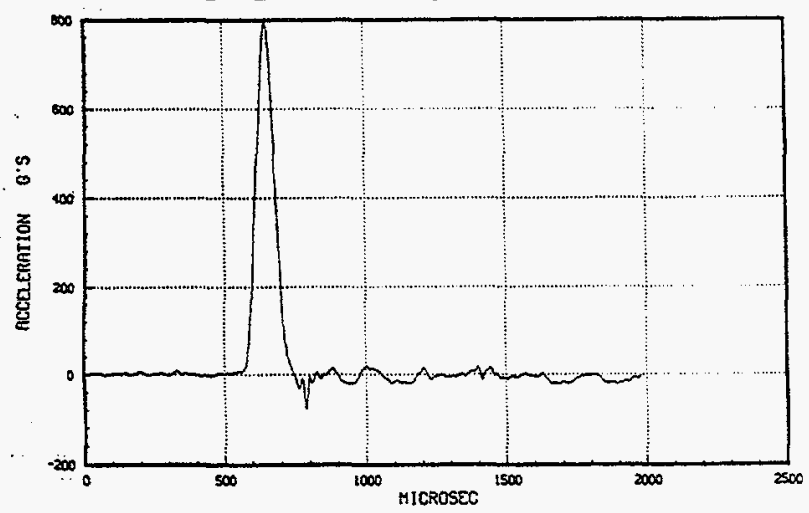

RESPONSE IS BASE STRAIN
BEAMS AT 90 DEGREES TO SHOCK

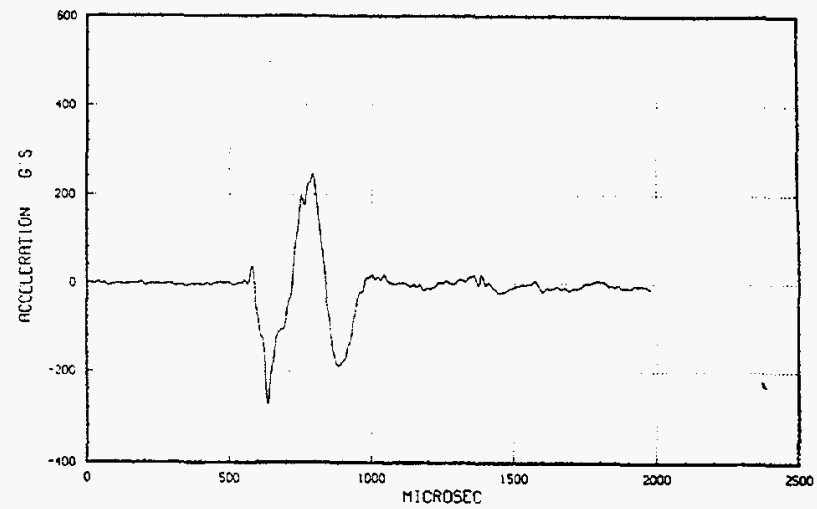

RESPONSE IS ACCELERATION

ENDEVCO 7270AM4 Response for a Compressive Shock Applied to the Beryllium Insert (0.75 in. Diameter).

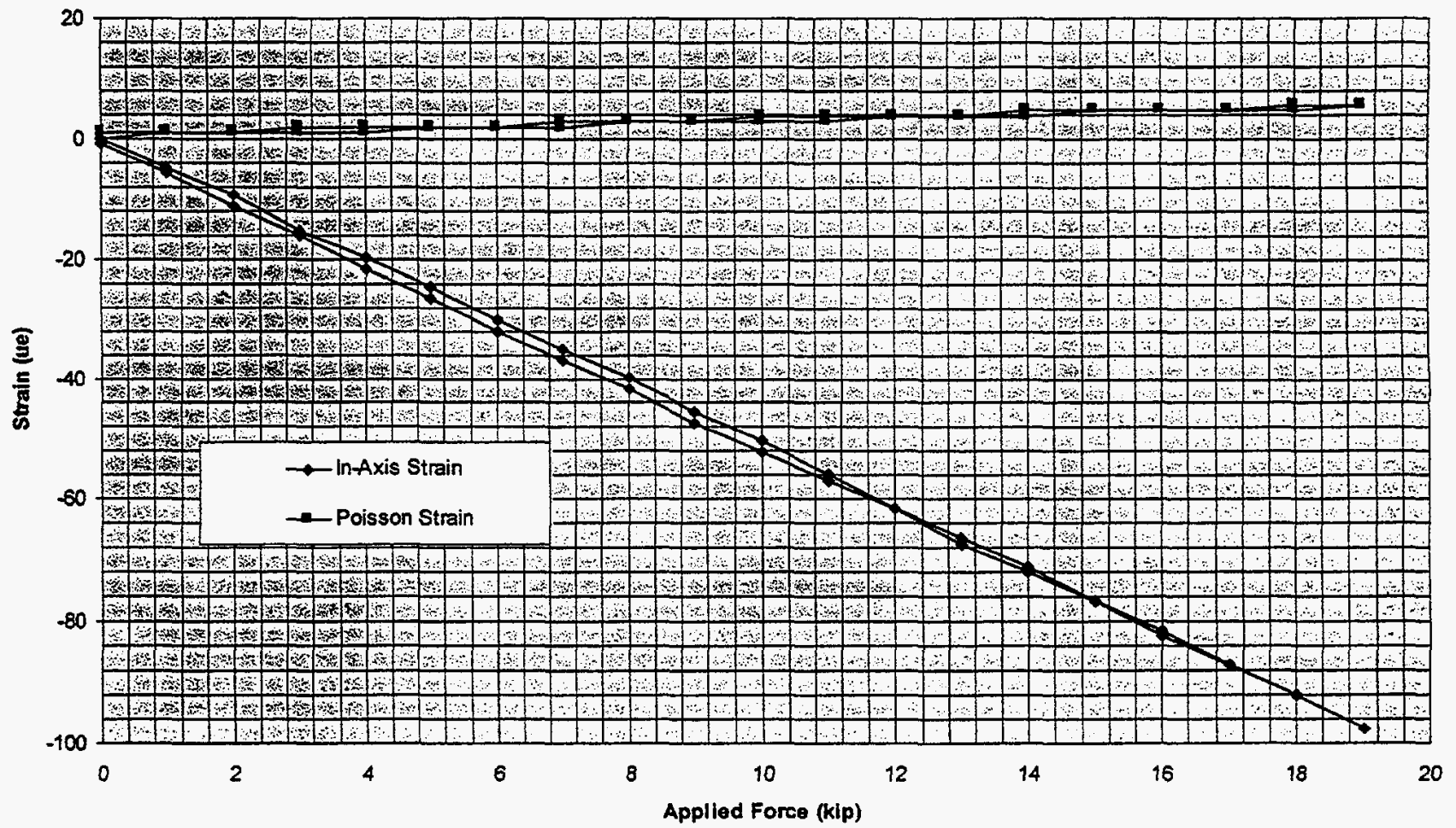

Strain Response for the Beryllium Insert (2.0 in. Diameter). 


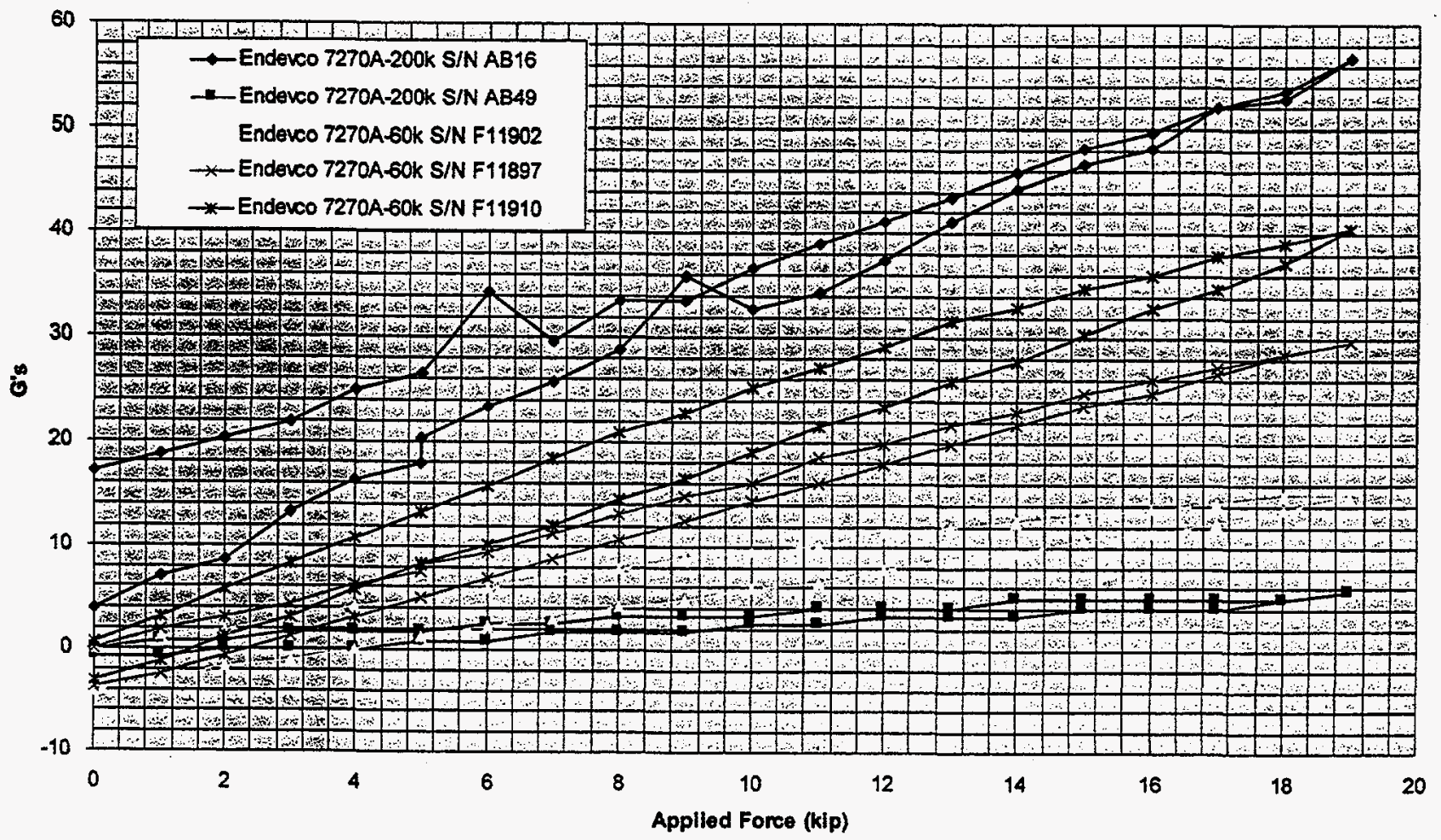

ENDEVCO 7270A-60K and 7270AM4-200K Response for a Static Strain (100 $\mu \varepsilon$ Amplitude) Applied to the Beryllium Insert (2.0 in. Diameter).

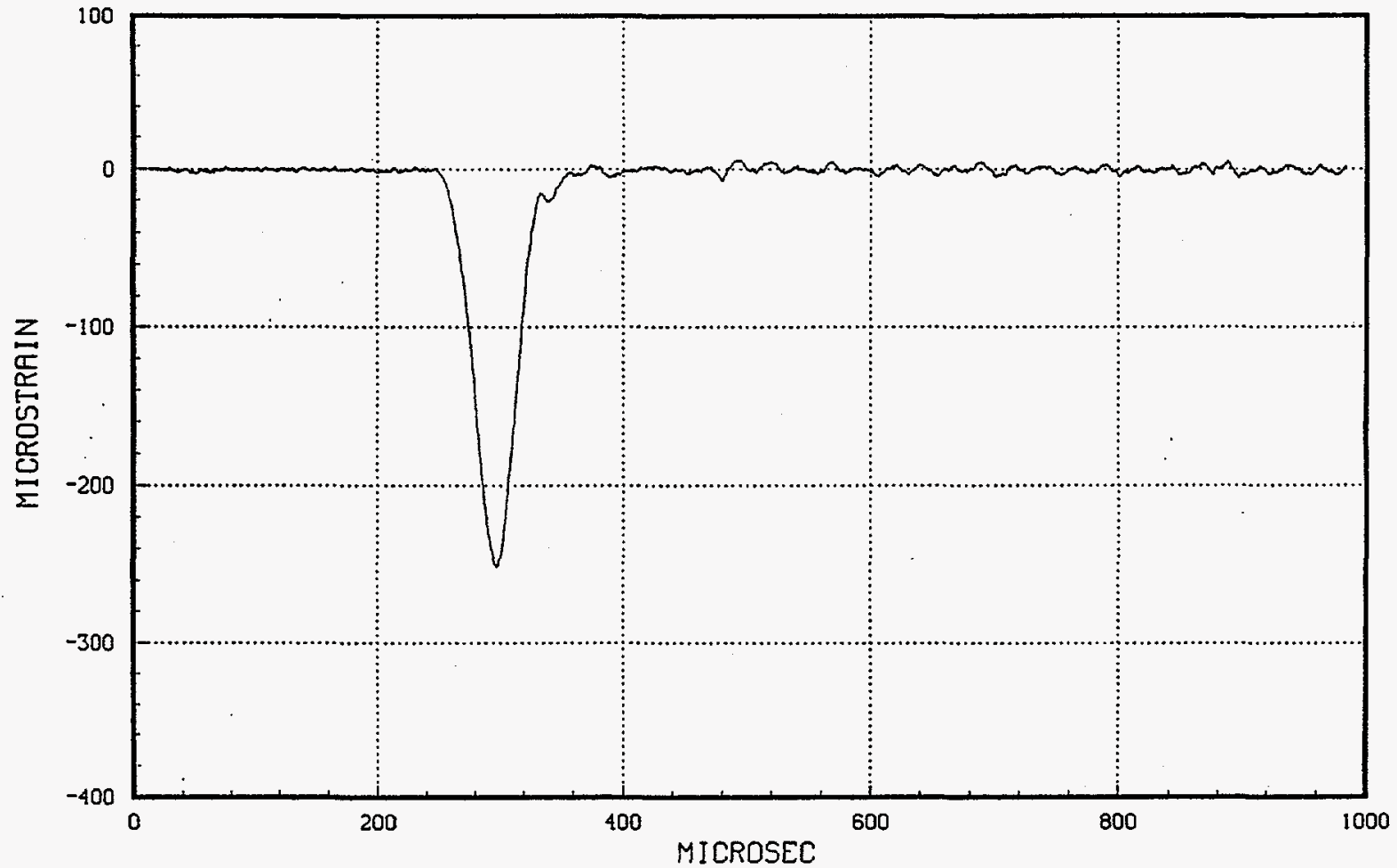

Axial Strain Response to Compressive Shock on the Beryllium Insert (2.0 in. Diameter). 


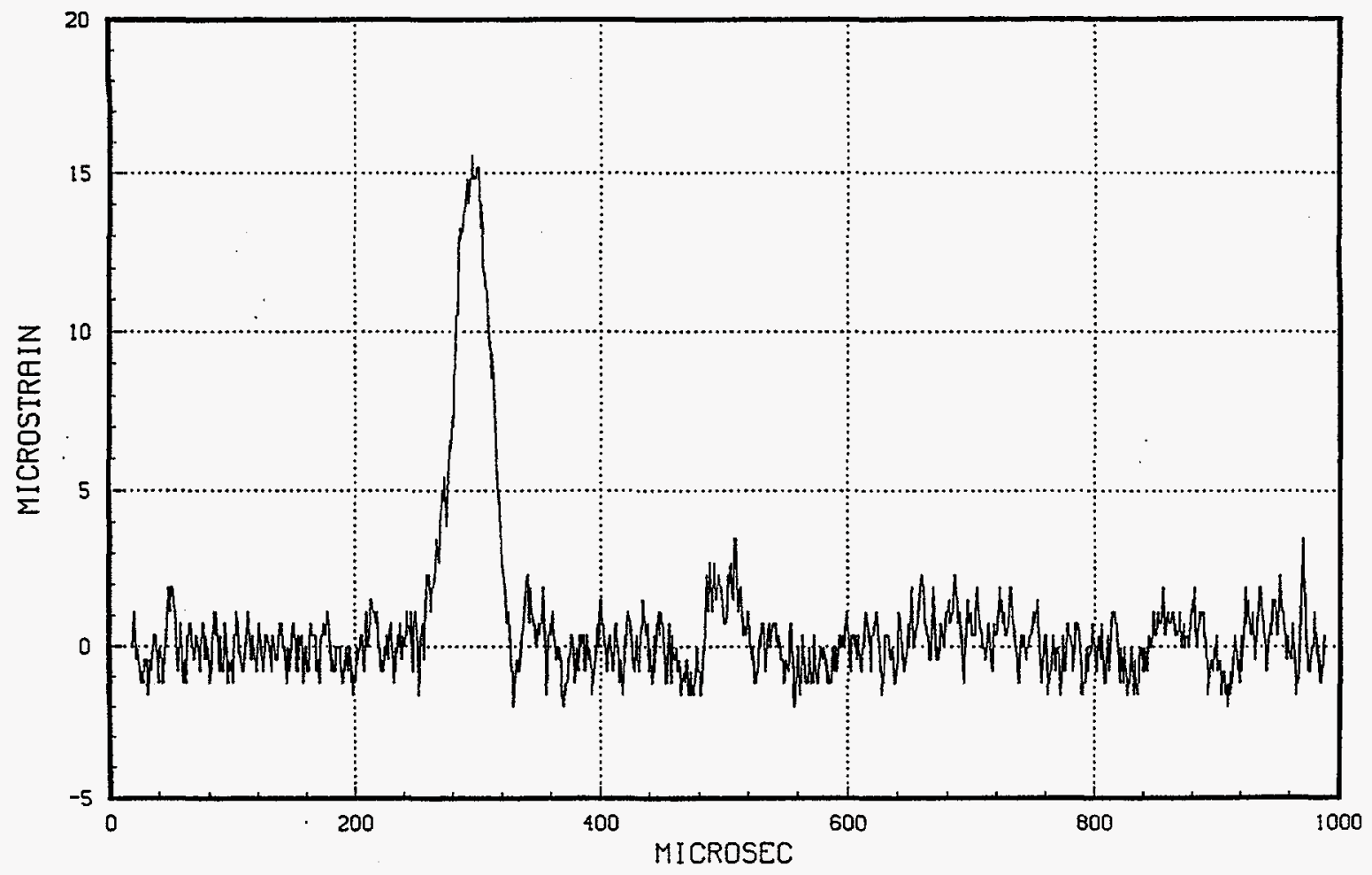

Lateral Strain Response to Compressive Shock on the Beryllium Insert (2.0 in. Diameter).

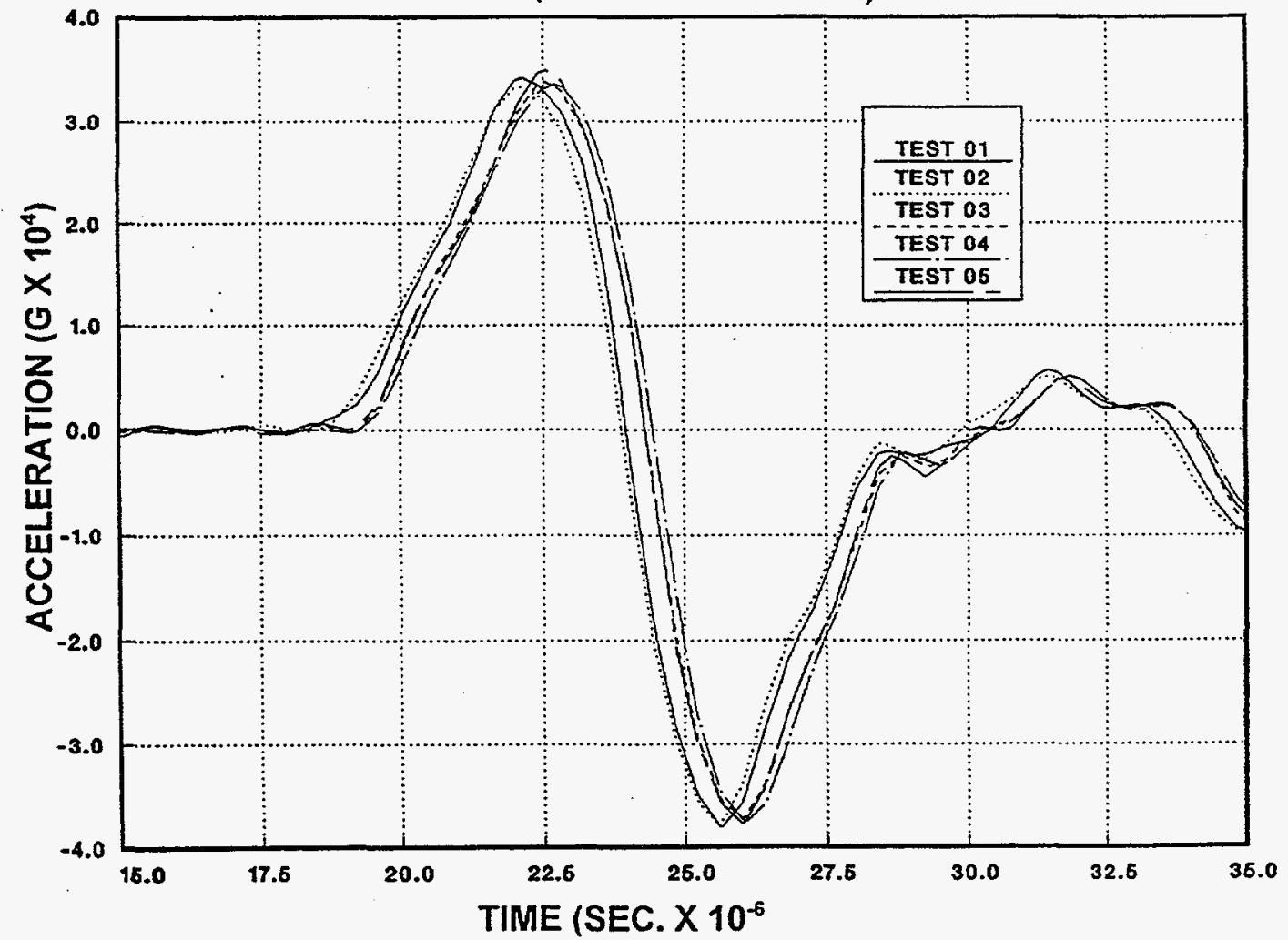

Consistent Axial Acceleration Measured on the Beryllium Insert (2 in. Diameter). 


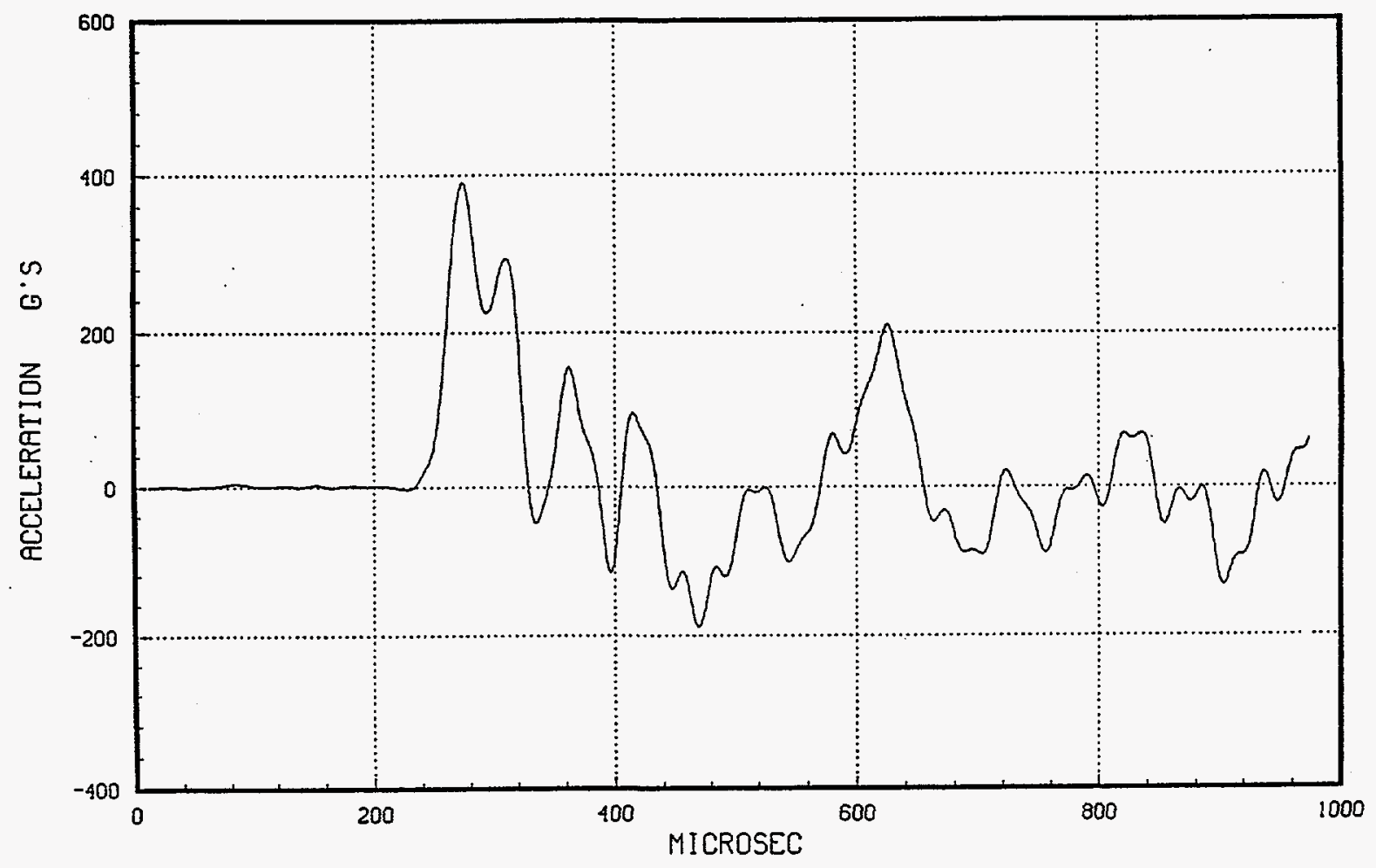

ENDEVCO 7270A-60K Base Strain Response to Cross-Axis Compressive Shock ( $250 \mu \varepsilon$ Amplitude) with $0^{\circ}$ Angle and $30 \mathrm{kHz}$ Analog Filter (2 in. Diameter Beryllium Insert).

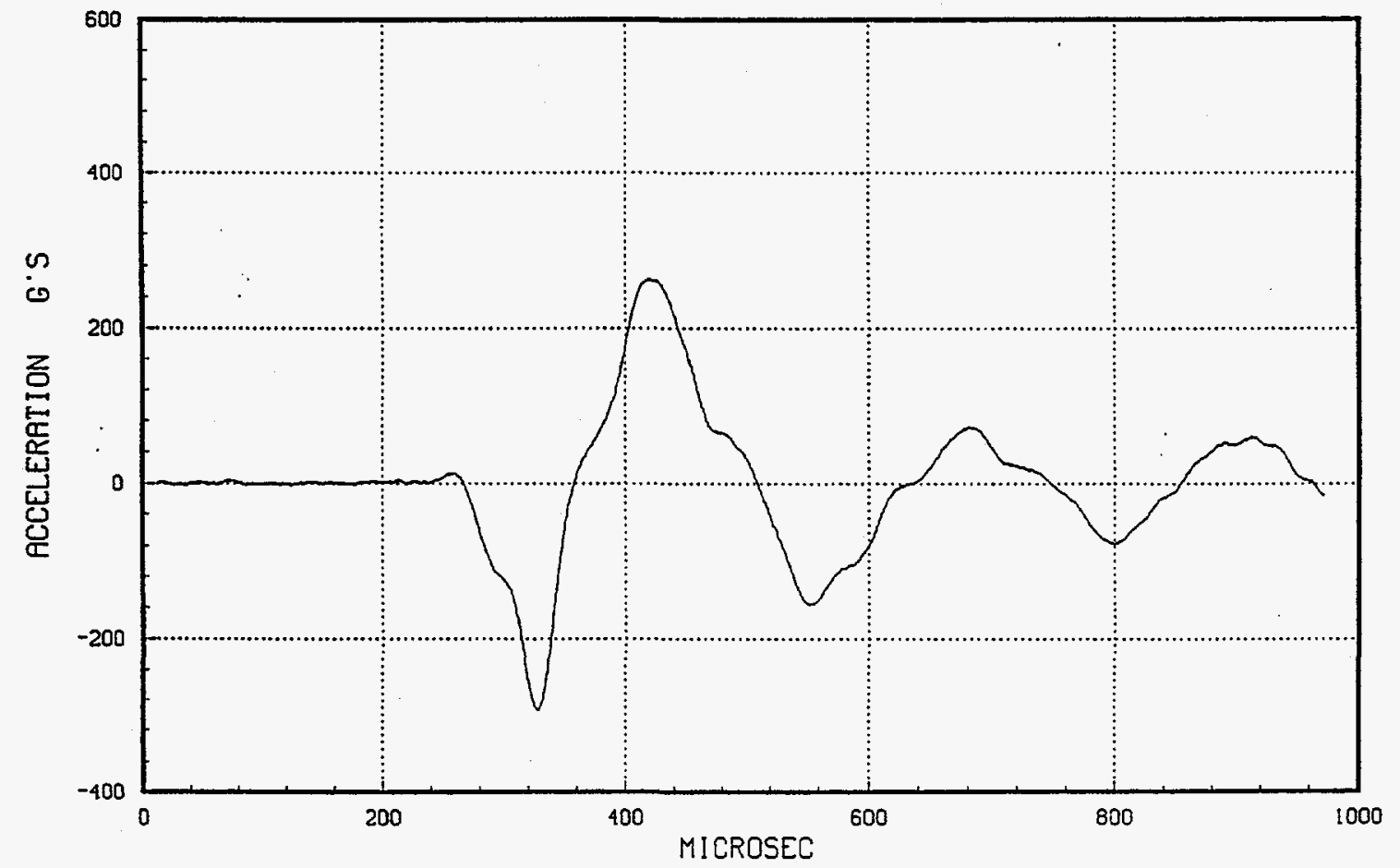

ENDEVCO 7270A-60K Base Strain Response to Cross-Axis Compressive Shock (250 $\mu \varepsilon$ Amplitude) with $45^{\circ}$ Angle and $30 \mathrm{kHz}$ Analog Filter (2 in. Diameter Beryllium Insert). 


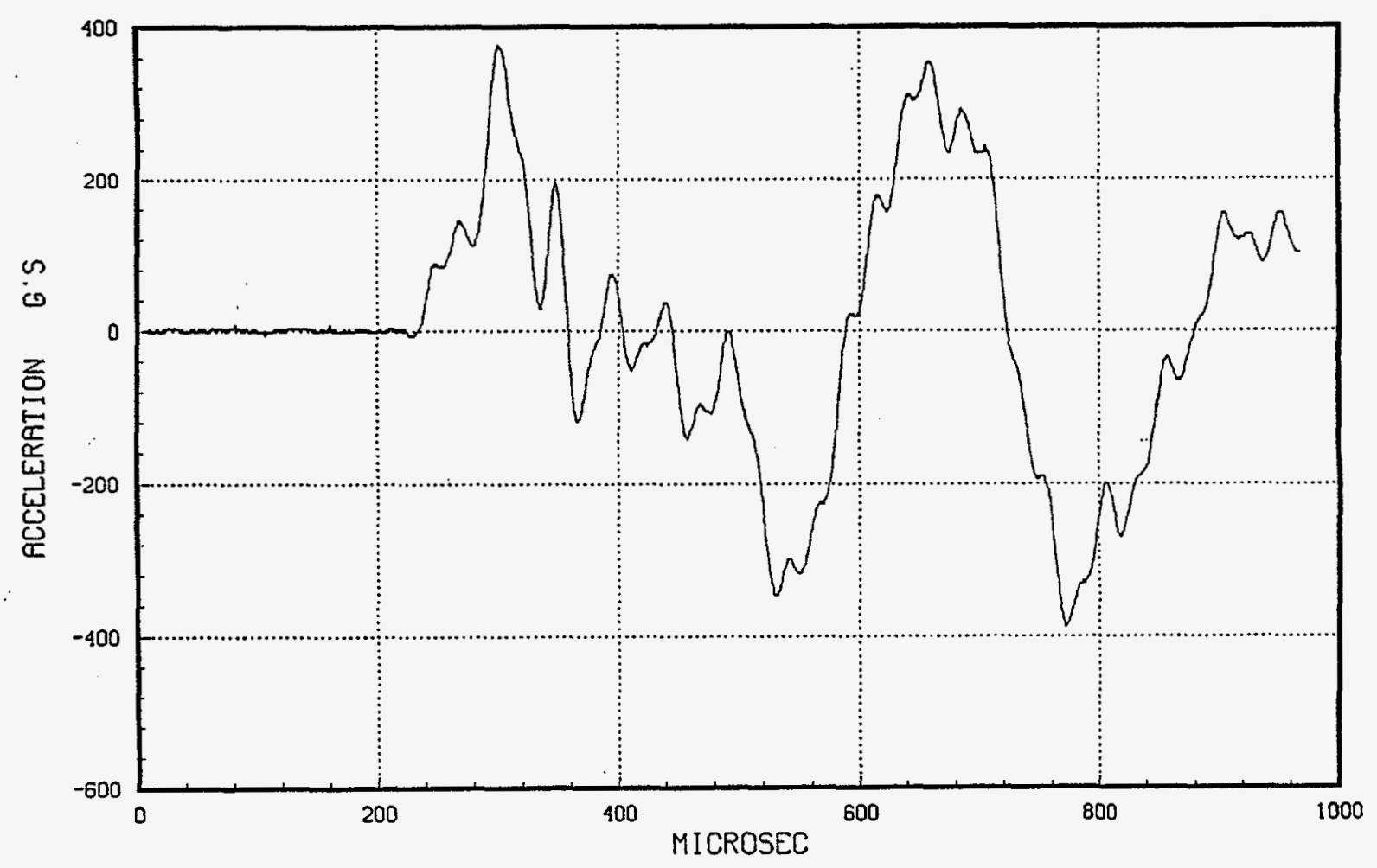

ENDEVCO 7270A-60K Base Strain Response to Cross-Axis

Compressive Shock (250 $\mu \varepsilon$ Amplitude) with $90^{\circ}$ Angle and $30 \mathrm{kHz}$ Analog Filter (2 in. Diameter Beryllium Insert). 


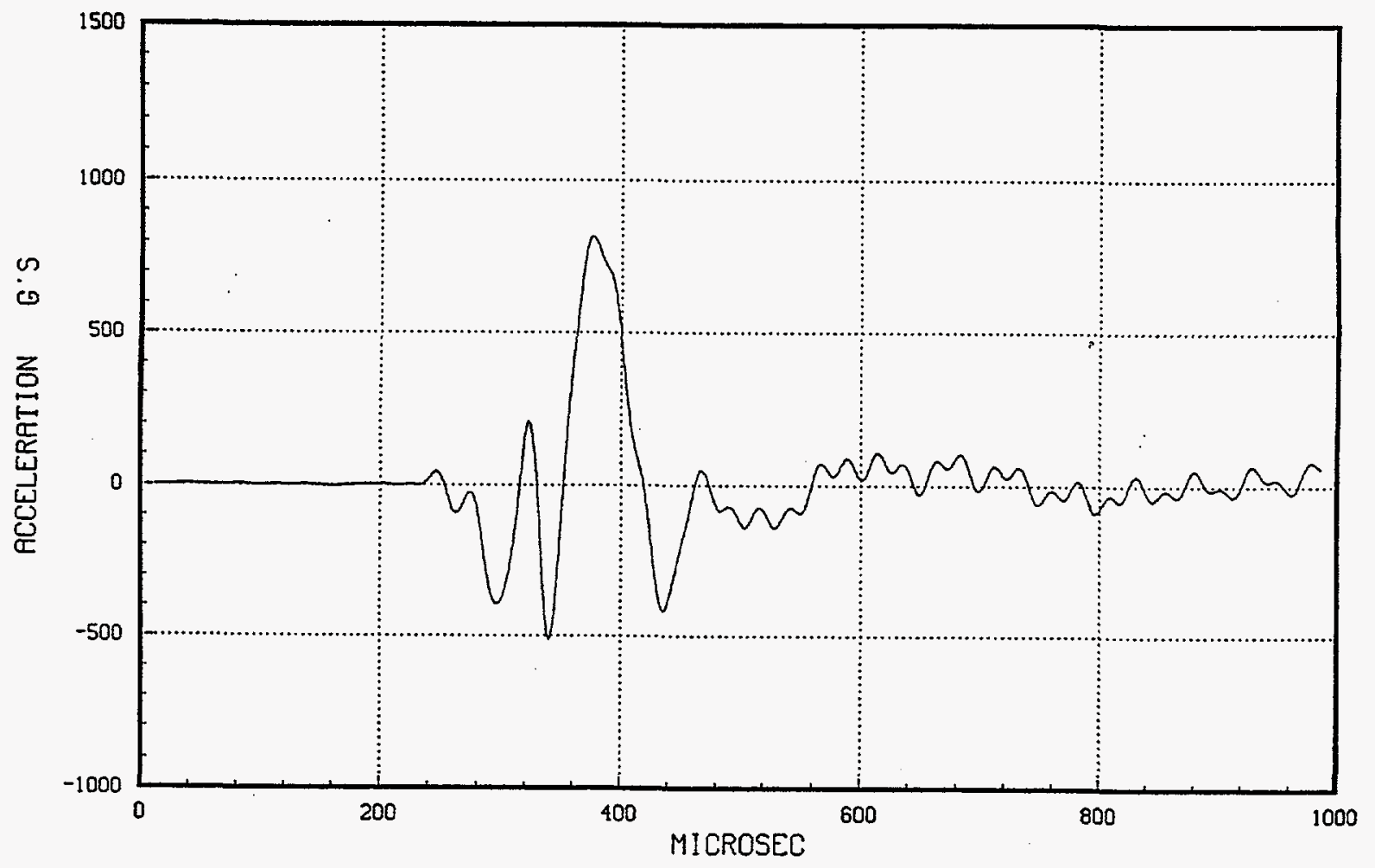

ENDEVCO 7270AM4-200K Acceleration Response to Cross-Axis Compressive Shock ( $250 \mu \varepsilon$ Amplitude) with $15^{\circ}$ Angle and $30 \mathrm{kHz}$ Analog Filter (2 in. Diameter Beryllium Insert).

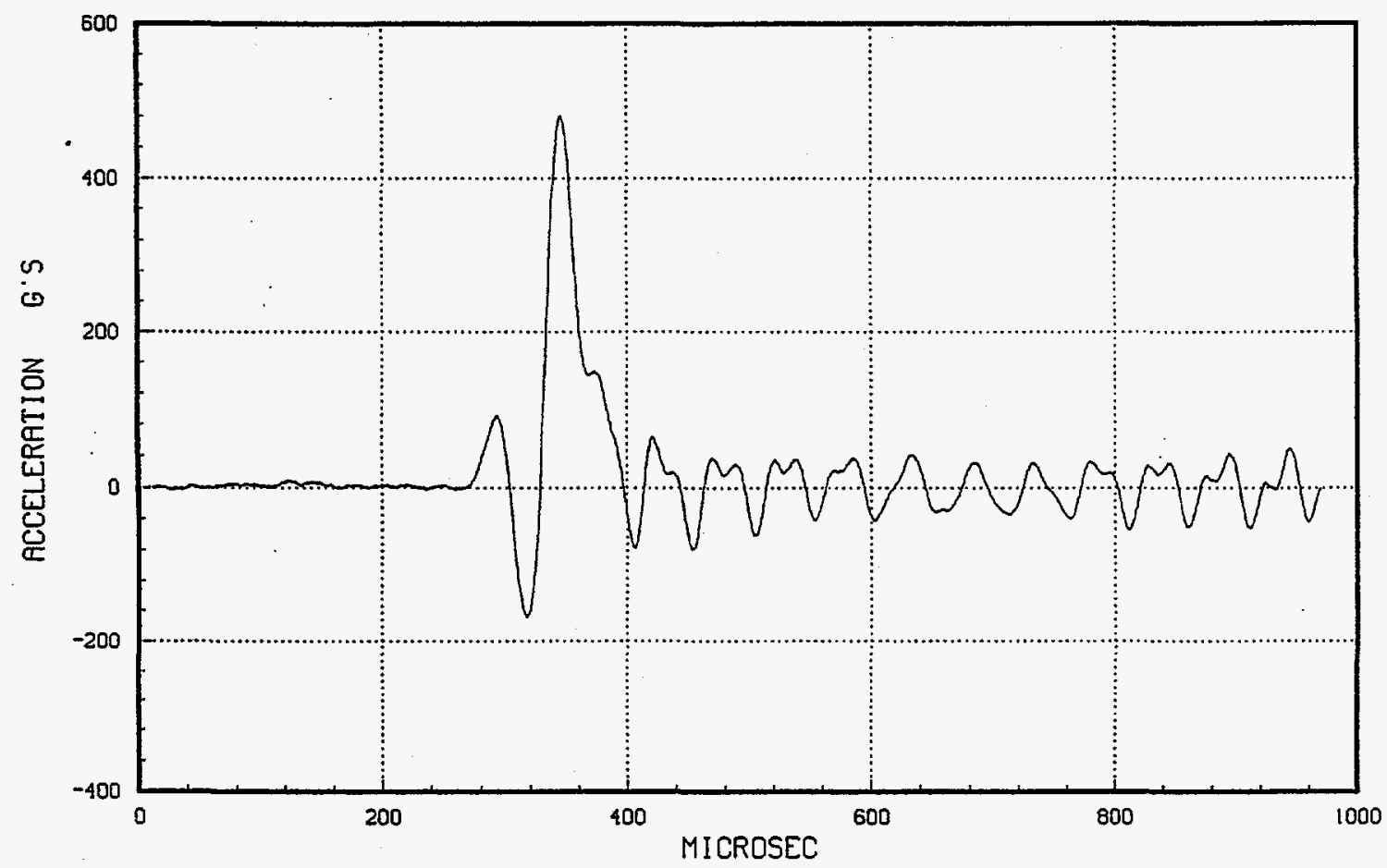

ENDEVCO 7270AM4-200K Acceleration Response to Cross-Axis Compressive Shock (250 $\mu \varepsilon$ Amplitude) with $65^{\circ}$ Angle and $30 \mathrm{kHz}$ Analog Filter (2 in. Diameter Beryllium Insert). 


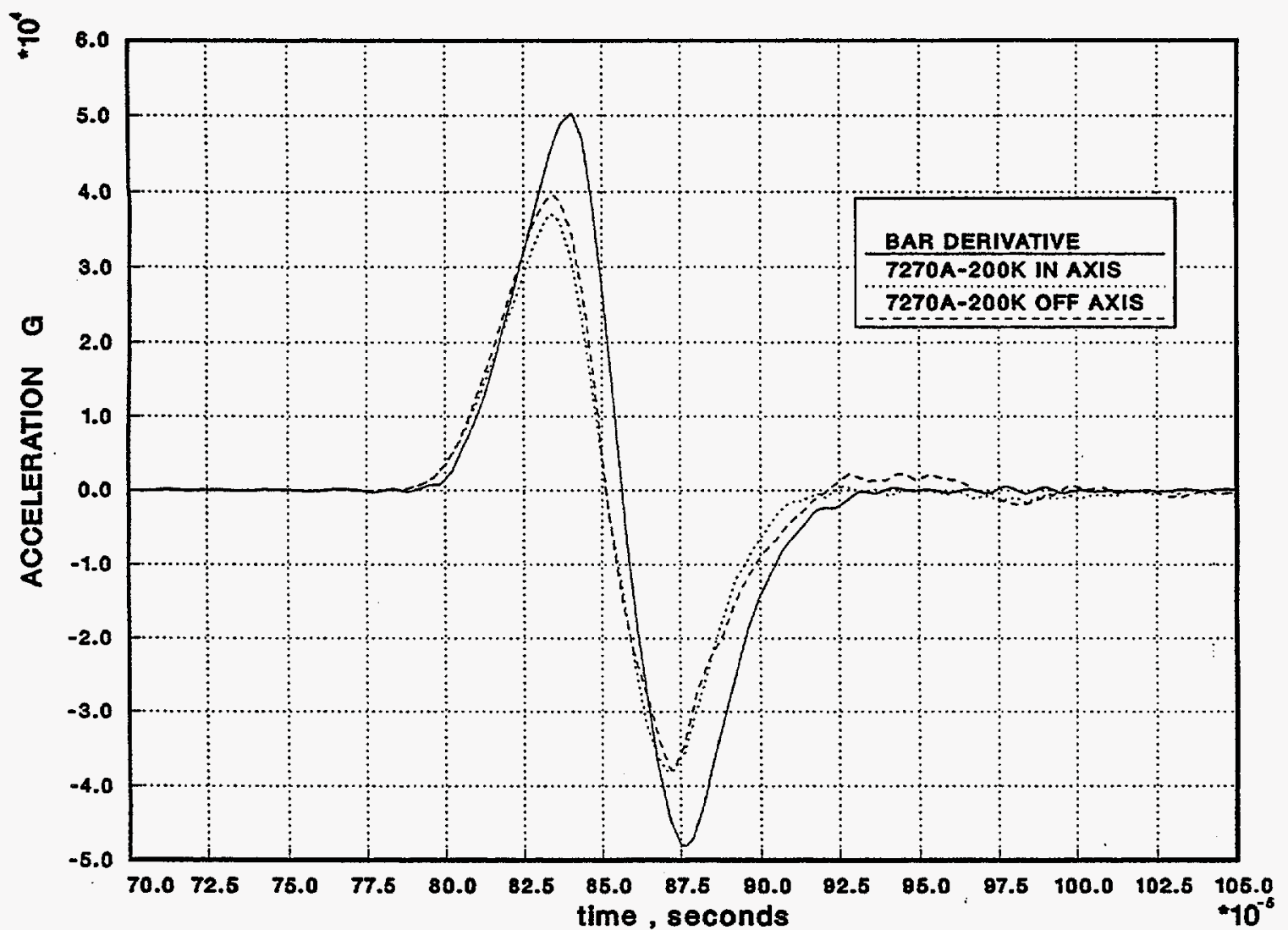

ENDEVCO 7270A-200K Response to Combined Shock at $45^{\circ}$

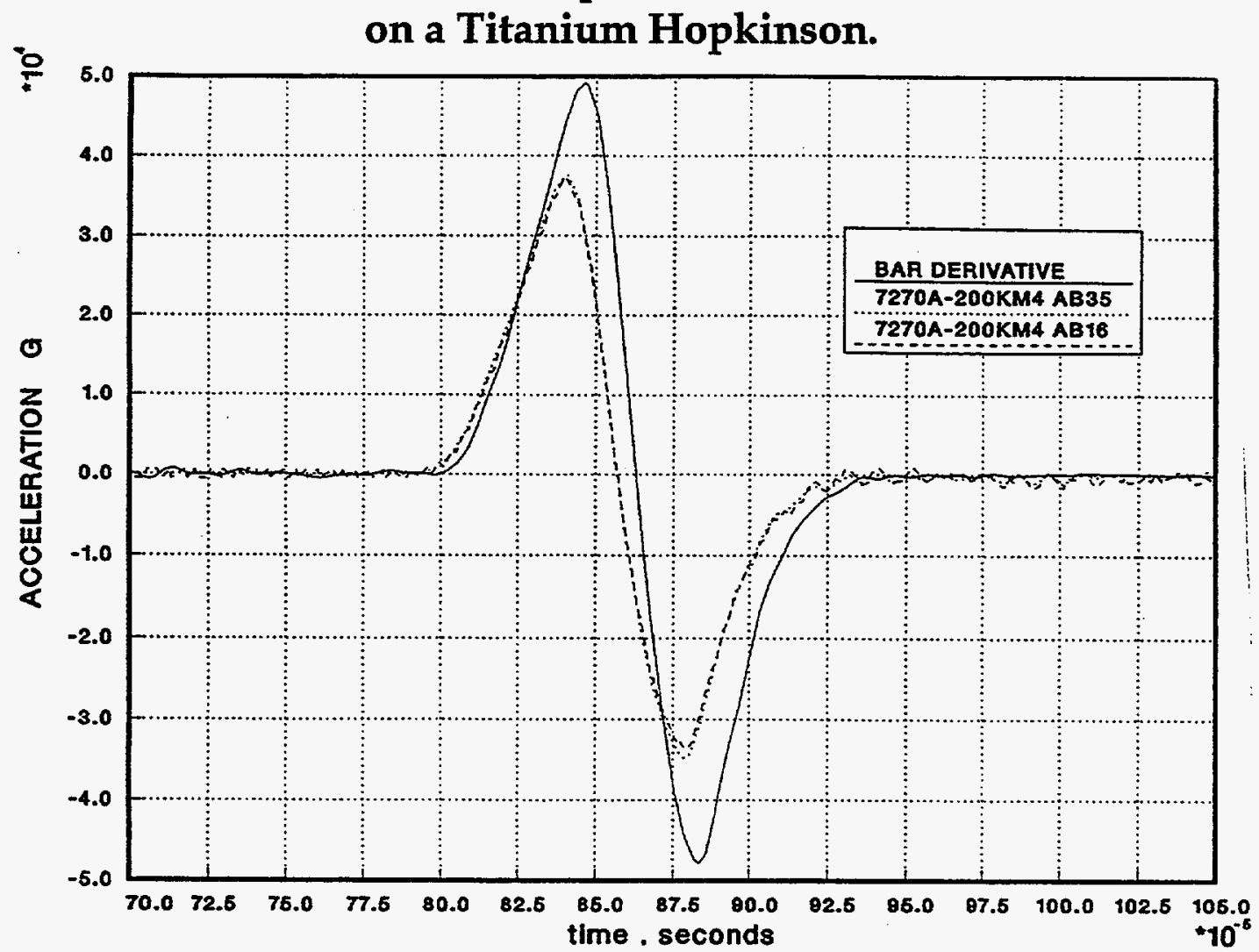

ENDEVCO 7270AM4-200K Response to Combined Shock at $45^{\circ}$ on a Titanium Hopkinson. 


\section{Appendix C}

\section{Piezoresistive Accelerometer Cable Response}




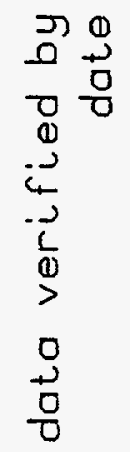

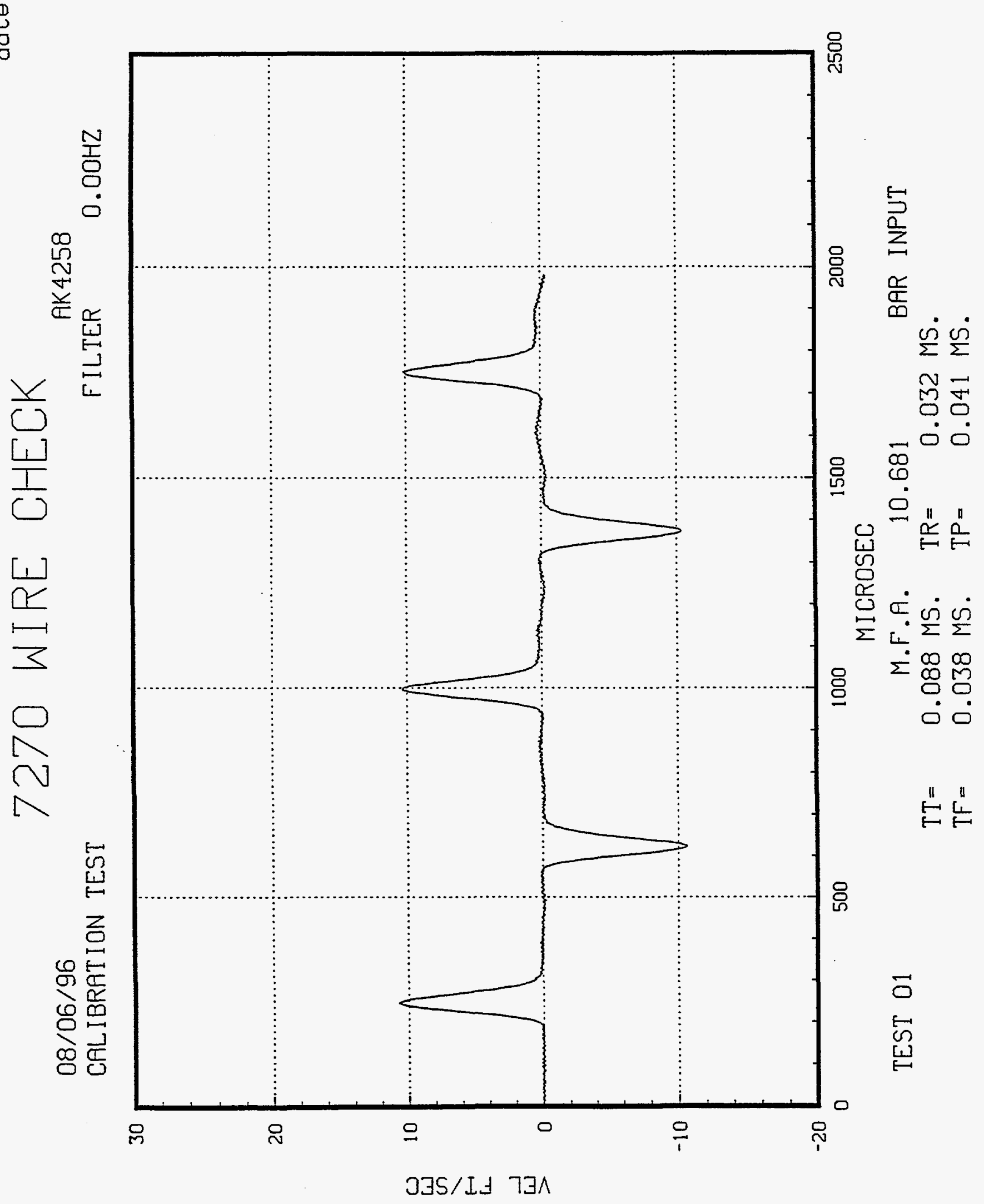


$\begin{array}{ll}\overrightarrow{0} & 0 \\ 0 & 0 \\ 0 & 0 \\ 0 \\ 2 \\ .2 \\ 0 \\ 0 \\ 0 \\ 0 \\ 0 \\ 0 \\ 0\end{array}$

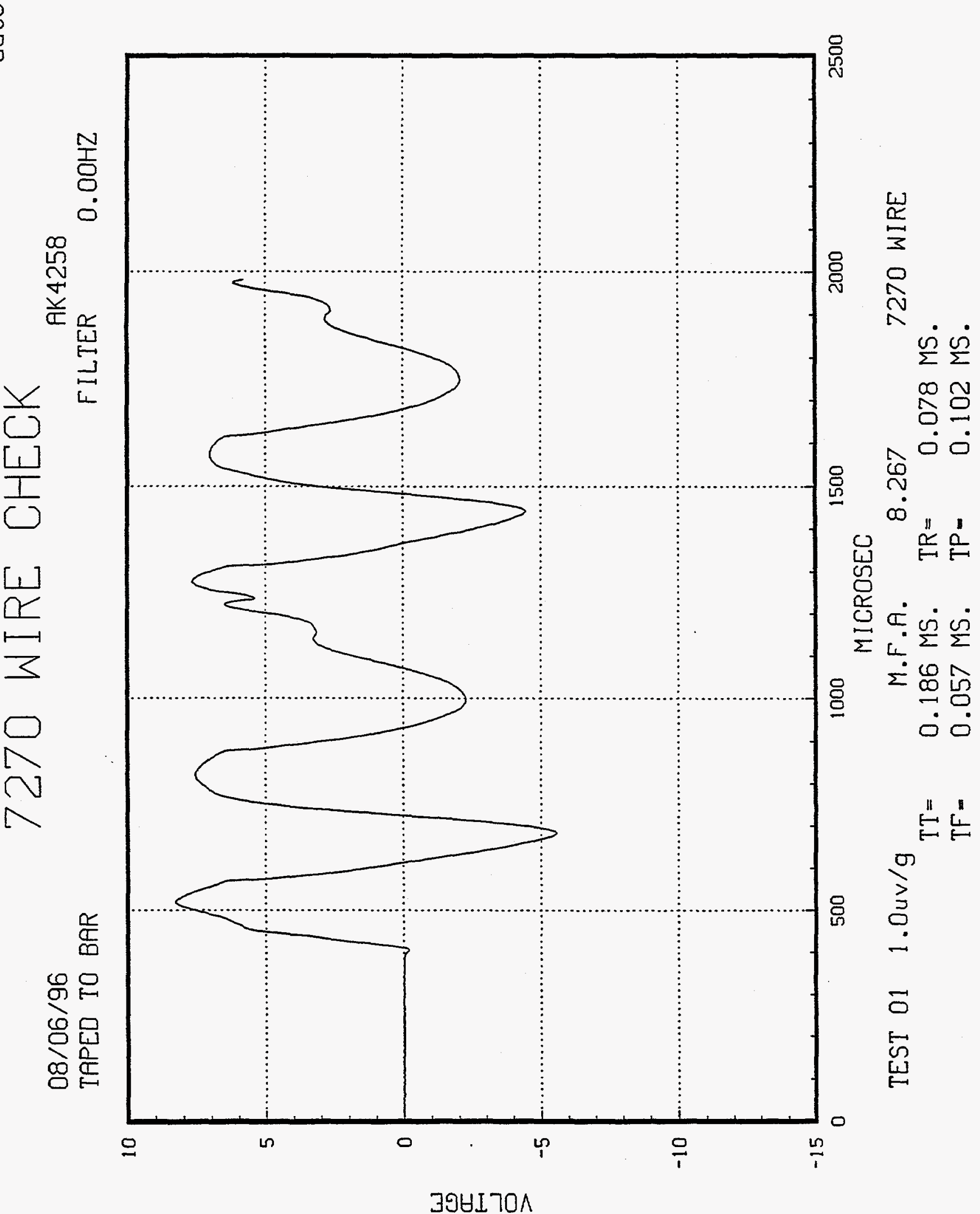




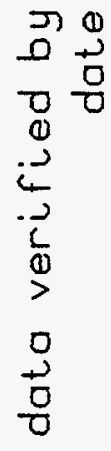

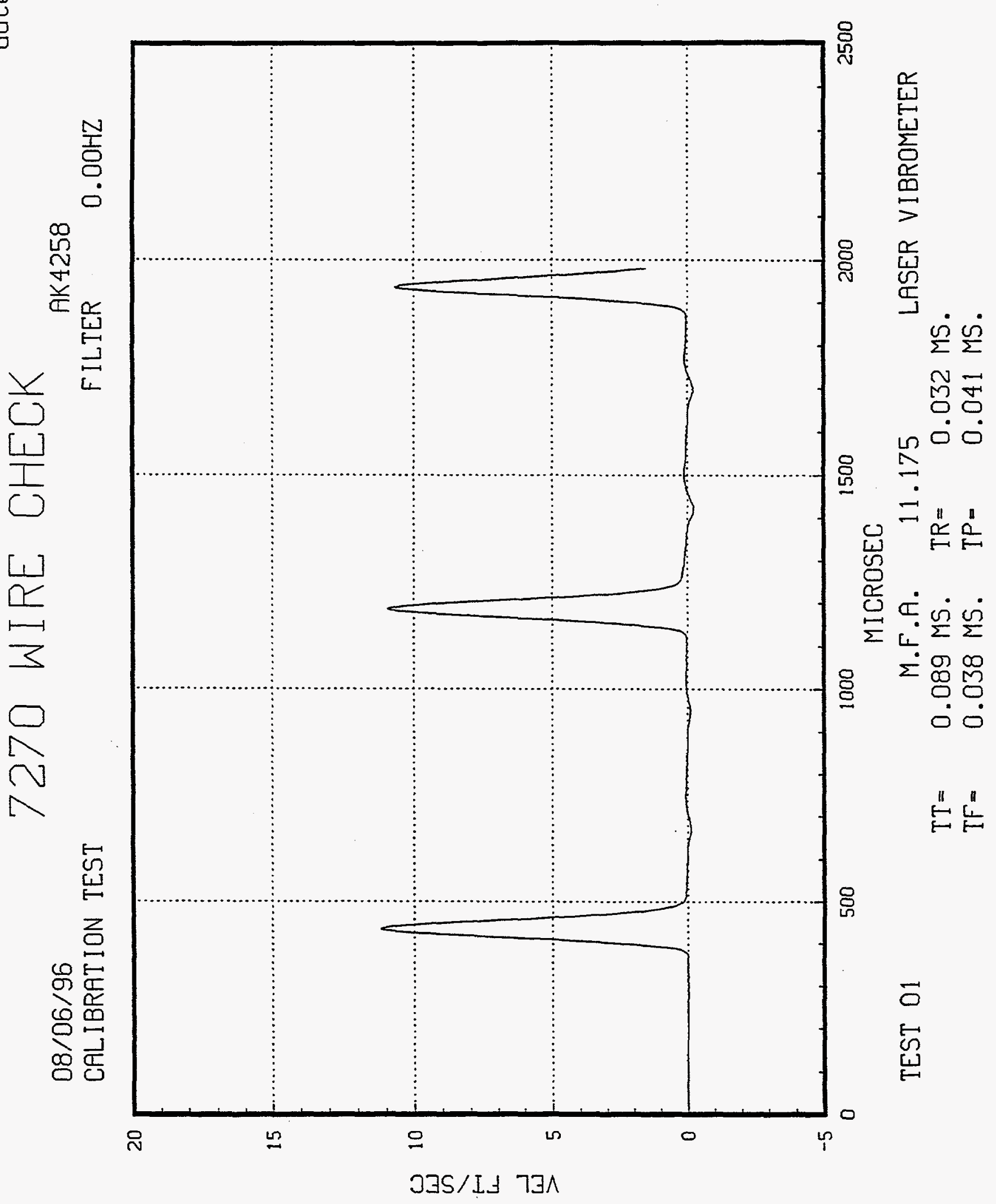


3
0
0
0
0
0
-2
4
$\cdot 2$
$\frac{1}{0}$
$>$
0
0
0
0

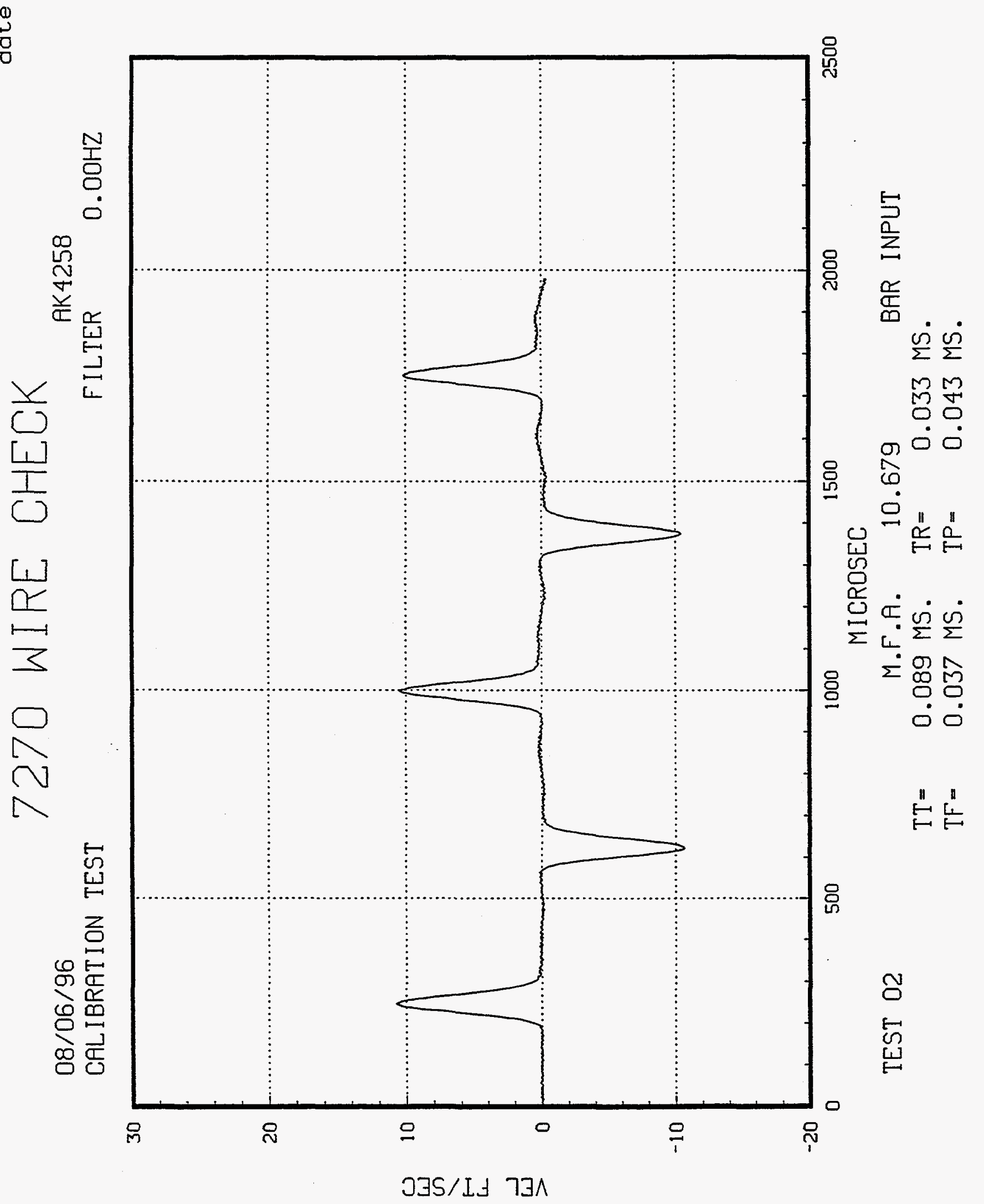


$\begin{array}{ll}D & 0 \\ 0 & 0 \\ 0 & 0 \\ 0 & 0 \\ ن & 0 \\ 1 & 0 \\ 0 & 0 \\ 0 \\ 0 \\ 0 \\ 0 \\ 0\end{array}$

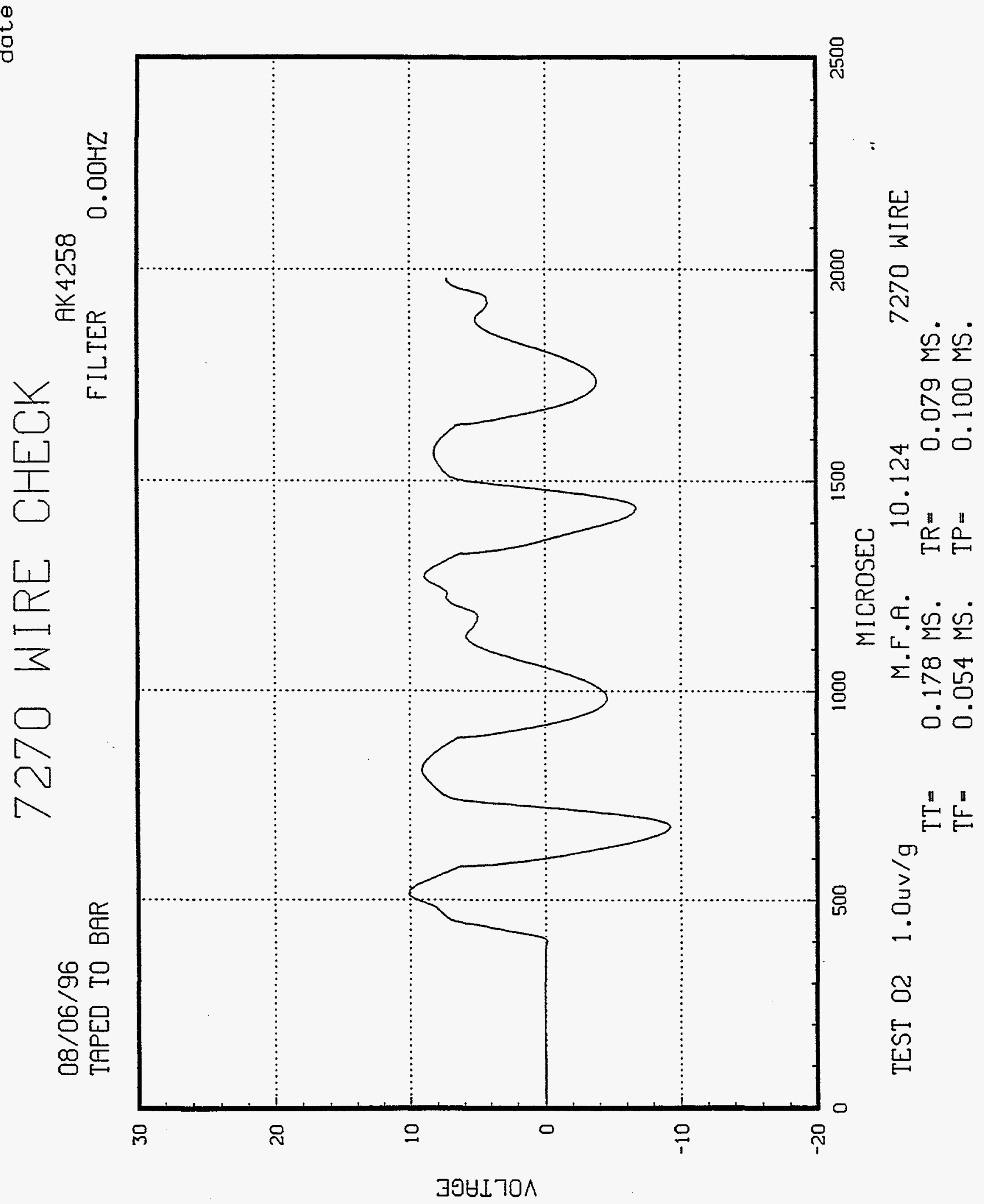




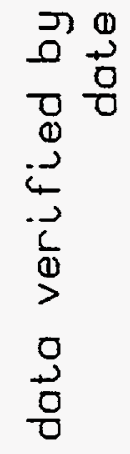

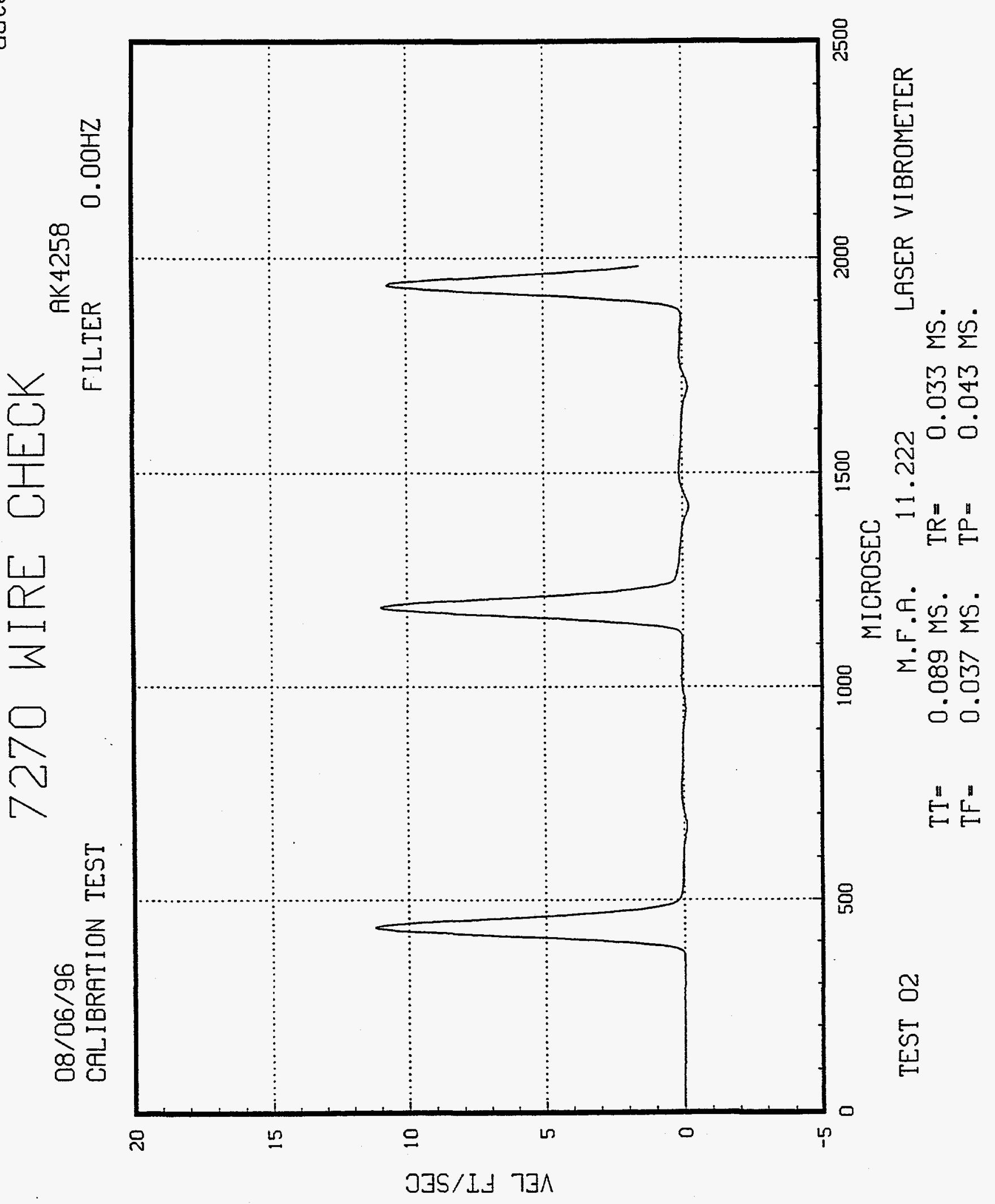


$\begin{array}{ll}\pi & 0 \\ 0 & 0 \\ 0 & 0 \\ 0 & 0 \\ 0 & 0 \\ -1 & 0 \\ 0 & 0 \\ > \\ 0 \\ 0 \\ 0 \\ 0\end{array}$

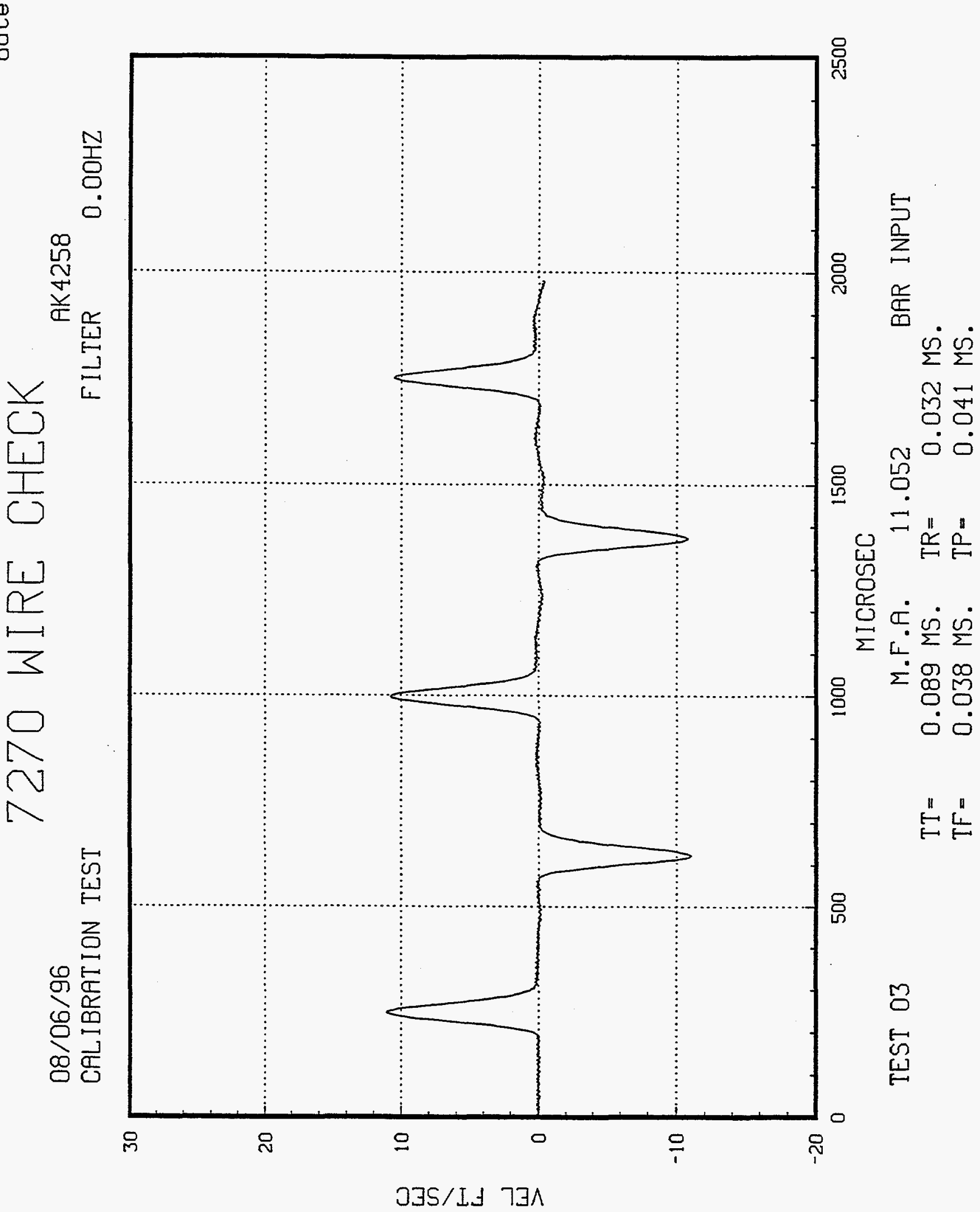




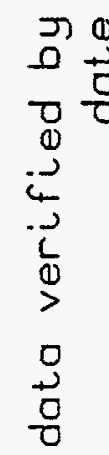

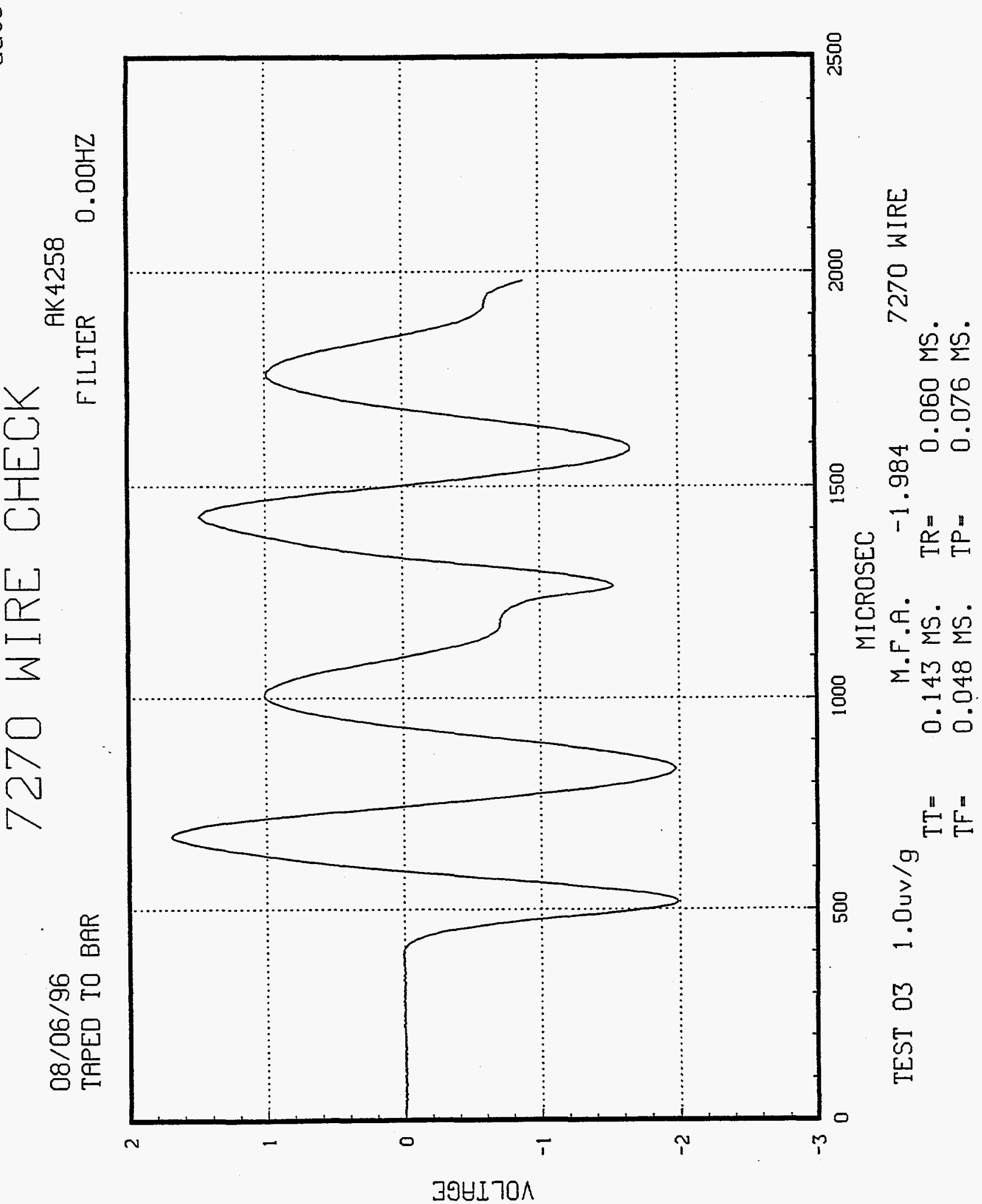




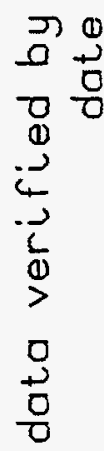

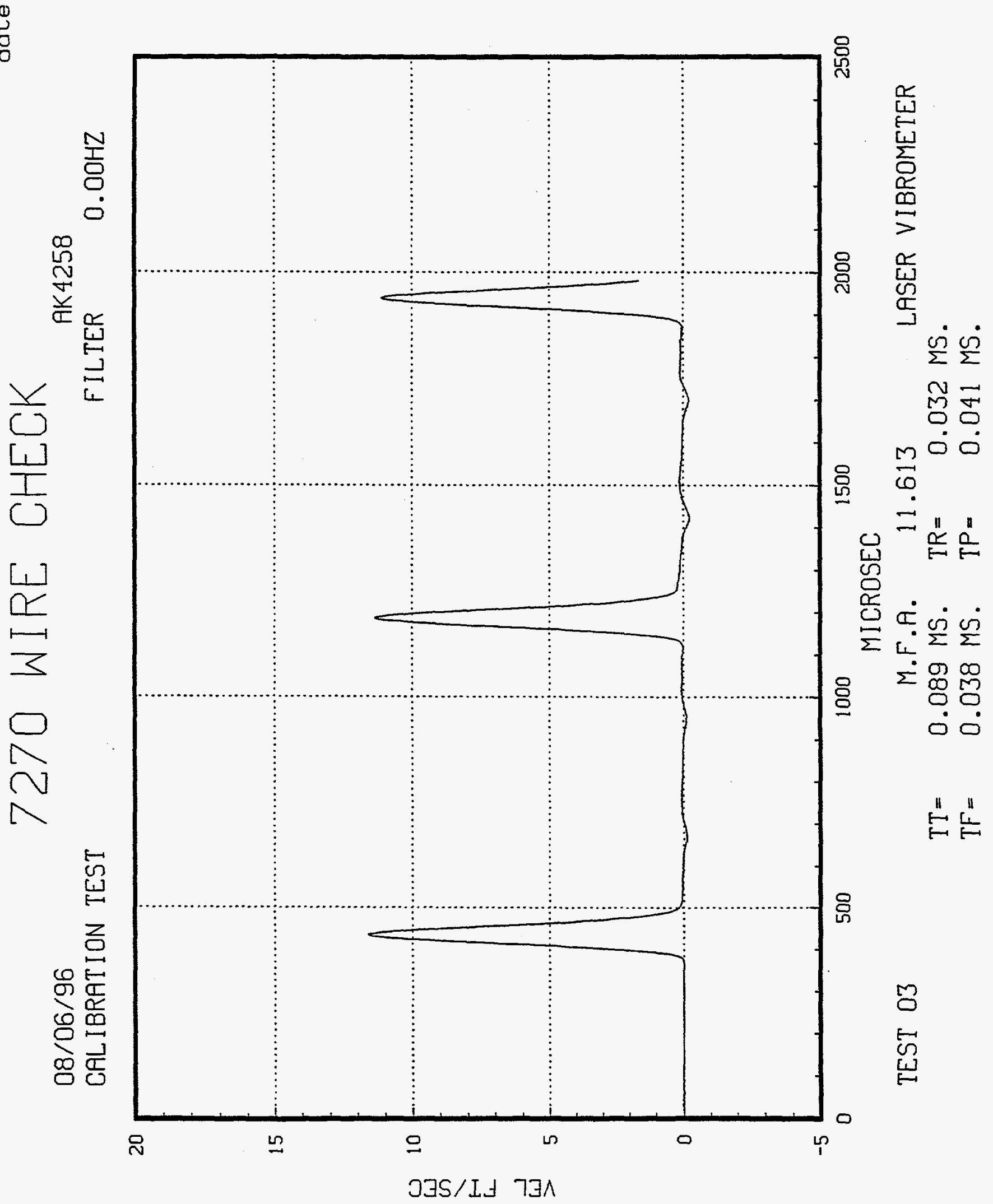




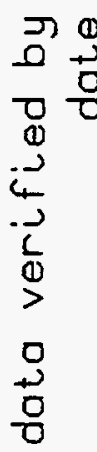

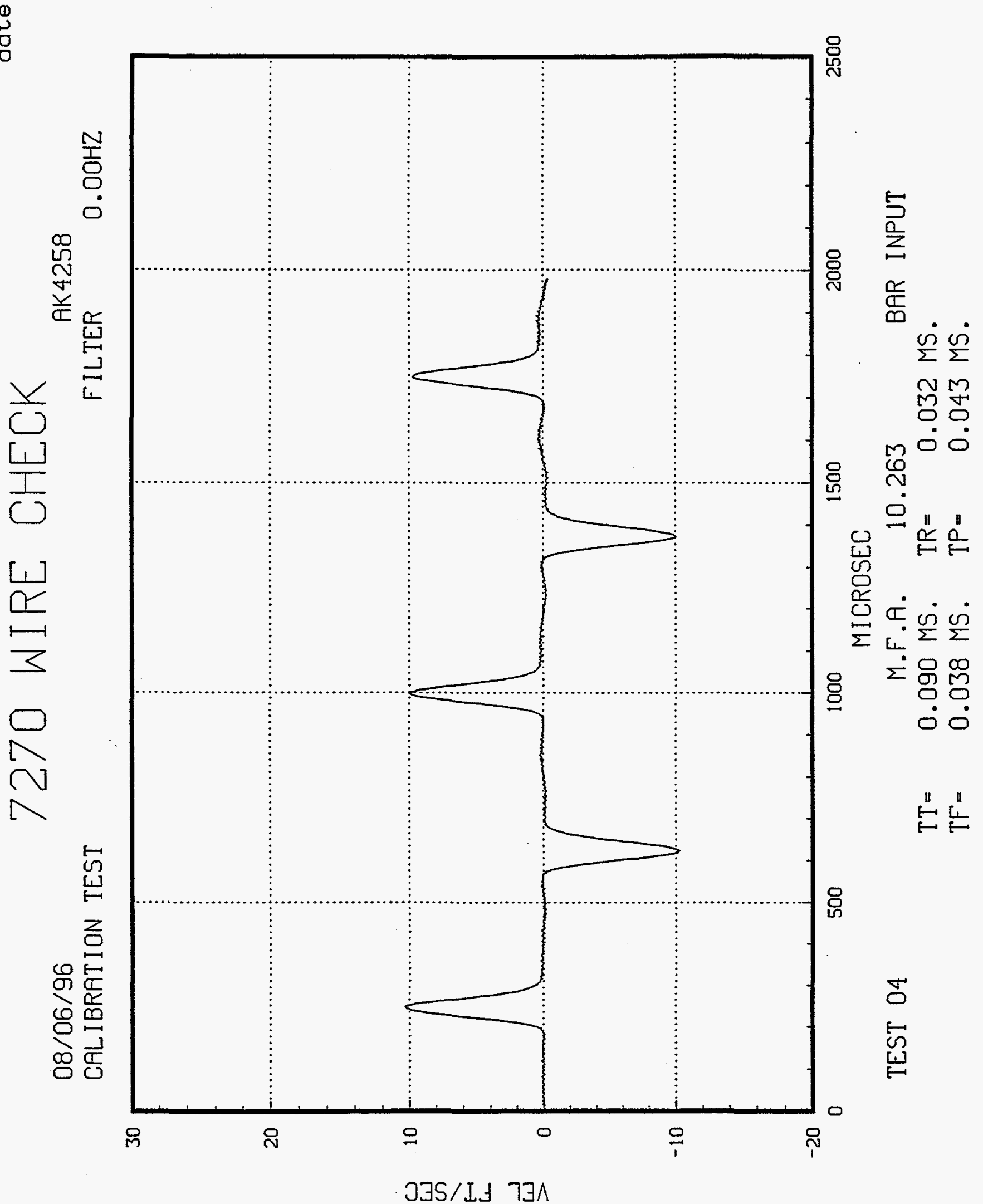


$J$
0
0
0
0
0
-2
-2
$\frac{1}{1}$
0
$>$
0
0
0
0

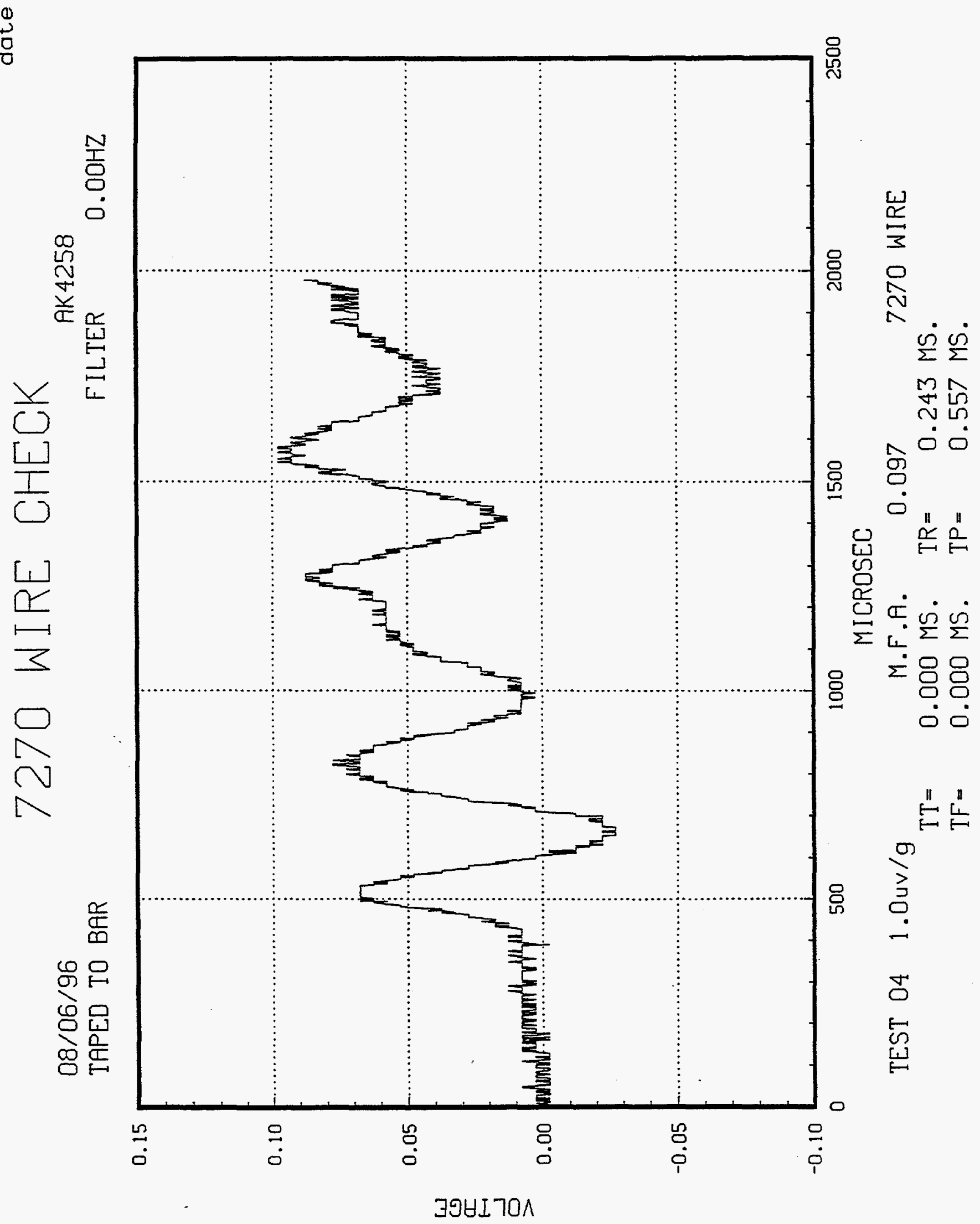




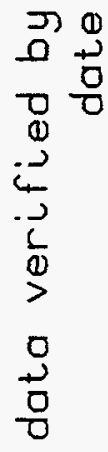

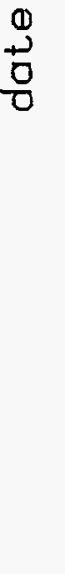

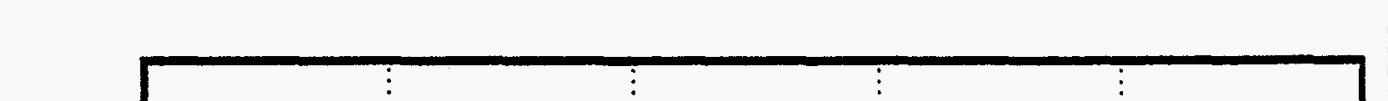

윰

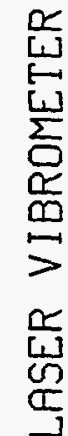

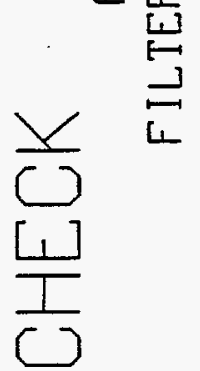

[1]

0
5

$\square$

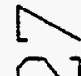

$\mathrm{O}$

它 
$\begin{array}{ll}\overrightarrow{0} & 0 \\ 0 & 0 \\ 0 & 0 \\ 0 & 0 \\ \overrightarrow{4} & \\ \vec{L} & 0 \\ 0 \\ > \\ 0 \\ +0 \\ 0 \\ 0\end{array}$

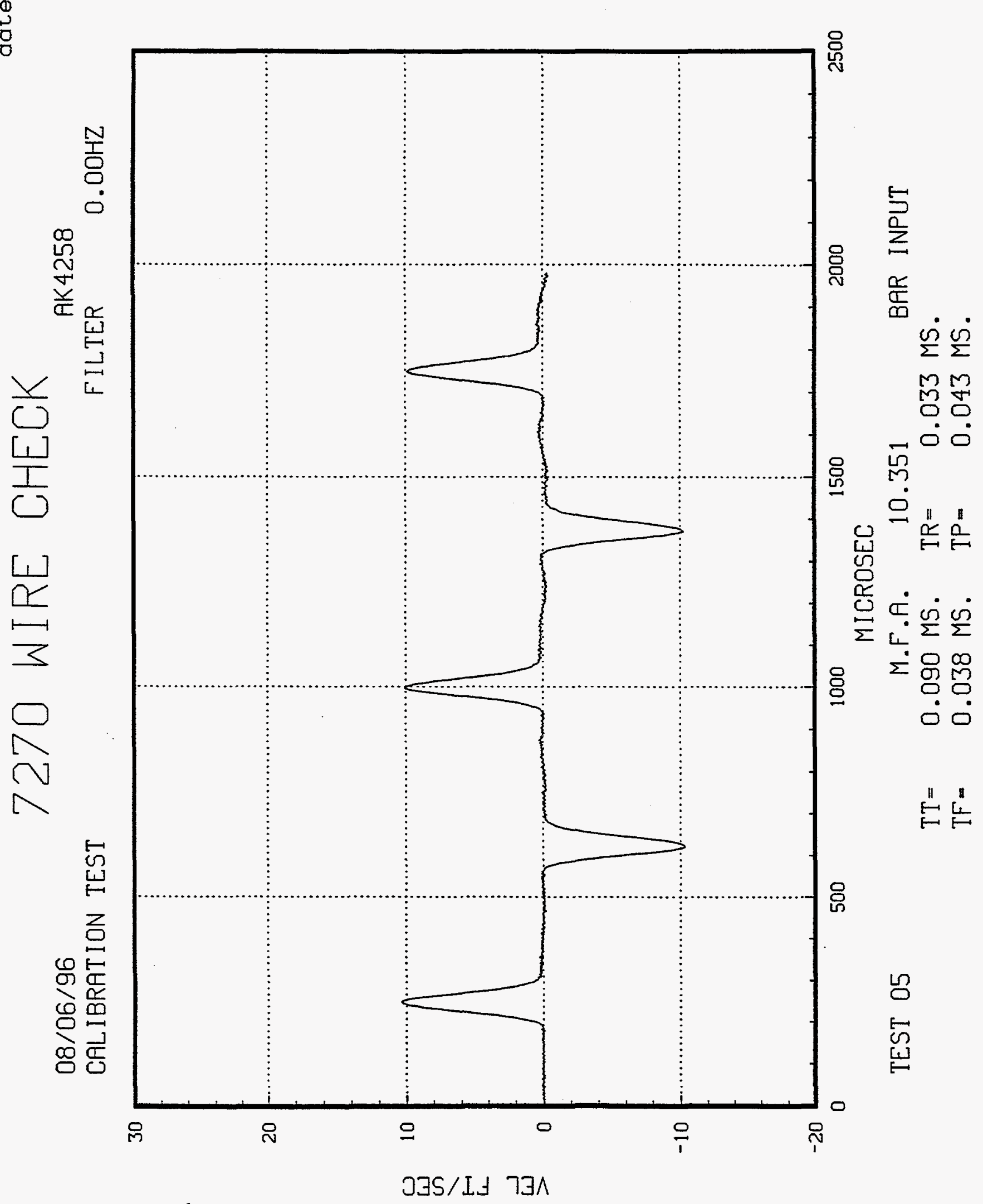




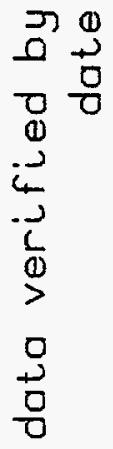

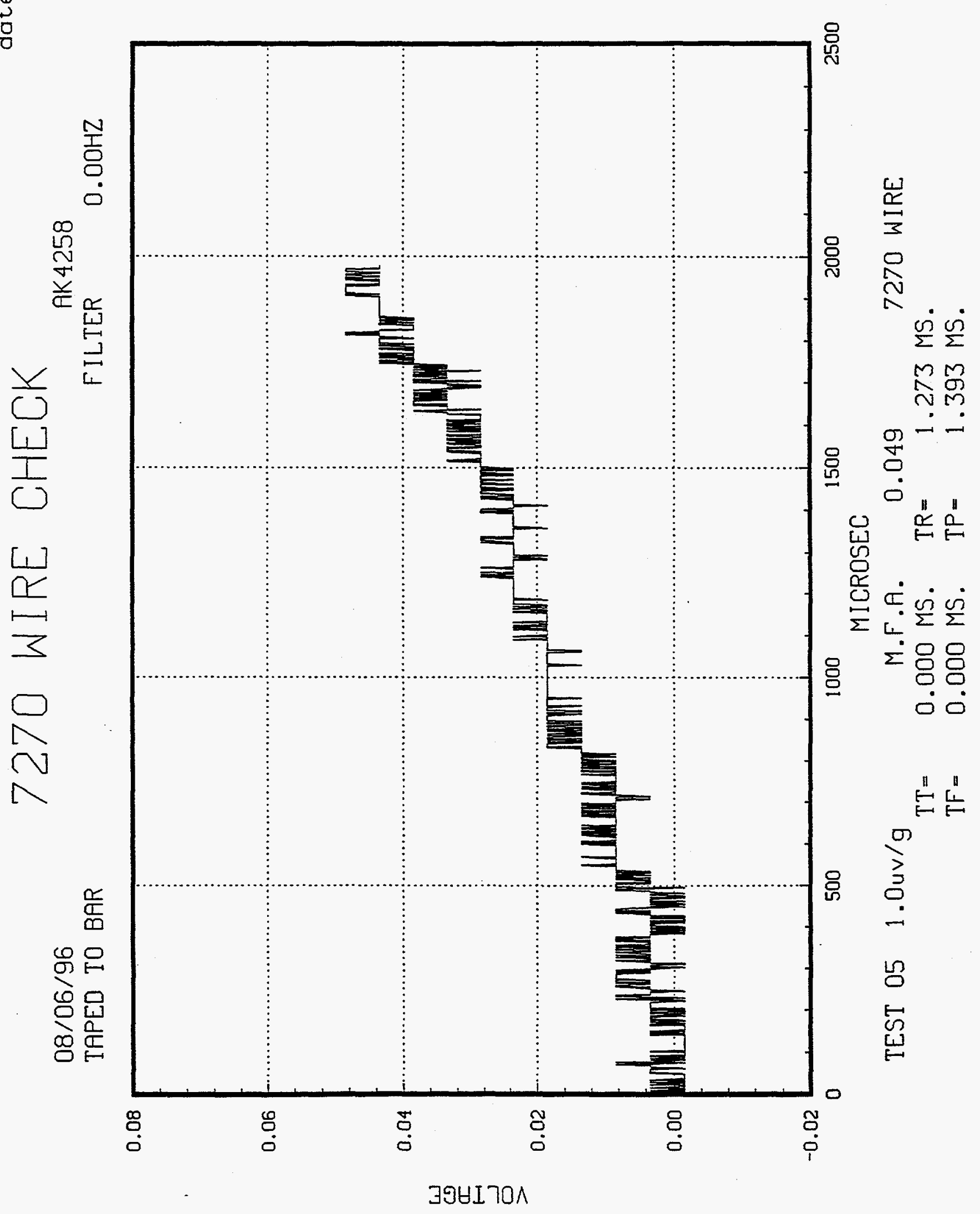


$\begin{array}{ll}7 & 0 \\ 0 & 0 \\ 0 & 0 \\ 0 & 0 \\ -2 & \\ . & 0 \\ 2 & 0 \\ > & \\ 0 \\ 0 \\ 0 \\ 0\end{array}$

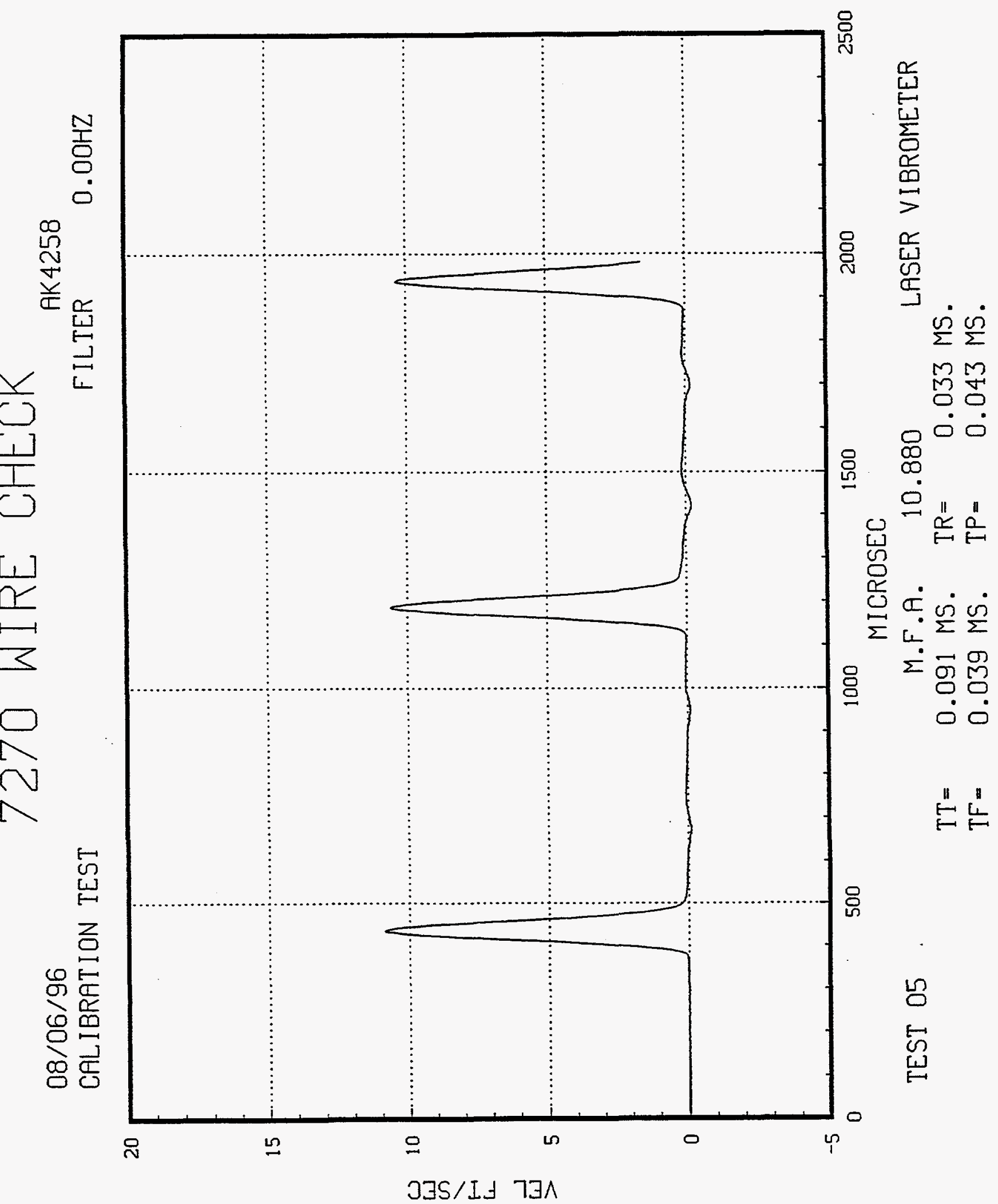


0
0
0
0
0
0
4
.2
0
0
$>$
0
0
0
0

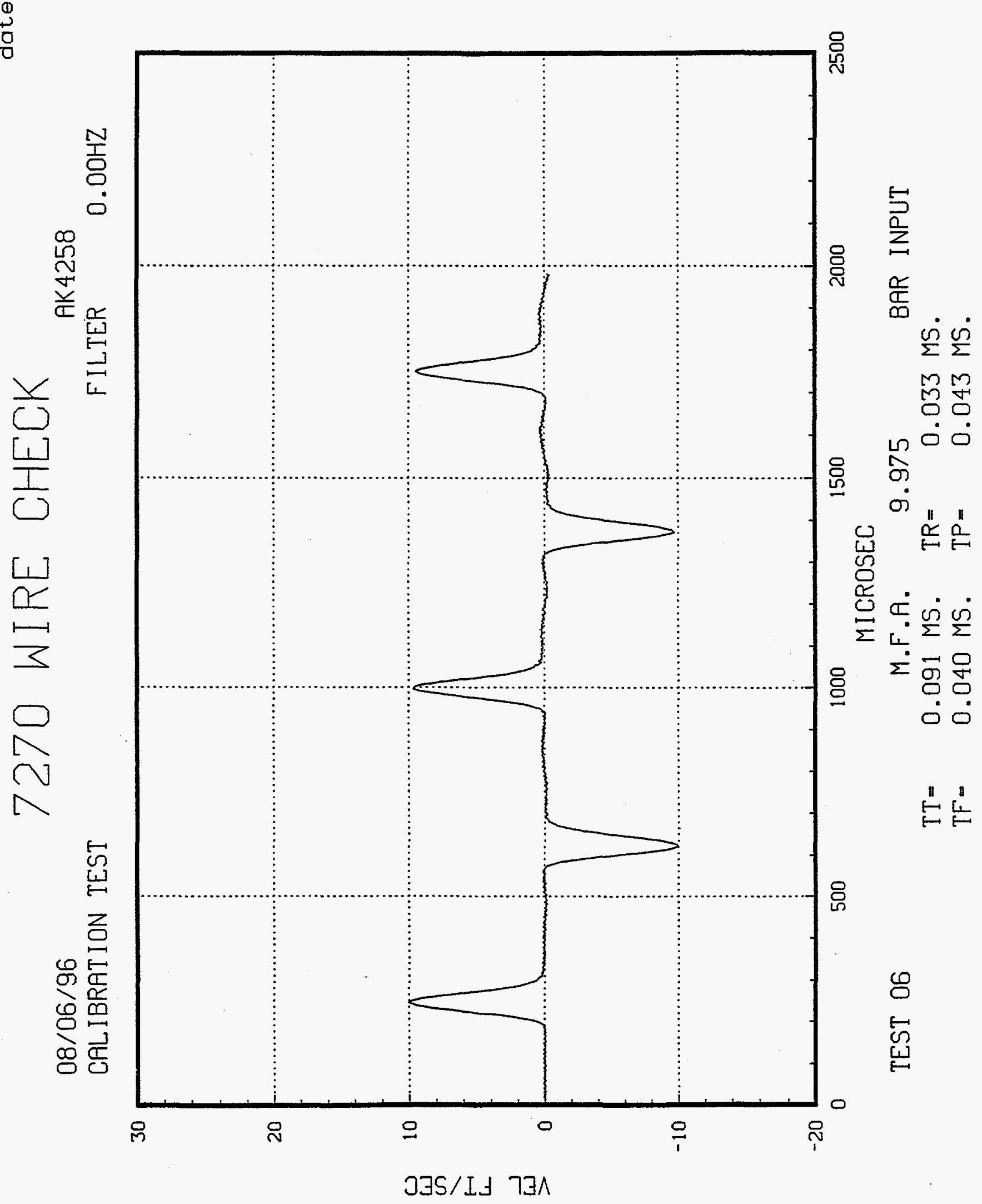


$\begin{array}{ll}D & 0 \\ 0 & 0 \\ 0 & 0 \\ 0 & 0 \\ -2 & \\ -\overrightarrow{4} & \\ \frac{1}{0} & \\ > & 0 \\ 0 \\ 0 \\ 0 \\ 0\end{array}$

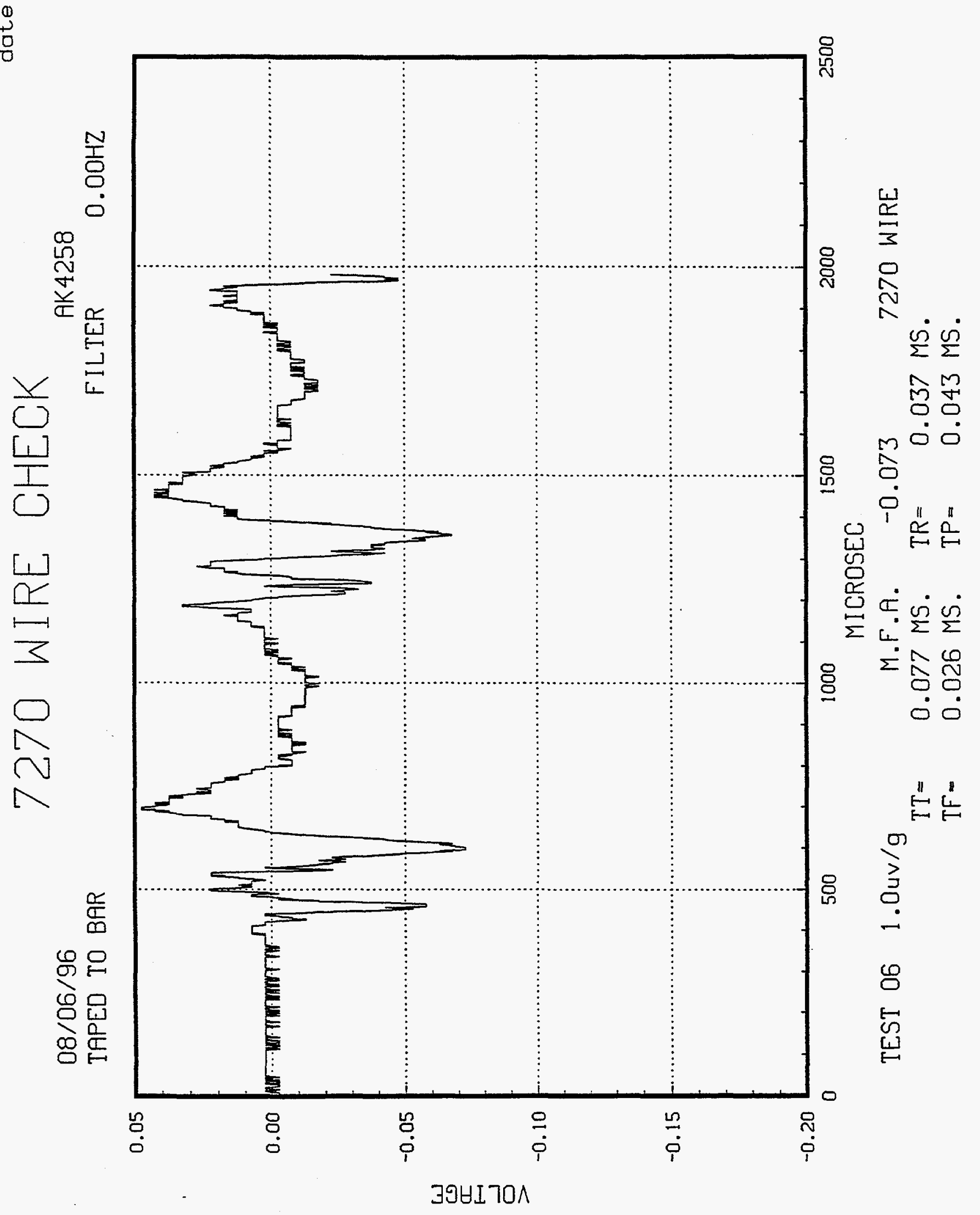


$\begin{array}{ll}\pi & 0 \\ 0 & 0 \\ 0 & 0 \\ 0 & 0 \\ 4 & 0 \\ 1 & 0 \\ 0 & \\ 0 \\ 0 \\ 0 \\ 0\end{array}$

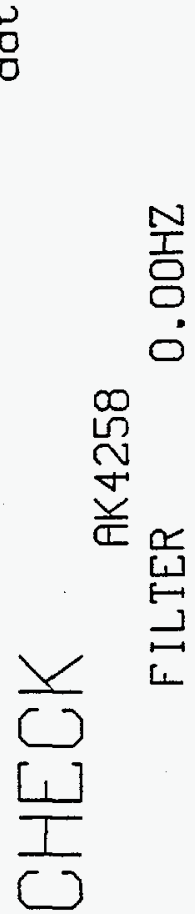

$\frac{[1]}{5}$

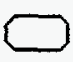

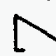

O

$\mathrm{C}$

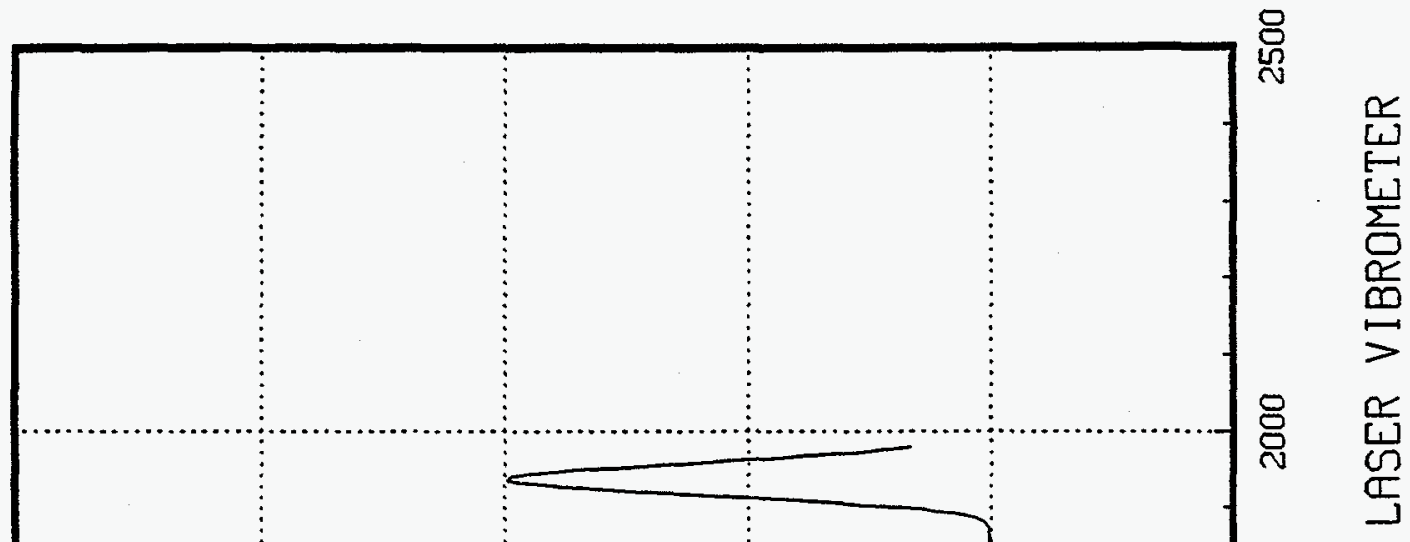

$\dot{\infty} \frac{\infty}{\Sigma}$

$M M$

M

$\dot{\sigma} \dot{0}$

号 뭄

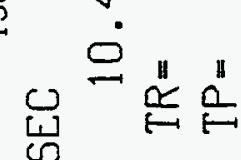

ฮี

$\stackrel{0}{\Sigma} \dot{\sigma} \dot{\Sigma}$

官 $\begin{array}{r}\dot{\sigma} \mathscr{O} \\ \dot{0} 0\end{array}$

$\stackrel{\text { EL }}{E}$

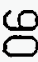

E

L.

只

J JS/L」 $7 \exists \Lambda$ 


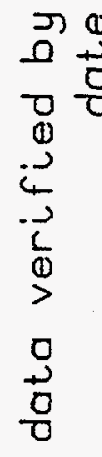

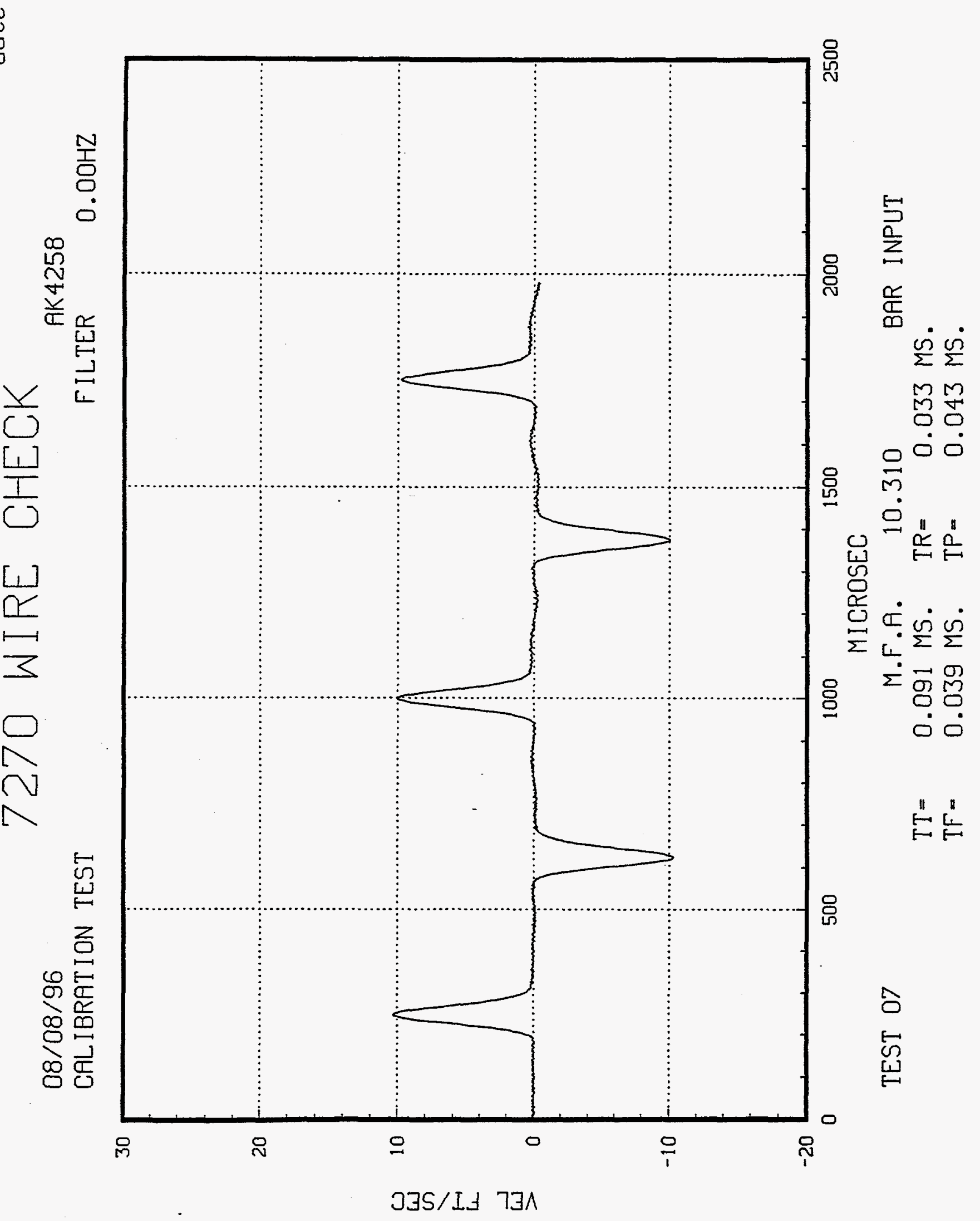




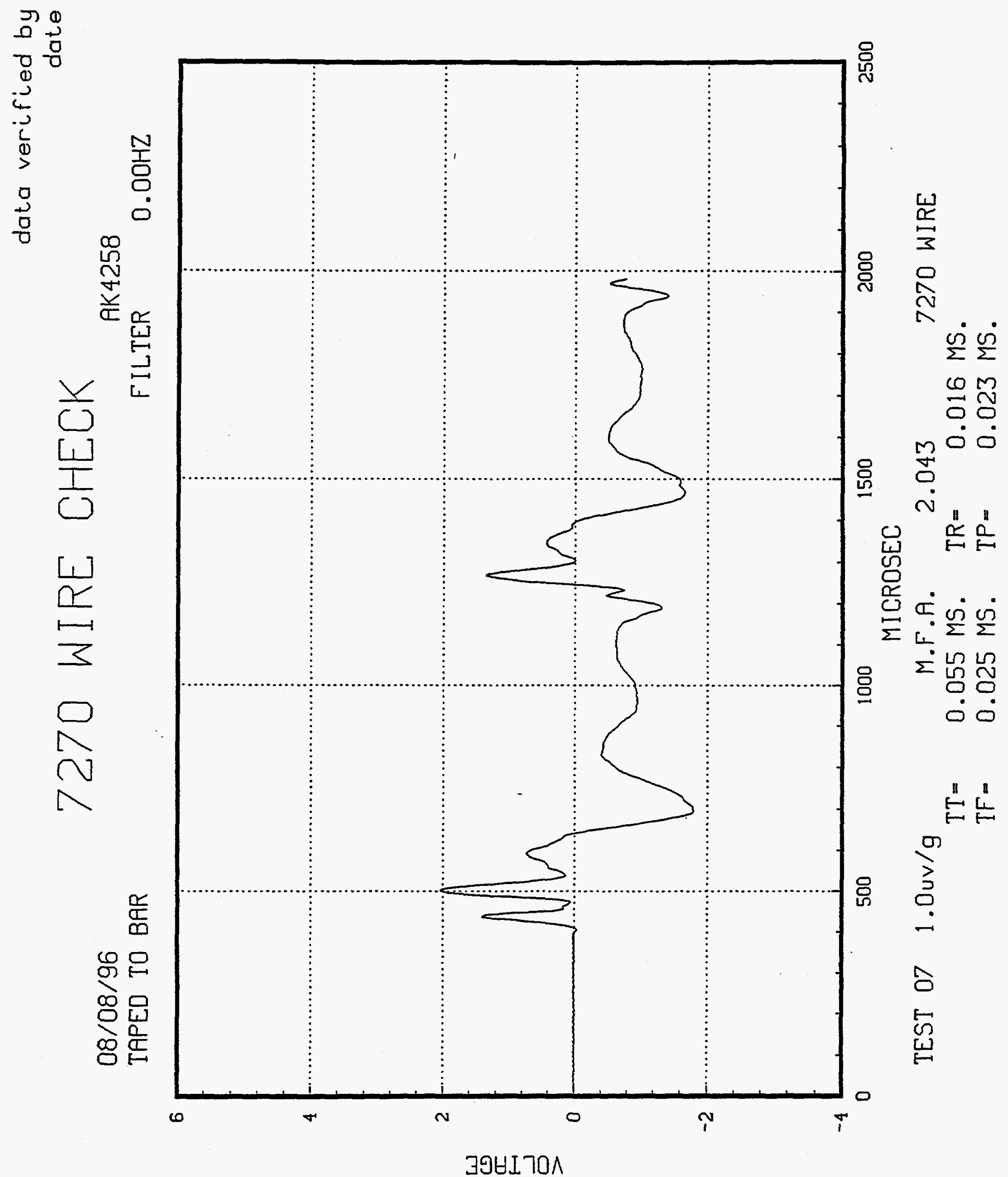




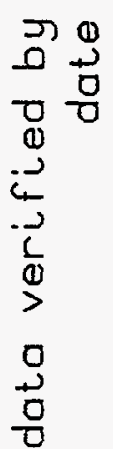

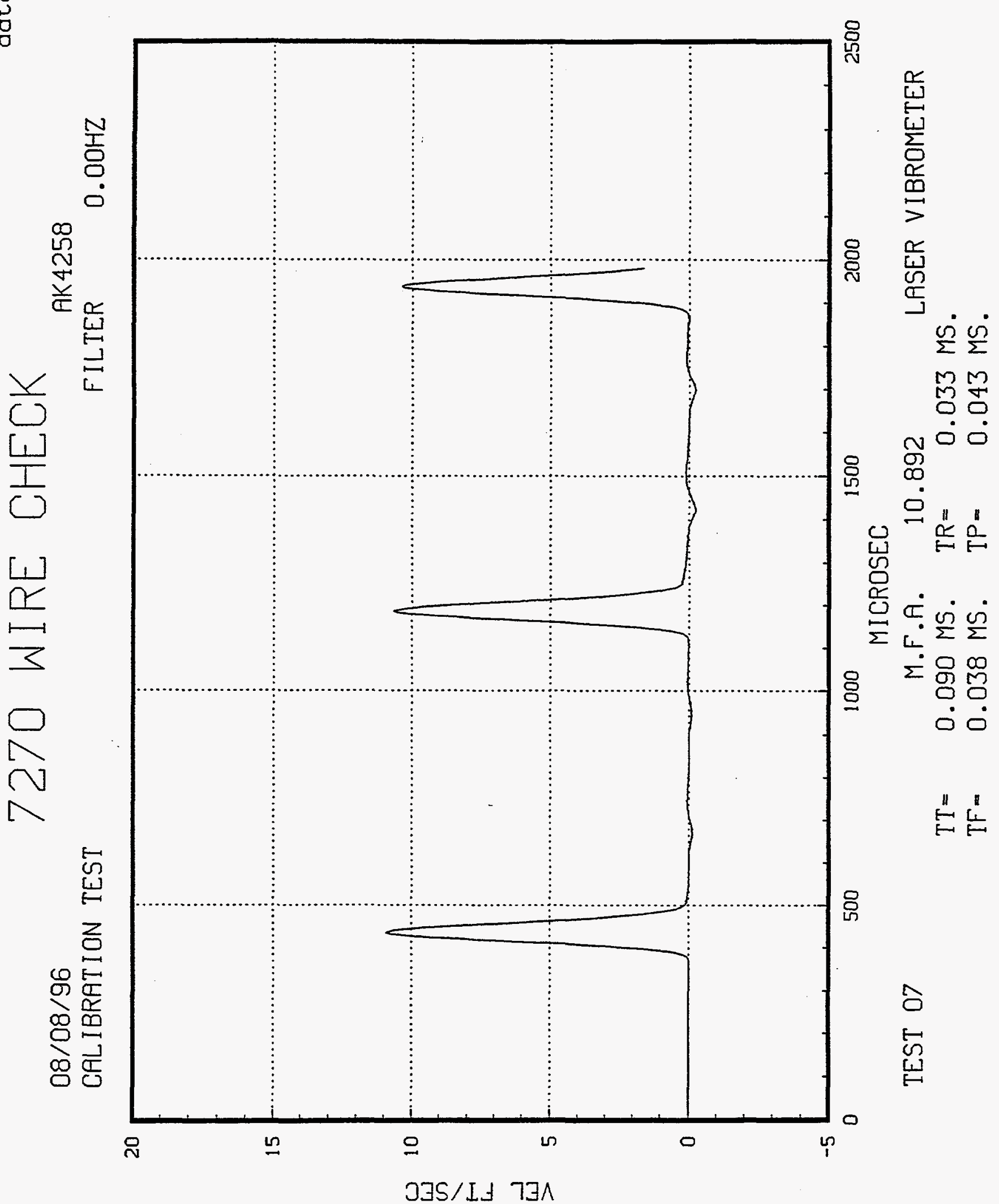




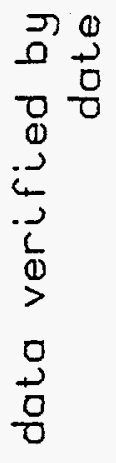

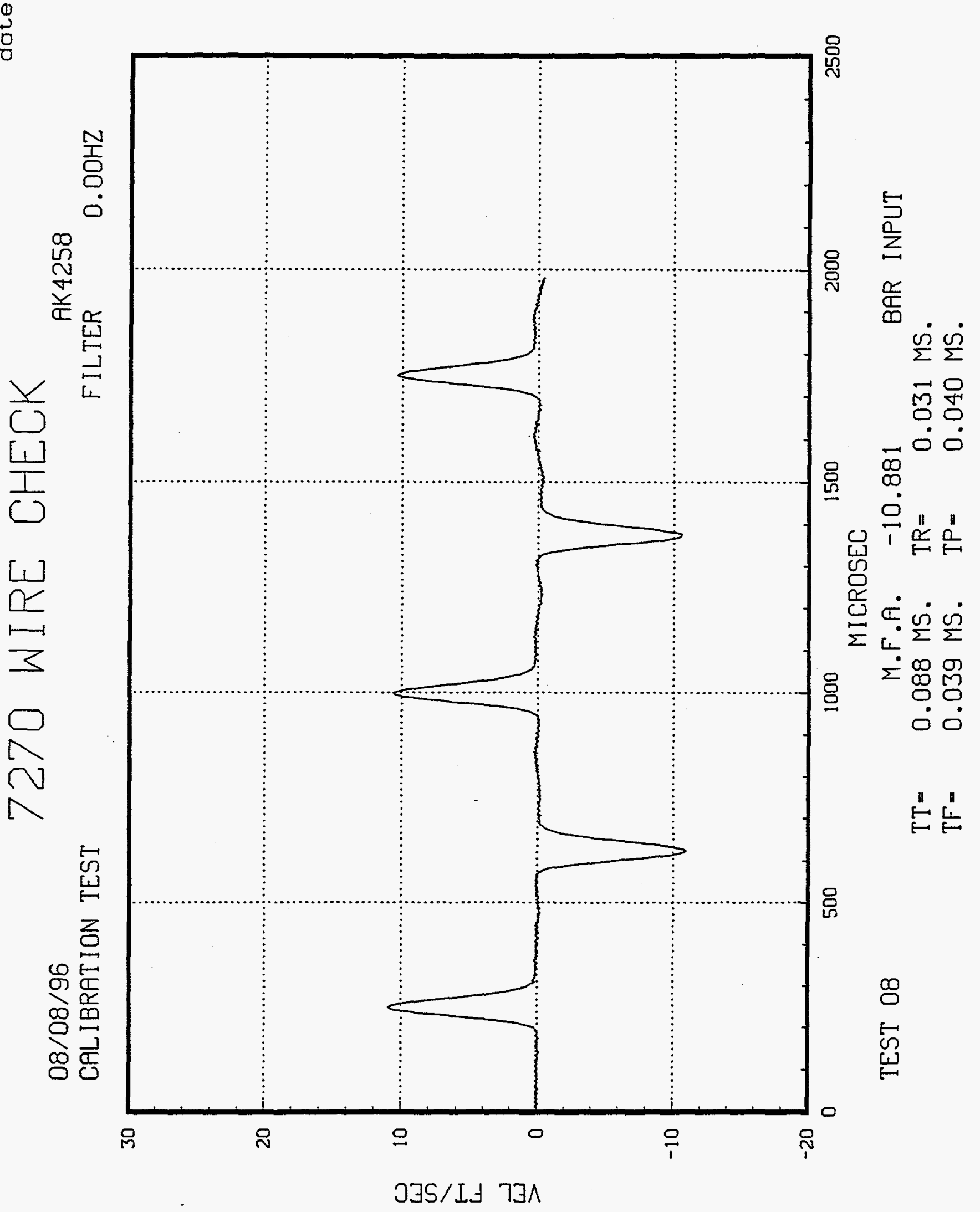


$\begin{array}{ll}0 & 0 \\ 0 & 0 \\ 0 & 0 \\ 0 & 0 \\ 2 & 0 \\ ن & 0 \\ 1 & 0 \\ > & 0 \\ 0 \\ 0 \\ 0 \\ 0\end{array}$

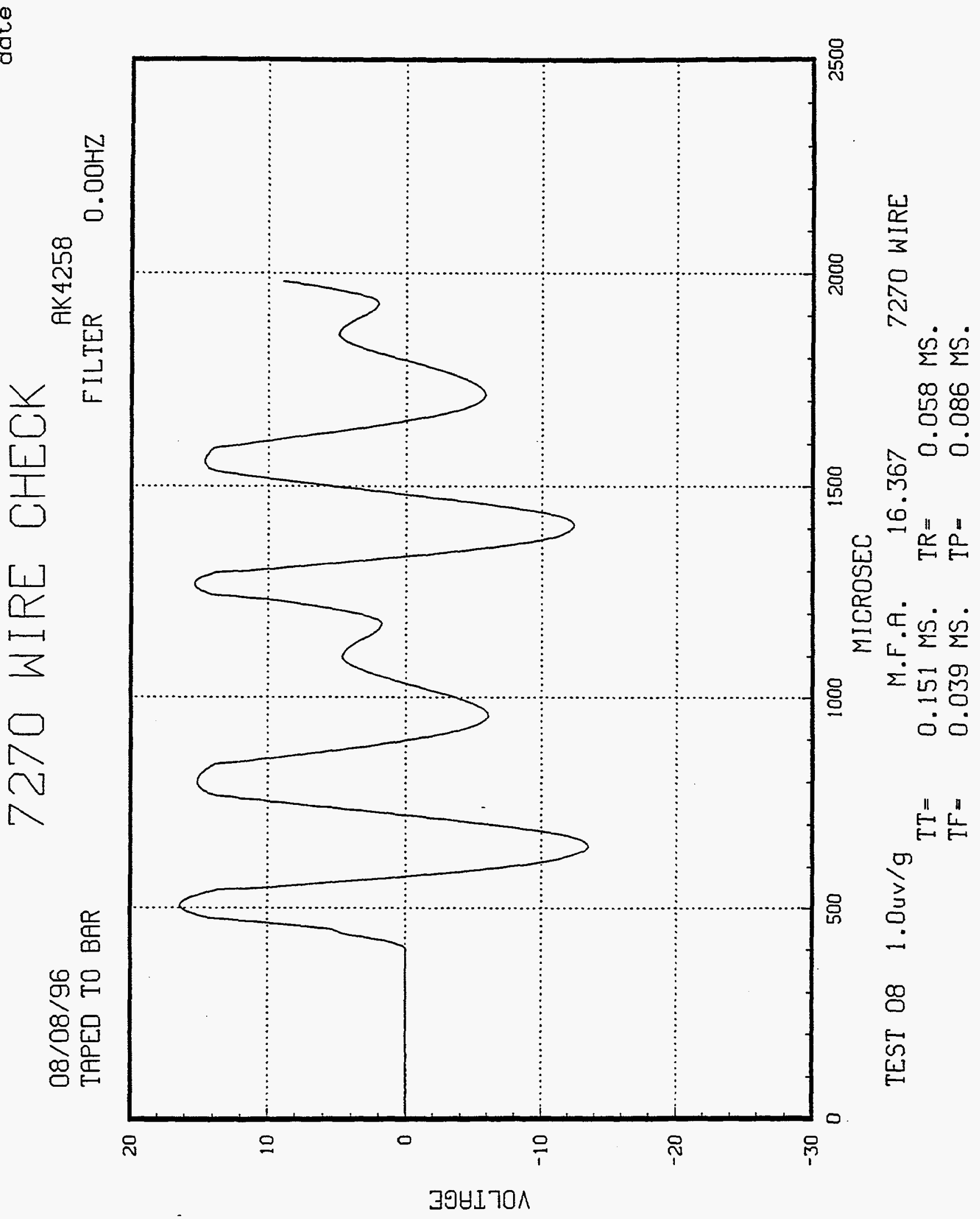




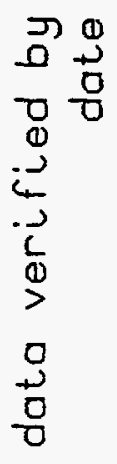

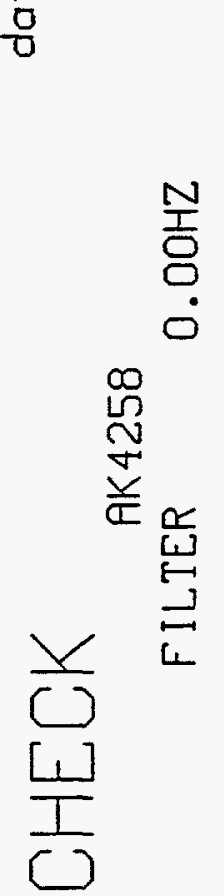

$[1]$
$\square$
$\square$

$\square$

0

D

$\mathrm{C}$

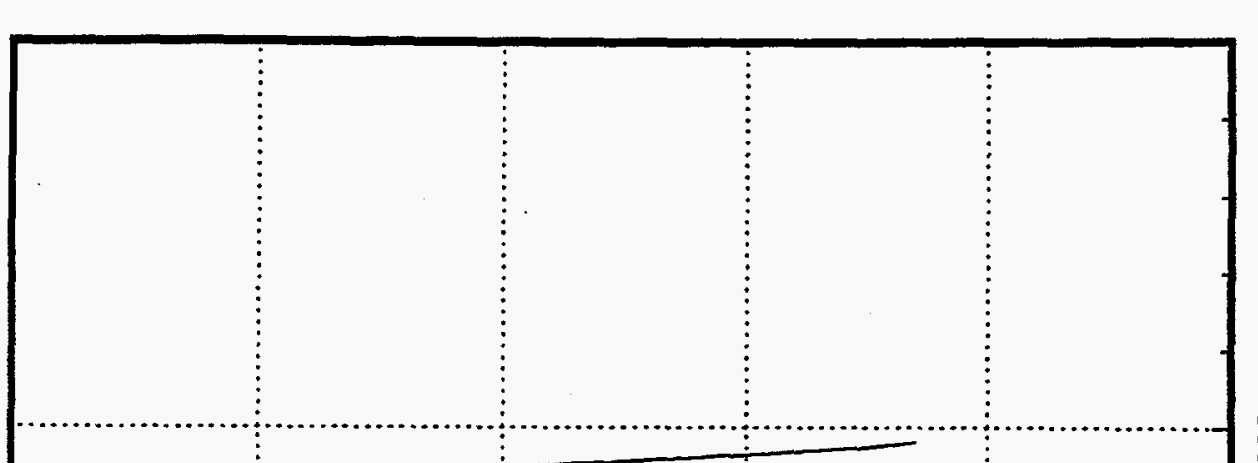

옹

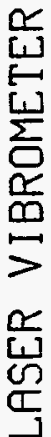

$\dot{\infty} \tilde{\Sigma}$

लㅁํㅁ

유 후

可哭迸

un

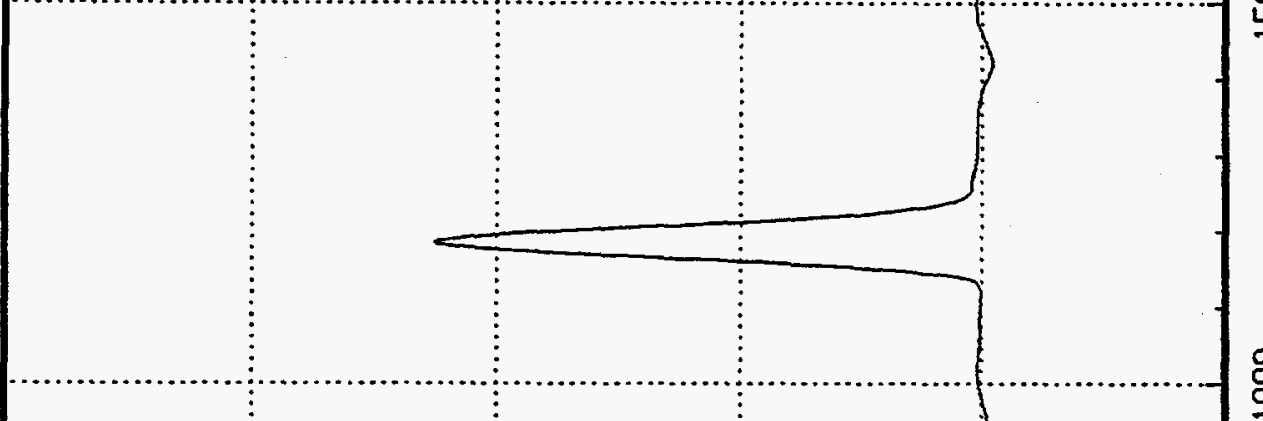

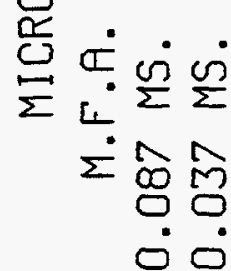

$\stackrel{⿱ ⺌ 兀}{\rightleftarrows}$

号

$@$

㫐 


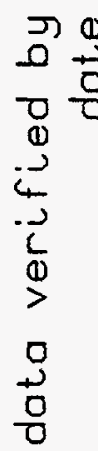

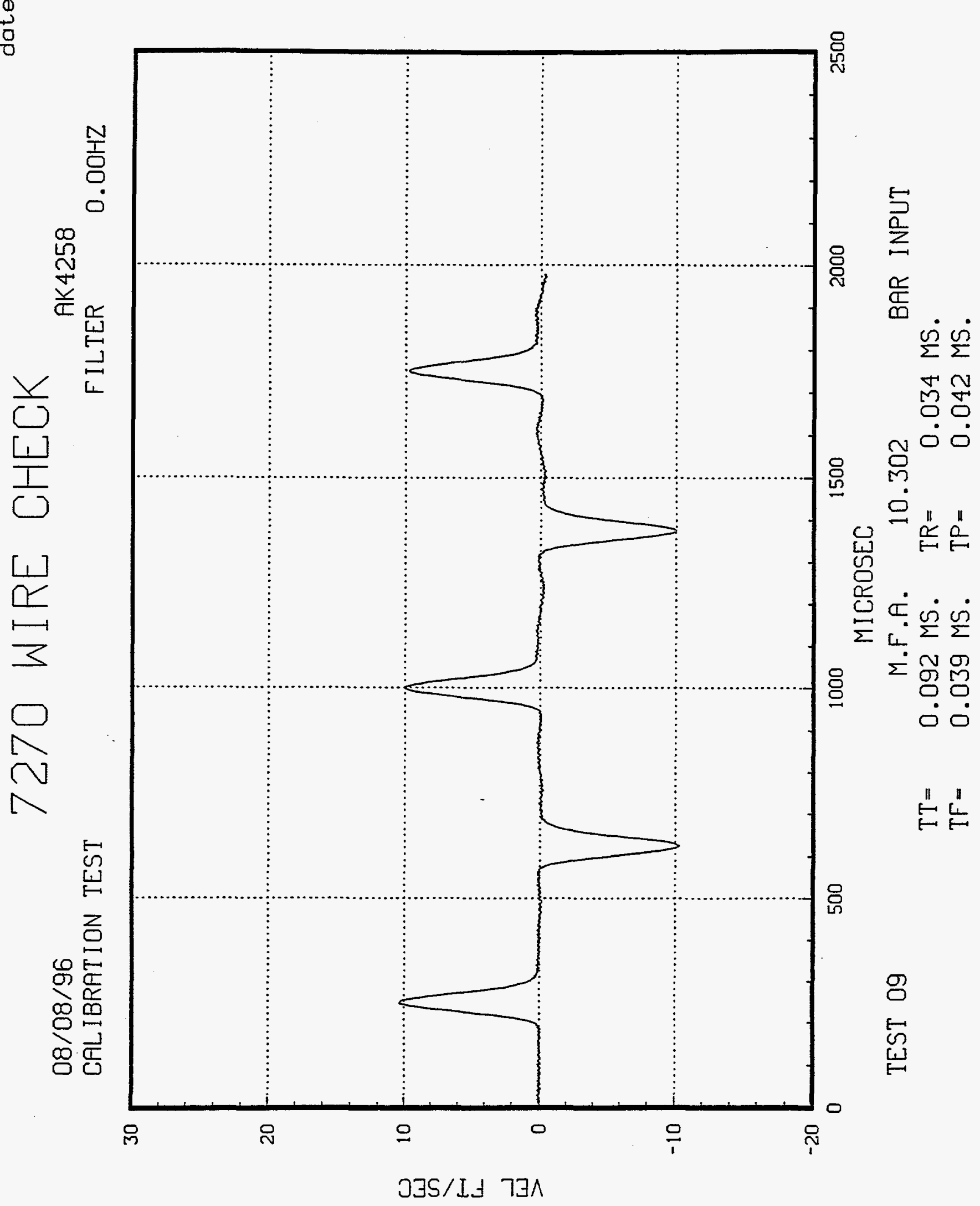

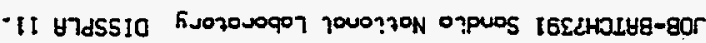




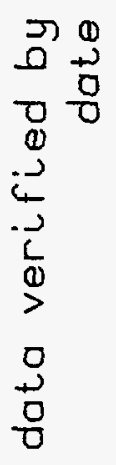

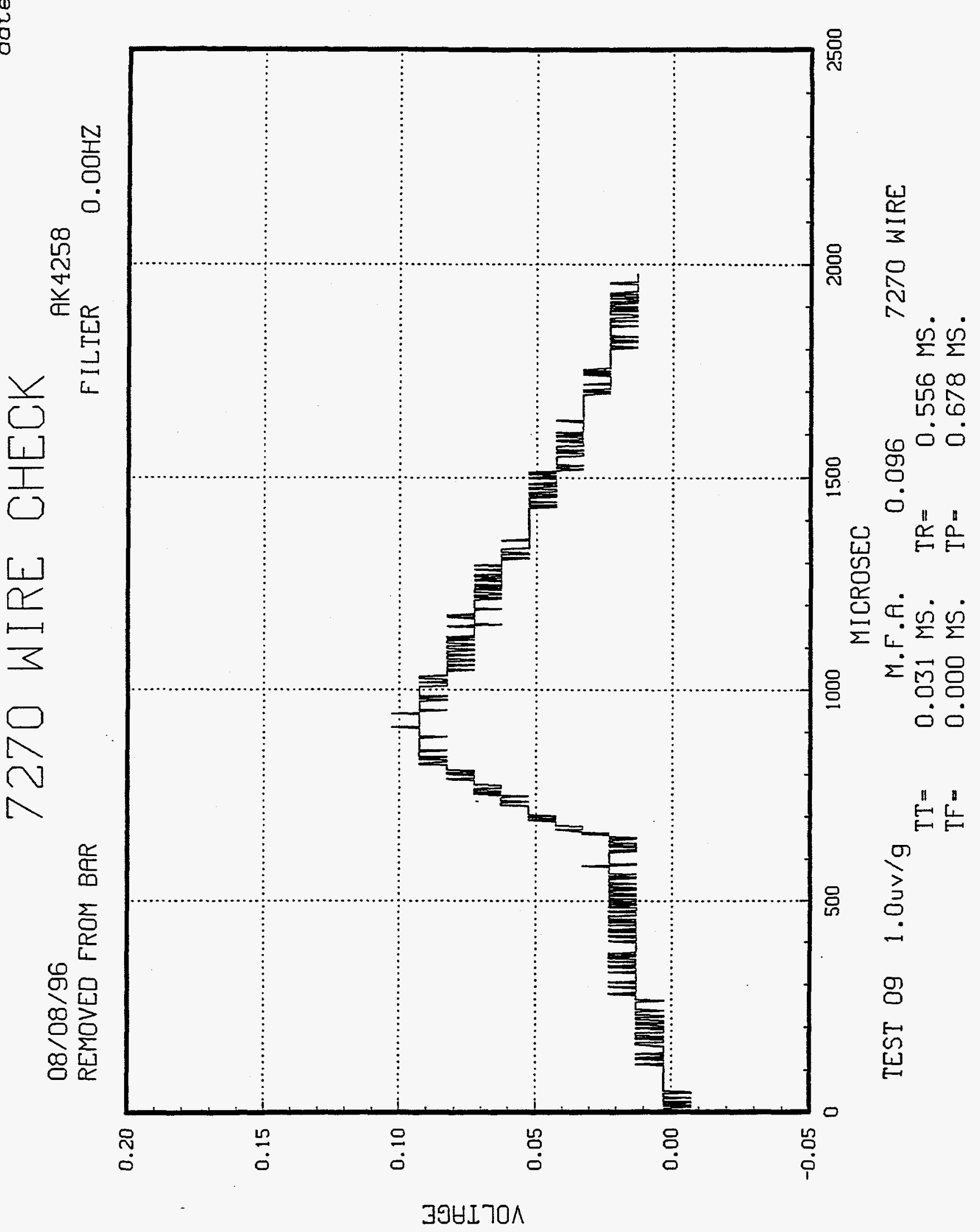




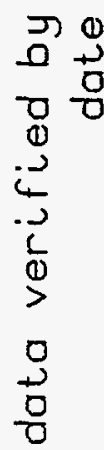

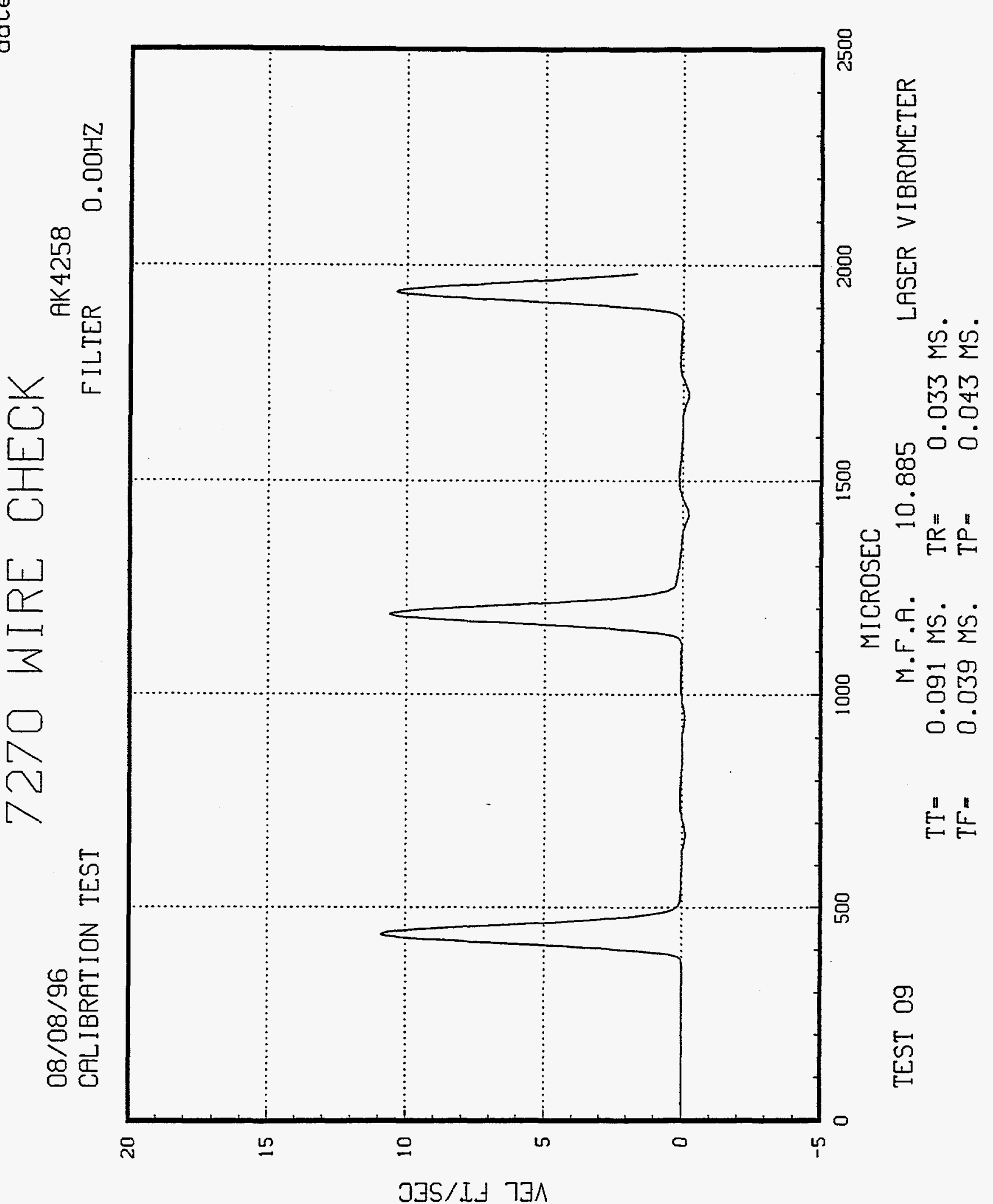


$\begin{array}{ll}0 & 0 \\ 0 & 0 \\ 0 & 0 \\ 0 & 0 \\ 2 & 0 \\ 0 & 0 \\ 0 \\ 0 \\ 0 \\ 0 \\ 0\end{array}$

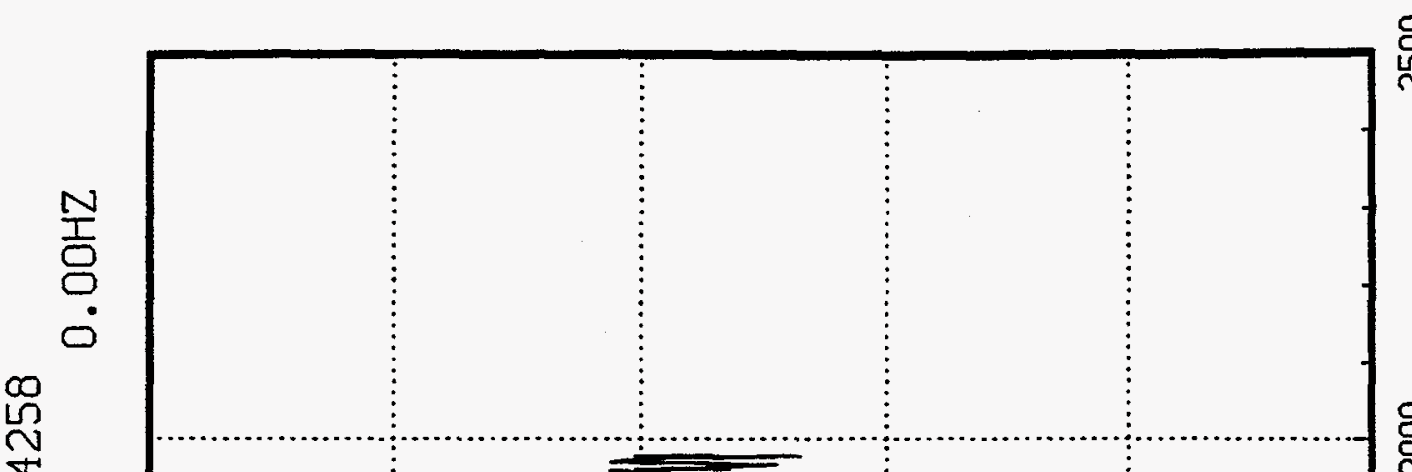

总

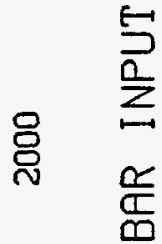

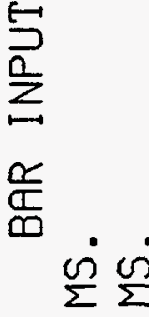

М

m $\dot{\varnothing}$

忠

药苫吕

心

[1]

O

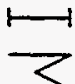

$\square$

工

D

$\mathrm{N}$

岕

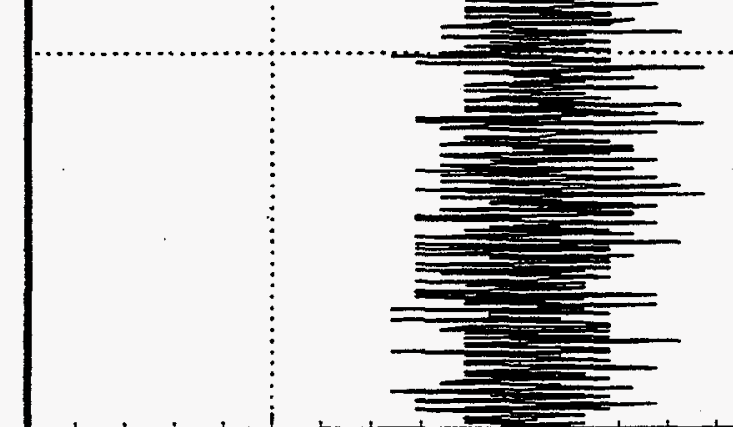

¿

$\stackrel{\circ}{\circ}$

$\dot{0}$

ì

$\dot{0} \quad \dot{i}$

i $\quad 0$

$\stackrel{\Perp}{\rightleftarrows} \stackrel{n}{\leftarrow}$

웅

$\circlearrowleft \dot{0} \dot{\omega} \dot{\omega}$

$\sum\left[\sum \Sigma\right.$

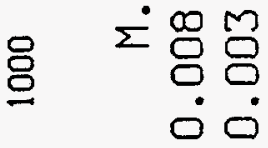

OJS/I」 $7 \exists \Lambda$ 


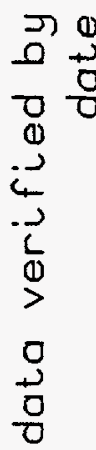

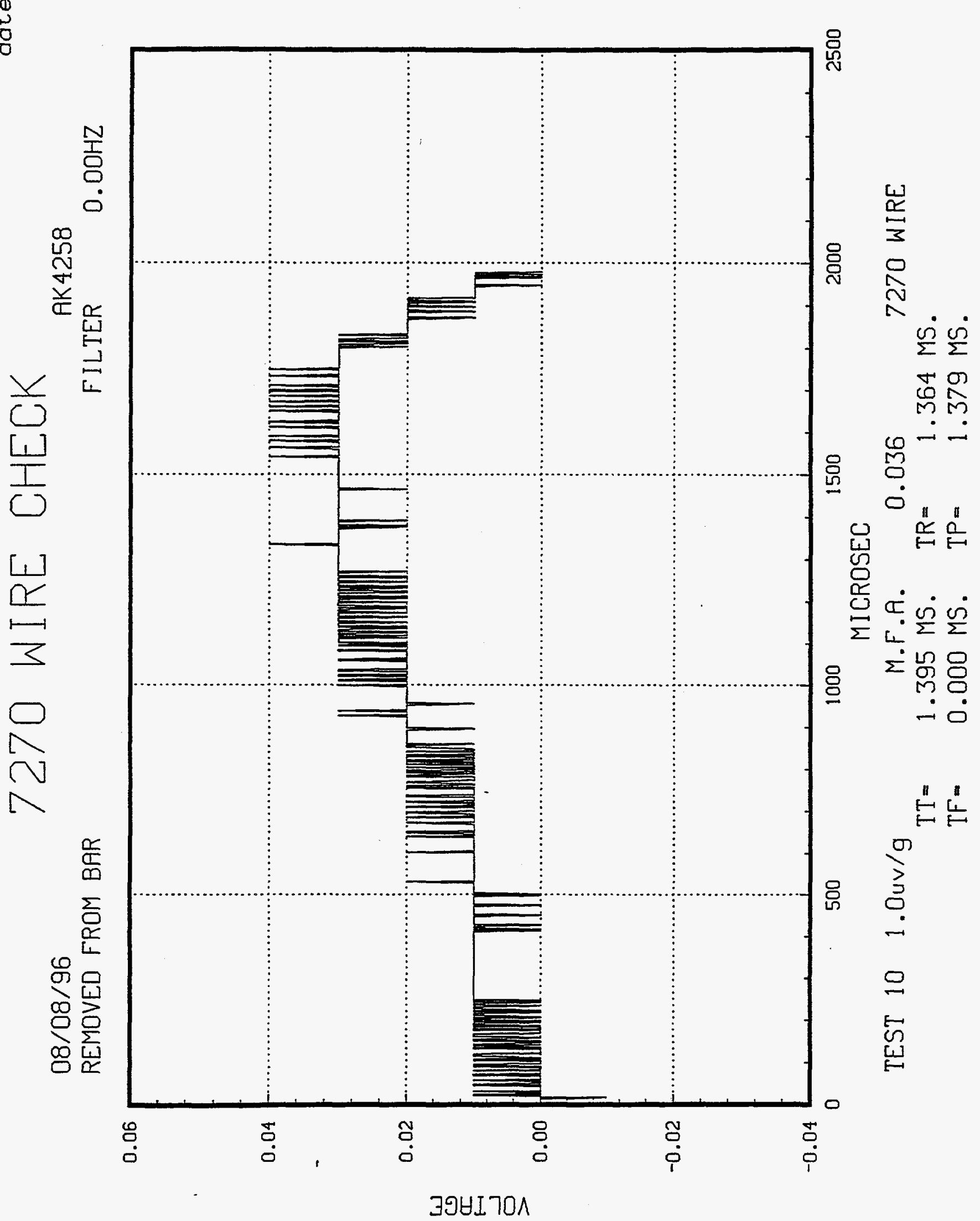




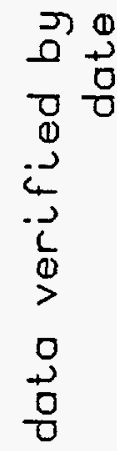

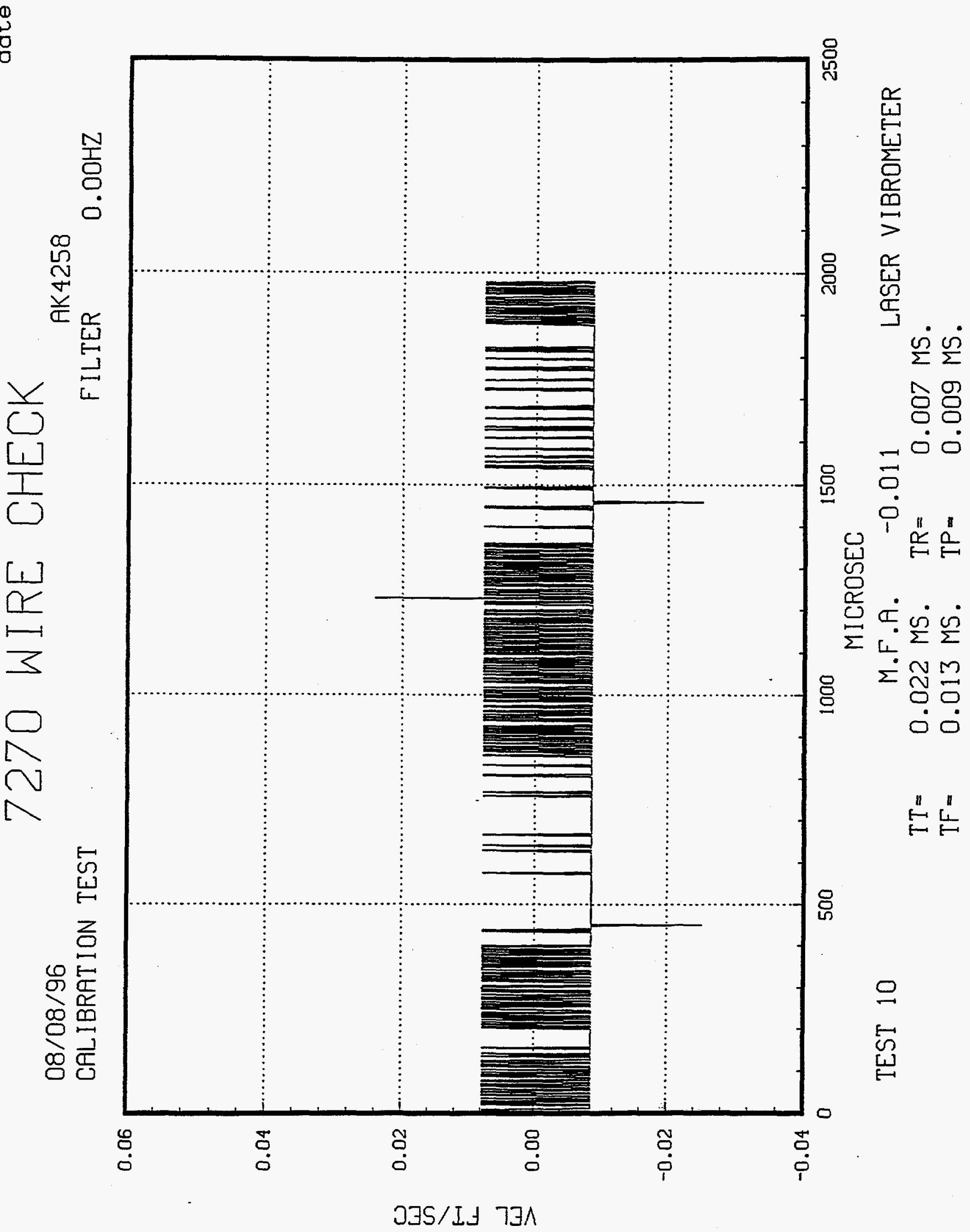


$\begin{array}{ll}3 & 0 \\ 0 & 0 \\ 0 & 0 \\ 0 & 0 \\ -2 & 0 \\ -2 \\ 2 \\ 0 \\ > \\ 0 \\ 0 \\ 0 \\ 0\end{array}$

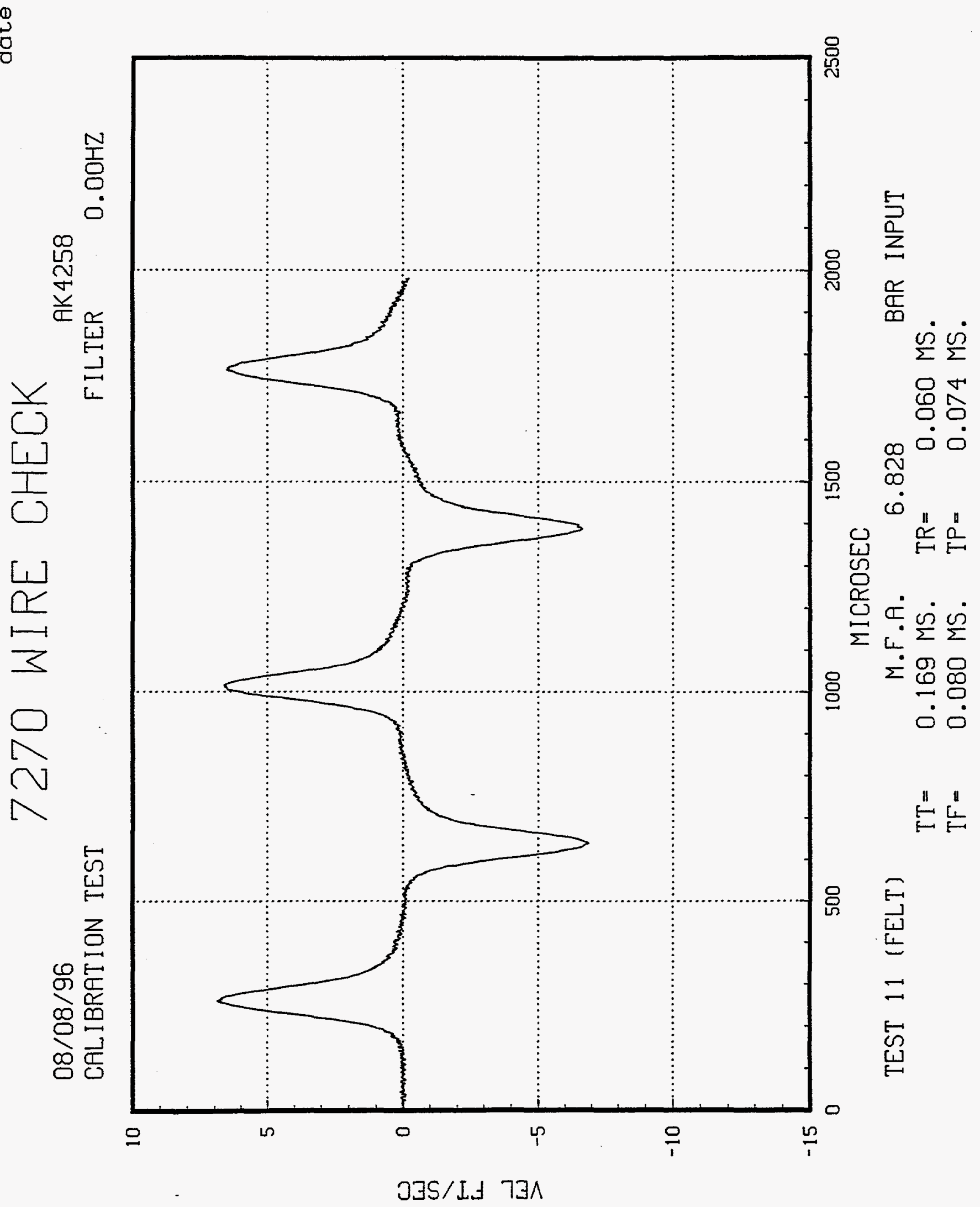


$\begin{array}{ll}\pi & 0 \\ 0 & 0 \\ 0 & 0 \\ 0 & 0 \\ 2 & \\ . & 0 \\ 0 & 0 \\ > \\ 0 \\ +0 \\ 0 \\ 0\end{array}$

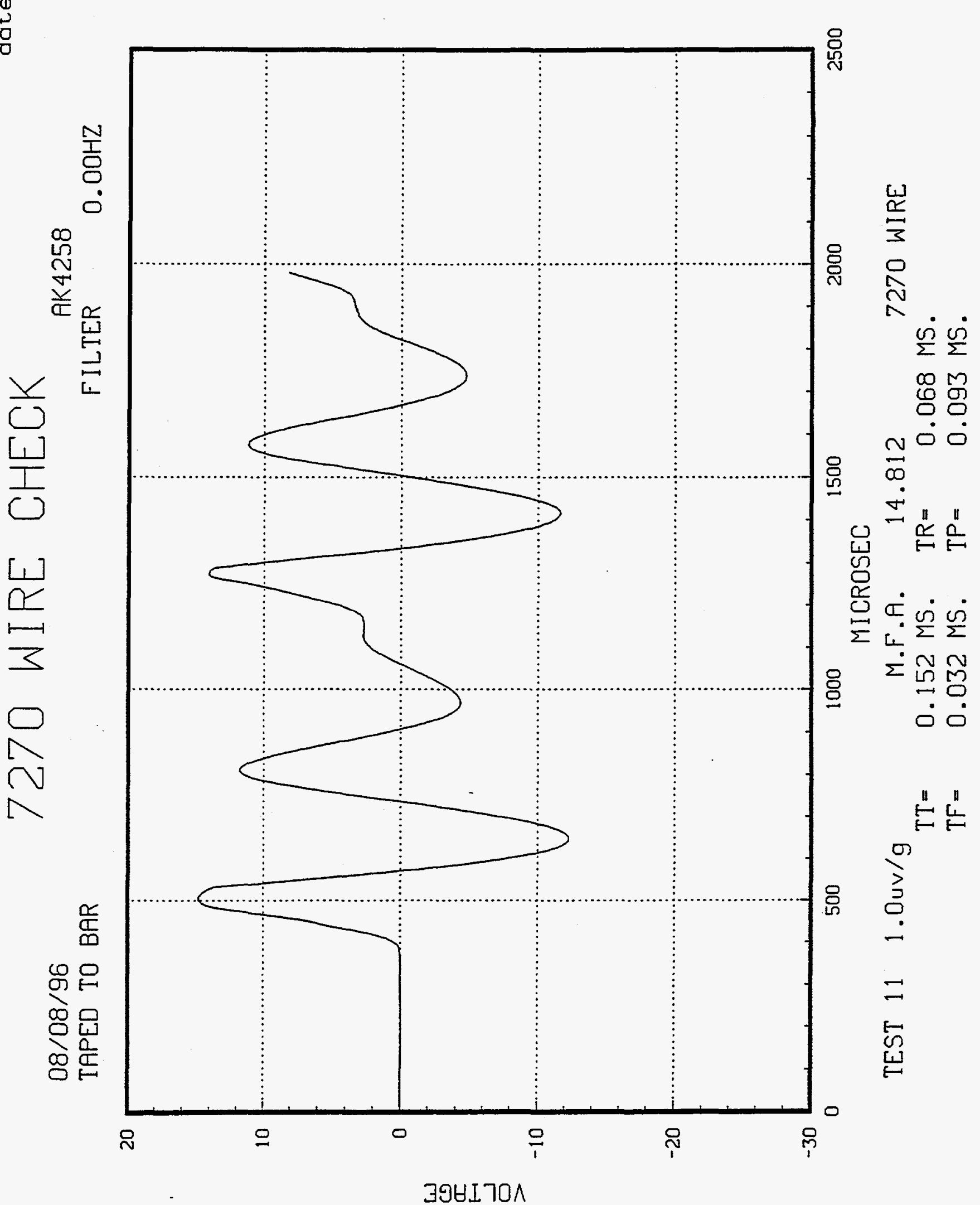


$\pi$
0
0
0
0
0
0
0
1
0
0
$>$
0
0
0
0

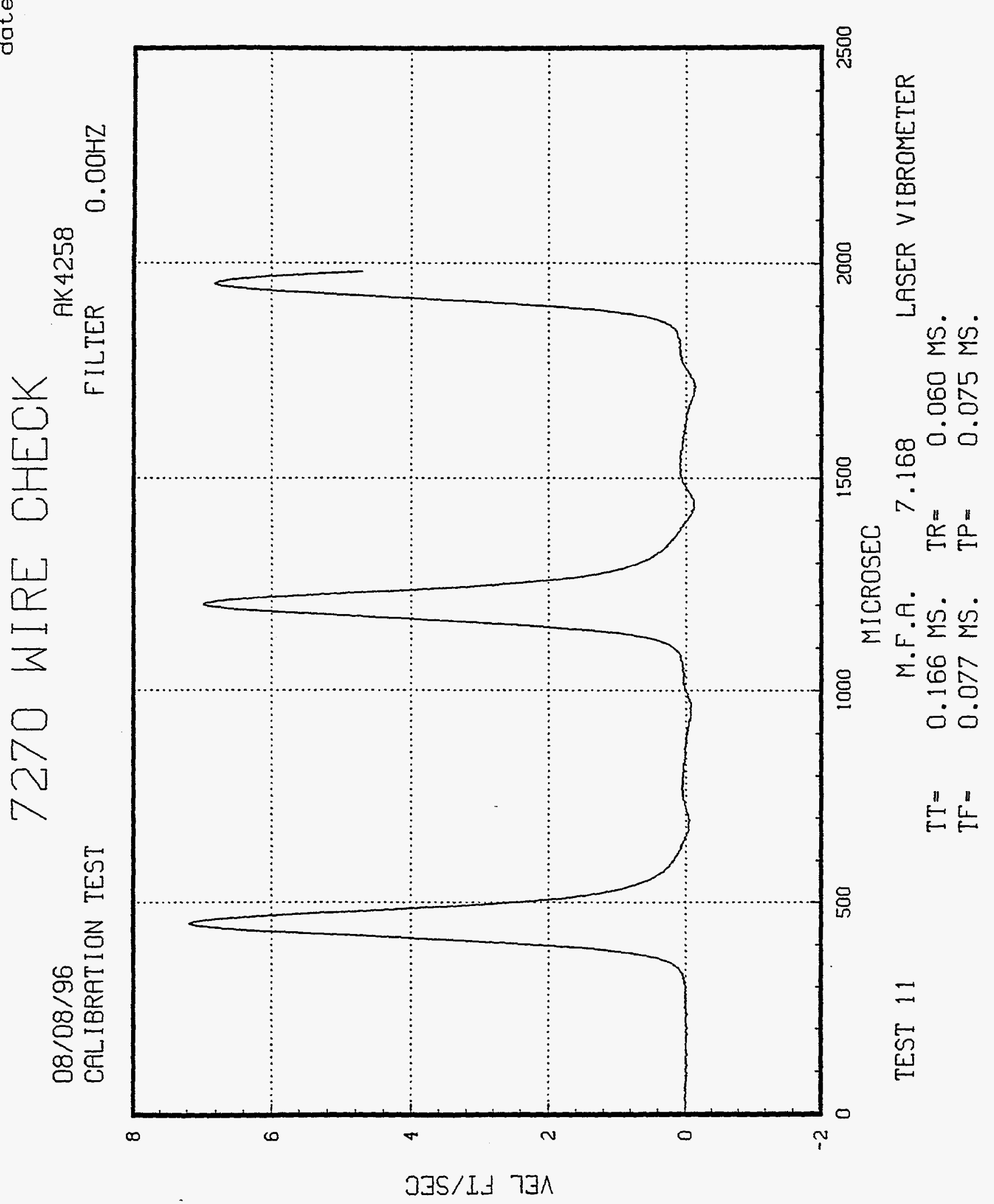




\section{Distribution:}

1 Bob Clark

ENDEVCO

30700 Rancho Viejo Road

San Juan, Capistrano 92675

1 Randall D. Cope

NAWCWPNS

Code 478600D

China Lake, CA 93555

1 M.Shannon Haataja

AMSMI-RD-ST-WF

Redstone Arsenal, AL 35898

1 Brad Hanna

NSWCDD/G22

17320 Dahlgren Road

Dahlgren, VA 22448

1 Danny Hayles

AFRL/MNMF

306 W. Eglin Blvd., Bldg. 432

Eglin AFB, FL 32542

1 George N. Hennings

NAWCWPNS

Code 473330D

China Lake, CA 93555

1 David Hollingsworth

NAWCWPNS

Code 473320D

China Lake, CA 93555

1 Chris Janow

US Army Fuze Management Office

B1

Picatinny Arsenal, NJ 07806
1 Ron Lee

L-281

Lawrence Livermore National Lab

Livermore, CA 94550

1 Richard Mabry

101 West Eglin Blvd., Suite 219

WL/MNMF

Eglin AFB, FL 32542

1 Brian Mary

US Army ARDEC

AMSTA-AR-CCF-A

2800 Powder Mill Road

Adelphi, MD 20783

1 David Montoya

LANL

P.O. Box 1663, MS C931

Los Alamos, NM 87545

1 Art Savarese

US Army ARDEC, Bldg. 6

Picatinny Arsenal, NJ 07806

1 Peter K. Stein

5602 E. Monterosa

Phoenix, AZ 85018

1 Keith Thomas

AFRL/MNMI

101 West Eglin Blvd., Suite 246

Eglin AFB, FL 32542

1 Dr. Patrick L. Walter, Chairman

Texas Christian Univeristy

Department of Engineering

Box 298640

Fort Worth, TX 76129 


\section{Distribution (cont.):}

1 Jim Kennedy

LANL, MSP950

Los Alamos, NM 87545
1 Commander US Army Aberdeen Test Center ATTN: STEAC-SL-B (Mr. Scott Walton) Building 359 Aberdeen Proving Ground, MD 21005-5059

1 William L. Konick US Army TACOM-ARDEC, Fuze Division Attn: AMSTA-AR-CCF-A 2800 Powder Mill Road Adelphi, MD 20783-1197
1 Bob Whittier

ENDEVCO

30700 Rancho Viejo Road

San Juan, Capistrano 92675
1 MS0303 R. G. Lundgren (2414)

1 MS0427 W. R. Reynolds (2103)

1 MS0453 $\quad$ D. L. McCoy (2104)

1 MS0453 N. R. Hansen (2104)

4 MS0555 V. I. Bateman (9135)

1 MS0555 F. A. Brown (9135)

1 MS0665 L. J. Azevedo (1541)

1 MS0665 R. R. Romero (1541)

1 MS0845 L. M. Wells (2521)

1 MS0860 M. A. Grohman (2522)

1 MS0860 $\quad$ B. J. Gomez (2522)

1 MS0987 $\quad$ D. E. Ryerson (2664)

1 MS9018 Central Technical Files

Dept. 8940-2

2 MS0899 Technical Library (4916)

2 MS0619 Review \& Approval Desk

Dept. 12690

For DOE/OSTI 